\title{
Measurement and Analysis of Child Well-Being in Middle and High Income Countries*
}

\begin{abstract}
Almas Heshmati ${ }^{1}$, Arno Tausch ${ }^{2}$, Chemen S.J. Bajalan ${ }^{3}$
Abstract

Starting from the recent UNICEF publications on child poverty in the developed countries, which received a wide audience in the political and scientific world, in this paper we further analyze the UNICEF study data base and present three composite indices that are multidimensional and quantitative measures of child well-being. While the original UNICEF studies simply added together the ranks on different measurement scales, we present a much more sophisticated approach, with the first of our indicators being a non-parametric measure, while the remaining two are parametric. In the non-parametric index of child welfare, the well-being indicators are given the same weights in their aggregation to form different components from which an overall index is being constructed. Two different forms of the parametric index are estimated by using principal component analysis. The first model uses a pool of all indicators without classification of the indicators by type of well-being, while the second model estimates first the sub-components separately and then uses the share of variance explained by each principal component to compute the weighted average of each component and their aggregation into an index of overall child well-being. The indices indicate which countries have the best system of child welfare and show how child well-being varies across countries and regions. The indices are composed of six wellbeing components including material, health and safety, educational well-being, family and peer relationships, behaviours and risks and subjective well-being. Each of the components is generated from a number of well-being sub-indicators.
\end{abstract}

JEL Classification Numbers: D31, I10, I20, I30, J13

Keywords: child well-being, multidimensional index, principal component, child poverty, child outcomes, OECD

\section{Introduction}

There is a growing literature on the well-being of children. It is a result of our growing ability and productivity in the use of resources and generation of economic growth. In addition to the formation of a higher wealth, a portion of economic growth is redistributed and invested in education, technology, productivity, management and welfare programmes. Institutions are also built up, which have enhanced and regulated the interest, needs and rights of children. As a result of improved welfare and better allocation of resources, significant progress is made in a number of areas such as child conventions, which regulate the rights and needs of children. Other areas subject to intensive development are education and learning techniques, compulsory schooling, measures to reduce child labour, physical, psychological and sexual abuse of children,

\footnotetext{
* The authors wish to thank two anonymous referees for their helpful suggestions and comments on an earlier version of this paper.

Contacts: heshmati@,snu.ac.kr, Arno.Tausch@uibk.ac.at, chemen kiffri@hotmail.com

${ }^{1}$ TEMEP, College of Engineering - Seoul National University, Seoul, Korea

2 Innsbruck University, Innsbruck, Austria

${ }^{3}$ Queens University, Belfast, North Ireland
} 
and measures to increase the society's responsibility for the safety and well-being of children. However, development has not been homogenous, yet a certain degree of homogeneity in the provision of basic needs and rights among the OECD countries can be found. In particular, it is easy to establish the presence of a positive association between economic development and child well-being.

In political terms, the issues of the rankings of child poverty in industrialized nations, which are under debate in this study, are very contentious, and call for a more thorough analysis. Is the UK best practice in terms of child welfare in Europe, as the current Labour Government often maintains, or it is the worst practice, as the UNICEF studies claim? Are the neo-liberal policies of "New Labour" an engine of poverty reduction, or is the opposite true? And are "continental European" or "European social model" policies much better adapted to reduce child poverty in rich nations? Are the current youth riots in Greece and the obvious massive discontent of young people in that country in any way reflected in the aggregate data?

Let us ponder two very contradictory quotations. In his famous speech before the European Parliament on June 23, 2005, the British Prime Minister Tony Blair said:

"And since this is a day for demolishing caricatures, let me demolish one other: the idea that Britain is in the grip of some extreme Anglo-Saxon market philosophy that tramples on the poor and disadvantaged. The present British Government has introduced the new deal for the unemployed, the largest jobs programme in Europe that has seen long-term youth unemployment virtually abolished. It has increased investment in our public services more than any other European country in the past five years. We needed to, it is true, but we did it. We have introduced Britain's first minimum wage. We have regenerated our cities. We have lifted almost one million children out of poverty and two million pensioners out of acute hardship and are embarked on the most radical expansion of childcare, maternity and paternity rights in our country's history. It is just that we have done it on the basis of and not at the expense of a strong economy." (http://www.number10.gov.uk/output/Page7714.asp)

UN puts UK at the bottom of 21 advanced nations. Children growing up in the United Kingdom suffer greater deprivation, worse relationships with their parents and are exposed to more risks from alcohol, drugs and unsafe sex than those in any other wealthy country in the world, according to a study from the United Nations. The UK is at the bottom of the league of 21 economically advanced countries according to a "report card" put together by UNICEF on the wellbeing of children and adolescents, trailing the United States which comes second to last. Today's findings will be a blow to the government, which has set great record by lifting children out of poverty and improving their education and prospects. Al Aynsley Green, the children's commissioner for England, acknowledges that the UN has accurately highlighted the troubled lives of children. "There is a crisis at the heart of our society and we must not continue to ignore the impact of our attitudes towards children and young people and the effect that this has on their wellbeing," he says in a response today. "I hope this report will prompt us all to look beyond the statistics and to the underlying causes of our failure to nurture happy and healthy children in the UK. These children represent the future of our country and from the findings of this report they are in poor health, unable to maintain loving and successful relationships, feel unsafe and insecure, have low aspirations and put themselves at risk. (...) The Unicef team assessed the treatment of children in six different areas - material wellbeing; health and safety; educational wellbeing, family and peer relationships, behaviours and risks; and the young people's own perceptions of their wellbeing. The Netherlands tops the league, followed by Sweden, Denmark, Finland and Spain. The bottom five are Portugal, Austria, Hungary, the US and the UK. Nine countries, all of them in the northern Europe, have brought child poverty down below $10 \%$, the report shows. But it remains at $15 \%$ in the three southern European countries - Portugal, Spain and Italy - and in the UK, Ireland and the US. Child poverty is a relative measure that shows how far the standard of living has fallen below the national average. The UNICEF report adds: "The evidence from many countries persistently shows that children 
who grow up in poverty are more vulnerable: specifically, they are more likely to be in poor health, to have learning and behavioural difficulties, to underachieve at school, to become pregnant at too early an age, to have lower skills and aspirations, to be low paid, unemployed and welfare-dependent". The Conservatives seized on the report, claiming that it endorsed their attack on the way in which Gordon Brown had addressed the issue of child poverty, and the prime minister had demonised the role of children in his drive against antisocial behaviour. The shadow chancellor, George Osborne, said: "This report tells the truth about Brown's Britain. After 10 years of his welfare and education policies, our children today have the lowest wellbeing in the developed world." Labour said it had taken 700,000 people out of child poverty and was mounting an unprecedented investment programme in a network of children's centres. A government spokesman argued that in many cases the data used in the report was several years old and "does not reflect more recent improvements in the UK such as the continuing fall in the teenage pregnancy rate or in the proportion of children living in workless households".

( http://www.guardian.co.uk/society/2007/feb/14/childrensservices.politics)

Following intensified research, numerous approaches to the conceptualization and the quantitative measurement of well-being of children are developed. These approaches differ depending on the nature of the study and research objectives. The main differences are attributed to whether one is interested in monitoring child wellbeing for the purpose of the evaluation of outcomes and effects of policies or the identification and the measurement of impacts of various factors on the outcomes. Understanding the mechanism and the underlying factors contributing to child wellbeing and the causal interrelationships between the different components of well-being are essential. In this regard, Hanafin and Brooks (2005) referred to the fact that different frameworks reflect differences in underlying perception of children. For instance, the issues emphasized may include children's rights, needs, development, outcomes, effects, and resilience. In general still, there is no clear consensus about frameworks and definitions used, but they suggest a multidimensionality and complexity of the children's life situations and well-being. In the next section we provide a review of the concepts and their development in the OECD countries.

The development of monitoring and measuring children's well-being from a cross country perspective and convergence in human development has been rapid. Ben Arieh (1997, 1999), Ben-Arieh and Wintersberger (1997) and Ben-Arieh et al. (2001), who report results from a collaborative effort of experts in the field, covering a wide range of disciplines and countries, were path breaking pieces of work. Their team work in a number of stages aimed at: conceptualizing child's well-being dimensionality and to identify appropriate well-being indicators as well as the development of scientific protocols for data collection and its utilization and validation by networks of researchers. Agreements are made on indicators, their formation in components and sub-components. Despite common features, certain differences are found in the national and international characteristics of the projects and their objectives. All together, they shed light on the concepts, measurement and practiced implementation of a better child well-being.

There are several surveys that are collected on a regular basis. ${ }^{4}$ For instance, in the CIVED survey, the focus is on the children's civic life, and in the German surveys, the focus is on the children's and their families life and economic situation, while in the

${ }^{4}$ See Sturgis (2004) and WHO/Europe (2006) for complex survey data issues. 
American survey, the focus is on the measuring trends in child well-being and its temporal changes. In the German surveys, the components include: safety, physical status, personal life, civic life, economic resources, contributions and activities. The American surveys refer to: material well-being, health, safety, production educational and community activities, social relationships and emotional well-beings (see Land 2005, 2006, 2007a and 2007b). In general, the information in the surveys covers: economic situation, health, behaviour, education, social relationships, emotional, spiritual wellbeing, poverty perspective and social exclusion. The poverty perspective is related to Sens's work (1985) on the limitation of capabilities or outcomes of physical, cognitive, behavioural and subjective/mental well-being. In the UK survey, the aim is different and tries to answer the question where the government focuses on the outcomes to monitor the public service providers in the provision of rights and achievements in: health, safety, and economic well-being, and also expectations in forms of educational outcome and positive behaviours.

Among important comparative researches is the work by Bradshaw et al. (1993), which is a comparative study of child support in 13 European countries, Norway and USA. It is a study of child support packages consisting of all social security benefits, child support arrangements and benefits for lone parents and other benefits, reducing the costs of housing, health care, schooling and child care. For a number of evaluations along the lines listed above see also the works of Bradshaw (2001, 2002), Bradshaw and Mayhew (2005), Hanafin and Brooks (2005) and Aber et al. (2002). Land (2007b) presents a special focus on international comparison, where a simple child well-being index (CWI) is used to compare the well-being of children in the USA and four English speaking countries namely Australia, Canada, New Zealand and UK. The comparison is based on 19 international indicators of child and youth well-being. They cover the same 7 domains of well-being as in the original CWI index: family economic well-being, social relationships, health, safety/behavioural concerns, educational attainments, community connectedness, and emotional well-being. The result shows variations in countries performance in individual indicators and domains.

In our study, based on the UNICEF data work (UNICEF 2005, 2007), we present three composite indices that are multidimensional and quantitatively measure child well-being. The first is non-parametric, while the remaining two are parametric. In the non-parametric index, just like in the mentioned CWI, the well-being indicators are given same weights in their aggregation, while in the parametric approach the weights

\footnotetext{
5 The foundation for child development, child and youth well-being index (CWI) project issues an annual human development measure of how children are faring in the USA. The index provides trends in wellbeing between 1975 and 2005 and it is based on 28 indicators of well-being grouped into 7 quality of life domains. These are economic well-being, health, safety, educational attainment, and participation in schooling, economic and political institutions. The non-parametric composite index which is an equally weighted average of the 7 domains is indexed by the base year of 1975 which gives an overall direction of changes in well-being. There is a negative trend in well-being from 1979 to 1995, followed by an increasing trend until 2002. The major trends suggest that: progress in children's quality of life has since 2002 stalled, children's health continues to decline, children are safer and engage less in risky behaviour than ever, progress in narrowing racial and ethnic disparities has stalled since 2002, the peak in quality of life in 2002 was a temporary reaction to 9/11, the economic recession and slow growth in 2001-2002 negatively impacted the family's economic well-being. In sum there is no strong link between economic progress and children's quality of life in USA. The report suggests proactive steps at the policy and community levels to be taken to improve children's life.
} 
are estimated. The first parametric model uses a pool of all indicators without classification of the indicators by type of well-being, while the second model estimates separately the sub-components first, and then computes the weighted aggregate child well-being index. The indices show how child well-being varies across countries and regions. The indices are composed of six domains or components: material, health and safety, educational well-being, family and peer relationships, behaviours and risks and subjective well-being. Each of the well-being components is generated from a number of indicators. A breakdown of the index into major components provides possibilities to identify sources of well-being and associate it with social, economic and redistribution policy measures. The empirical results show that in general aggregated child well-being is positively associated with economic development. However, in the disaggregated form there is no systematic link between level of development and well-being of children.

The main contributions of this paper are as follows. First, we utilize data, which are collected and used by professional networks in the evaluation of child well-being with both a national and cross country emphasis (UNICEF, 2005 and 2007). Second, and in contrast to the "beauty contest method", employed by UNICEF, which is based on aggregated ranks, we extend previous work using the same data but by focusing on the measurement of composite indices. Third, we produce single non-parametric and parametric multidimensional well-being indices, in which one accounts for various dimensions of well-being and properly weight them together, applying advanced statistical methodology beyond simple rank aggregations to form a single index used to rank the sample countries in one single way. Fourth, based on the computed index and its underlying components, we compute efficiency levels for individual countries in child well-being policy and compare it to the countries with so-called best practice well-being policies. Fifth, given the acquired experience from this study, we suggest improvements in data collection, processing and computation. Finally, by identification of the strength and weakness of different welfare systems, we suggest policy measures to enhance child well-being in countries experiencing disparity in this area.

The rest of the paper is organized as follows. In Chapter 2, we outline the concept of child well-being from the perspectives of rights, needs, development, outcomes and effects. In Chapter 3, we review the literature by looking at different approaches to well-being, and in particular an emphasis is made on the capability approach. The data and variable definitions are described in Chapter 4. Chapter 5 discusses the literature on the parametric and non-parametric index methodology. Various indices used in the measurement of child well-being are reviewed and their properties, benefits and limitations are discussed. The analysis of the results is outlined in Chapter 6, which is followed by a debate on the policy implications of the results in Chapter 7. Finally, Chapter 8 provides a summary and concludes this study. Although this agenda might seem to be limited in view of the possible requirements of an "ideal" research agenda, comprising such intricate but hardly internationally measurable phenomena as inter-generational household income distribution, child labour in advanced western democracies etc., a sounder statistical treatment of the widely used UNICEF data (2007) could be regarded as a necessary first scientific achievement, from which some policy conclusions can be drawn. 


\section{Child Well-Being}

Numerous approaches to the conceptualization and quantitative measurement of the well-being of children have been developed. These approaches differ by the study's nature and objectives. The main differences are attributed to whether one is interested in monitoring child well-being for the purpose of evaluation of outcomes and effects of economic and social policies or the identification and measurement of impacts of different factors on the outcomes. An understanding of the mechanism and the factors contributing to child well-being and interrelationships between different wellbeing components are considered as being essential. Thus, as Hanafin and Brooks (2005) indicate, the differences in frameworks may reflect differences in underlying perception, multidimensionality and complexity of the children's life situations and wellbeing. The development process of monitoring and measurement has been rapid (BenArieh and Wintersberger, 1997; Ben-Arieh et al., 2001). In this study, the main focus is on the rights-based approach, capability approach, and children outcomes.

The framework for the analysis of child well-being is described in Bradshaw, Hoelscher and Richardson (2006). The different approaches include: a rights-based approach, creating well-being, children's interactions with their environment, dimensions of child well-being, conditions for child well-being, and child outcomes. The rights-based approach uses the UN convention on the rights of the child as a partial reference. It offers a normative framework for the understanding of children's wellbeing. Its four general principles include: non-discrimination, best interest of the child, survival and development, and respect for the views of the child. These are found fitting well to the conceptualization of child well-being. Bradshaw et al. (2006) point out that some children in some countries face structural disadvantages due to their belonging to ethnic minorities, having disabilities, living in institutions or temporary housing and being refugees. Many of these children tend not to be included in child surveys. Nondiscrimination thus points to the need to both capture the life situations and well-being of both categories of children, and to analyze the distribution of data by various child characteristics. Children have a double role as citizens with their own right and as dependent on their families, schools, communities, societies and the state. From the latter perspective, child well-being is understood in terms of focusing on their education, capability and future employability.

Well-being is a realization of the children's rights and the fulfilment of the objectives to provide them with abilities, potential and skills through effective protection and provision of assistance by families and their institutional environment. Thus, well-being is the positive outcome, while the opposite or deprivation is a result of the neglect of their rights. The outcome depends on individual characteristics and dynamic processes. It is a result of changing resource inputs and risk factors, affecting both well-being and health conditions. The main factor in this relation is what is called the sense of coherence, which describes a person's overall orientation and capacity to make the best use of the resources available to them. It consists of three key elements: comprehensibility, manageability and meaningfulness (Lindström and Eriksson, 2005). The degree of dependency of children on environment and resource assistance is found to be negatively related to their age.

Children's capability to develop their potential is a result of their development and well-being is a dynamic process that is influenced by a multitude of environmental 
factors. Children interact with their environment and play an active role in creating their well-being by making use of available resources. The bio-ecological model of human development (Bronfenbrenner, 1979; Bronfenbrenner and Morris, 1998) conceptualizes child development on the basis of four environmental influences. The strongest direct influence is from interaction with family, other people and the system labelled as microsystem. Connections between the different structures within the microsystem are described as the second level and are labelled as mesosystem. The third level, the exosystem, stands for the societal context in which families live and it affects the child mainly indirectly by influencing the microsystem. The fourth level of the macrosystem points to the wider societal context, like economic conditions and global developments. The different systems are dynamic and interdependent, influencing each other and also changing over time (Stevens et al., 2005; Kolar and Soriano, 2000; Lippman, 2004). In their interaction with the different systems, children encounter both barriers and facilitators. Match or mismatch between an individual with their development infrastructure may lead to inclusion or exclusion processes.

The child outcomes in child well-being literature (see Innocenti, 2006; Ackerman et al., 2003; Attree, 2004; and European Commission, 2003) include: child poverty, social exclusion, child abuse and neglect, unsatisfactory child development, poor school performance and deaths by accident or injuries. Social exclusion is a multidimensional concept involving economic, social, political, cultural and social aspects of disadvantage and deprivation. It is a process by which individuals and groups are excluded from participation in society as a consequence of - for instance - low income or education. The detailed list of child outcomes include other outcomes such as: children living in families receiving welfare benefits, suicide, alcohol and drug abuse, homelessness, minorities, immigrant children, children of divorced parents, children in single parent families, bullying and victimization, low birth weight and births outside marriage. In our next section, which will deal with reviewing the literature, further details on the issues discussed above are provided.

\section{Review of the Literature}

In the past scientific debate on the issue, a child well-being dimensionality has been conceptualized and appropriate well-being indicators were identified along with standardized protocols for data collections; and the utilization and validation of these data has been initiated. In general there is agreement on indicators, their formation in components and sub-components, but yet certain differences are found in the national and international characteristics of the projects and their objectives. There are several surveys on child well-being that are collected on a regular basis with difference in their focus. These include the CIVED survey, and German, British and American surveys

In the CIVED survey, the focus is on the children's civic life, while in the German survey the focus is on the children's and their families life and economic situation, and in the American survey (Land, 2005) the focus is on the measuring trends in child well-being and its temporal changes. In the UK survey (Bradshaw and Mayhew, 2005) the aim is to monitor the public service providers and their provision of rights of children.

The components differ among the surveys conducted in the OECD countries as a reflection of the focus. In the German surveys the components include: safety, 
physical status, personal life, civic life, economic resources, contributions and activities. The American surveys refer to: material well-being, health, safety, production educational and community activities, social relationships and emotional well-beings. In the UK survey, the focus is on outcomes to monitor the provision of rights like achievement in health, safety, contribution and economic well-being, and also expectations in forms of educational outcome and positive behaviours. In general, the information in the surveys covers: economic situation, health, behaviour, education, social relationships, emotional, spiritual well-being, the poverty perspective and social exclusion.

Research in the area has led to the development of different approaches to understanding and measurement of children's well-being. It highlights the complexity of children's life situations. The degree of complexity is positively associated with the difficulties to capture child well-being within a simple index based on a limited number of indicators. Several aspects, such as the dynamics of the process and interrelationships between different sub-components and regional factors, are not measured. Despite these limitations, a set of carefully selected indicators covering different dimensions of well-being sheds light on the state of well-being and the realization of children's rights in different countries. Following the UNICEF (2007) report, we analyze children's wellbeing in six dimensions containing 18 components based on 40 indicators. ${ }^{6}$ The six dimensions are: material well-being, health and safety, education, peer and family relationships, subjective well-being, and behaviour and risk. It should be noted that all dimensions focus mainly on the children's microsystem, i.e. on the children themselves and the different subsystems that directly impact on their life. A detailed description of the data, different dimensions, components and indicators is given below in the data section.

The outcomes can be classified in positive or negative terms focusing on wellbeing or deprivation. The positive outcome indicates a capability, while the negative reflects vulnerability of children. The negative outcome as a measure of the gap in the realization of the rights of children suggests a focus on deprivation to be more appropriate in international comparisons. Gabel and Kamerman (2006) and Kamerman et al. (2003) identify child outcomes in selected OECD countries. They explore child poverty and its effects on children, they identify families of concern, and social policies linked to these outcomes. Corak (2005) discusses the major issues involved in defining and measuring child poverty and outlines a set of six principles and practicalities in measuring child poverty for the rich countries. Bradshaw (2002) analyzed child poverty and child outcomes in Britain with focus on characteristics of poor children and changes in child poverty over time as well as the effects of public policy to abolish child poverty. Bradbury and Jäntti (1999), while emphasizing child poverty as an important social problem, find considerable variations in both anti-poverty policies and poverty outcomes across industrialized nations. They present new estimates of child poverty

\footnotetext{
${ }^{6}$ Bradshaw, Hoelscher and Richardson (2007) introduced an index of child well-being in 25 European Union countries. The aim was to use the index in monitoring the well-being of children on the European level. The index is based on rights-based approach and is a multi-dimensional understanding of child well-being. The performance of countries on 8 clusters with 23 domains and 51 indicators is studied. The clusters are children's material situation, housing, health, subjective well-being, education, relationships, civic participation and risk and safety.
} 
using a range of alternative income poverty definitions and analyze sources of the variations in child poverty. In addition to differences in welfare state institutions and social transfer outcomes, they find variations in family or household market incomes to be more important.

In a few other studies, outcome is measured somewhat differently and does not complement the factors mentioned above. The children outcomes in UNICEF (2005 and 2007) are measured in terms of: health, subjective well-being, education, civic participation, friendship, and risky and healthy behaviours. Ackermann et al. (2003) reviewed the literature on current approaches to the evaluation of projects on children's participation in development with a focus on local level activities. The concepts, the process, the success or failure of participatory programs, their impacts, ethical concerns and evaluation of participation are discussed. Attree (2004) reviews the quantitative studies on the impacts of poverty and associated disadvantages on children's lives as children. The focus is on the children's subjective accounts of growing up in disadvantage, exploring the value of social resources available to children living in poor circumstances. Asher and Paquette (2003) studied loneliness and peer relations in childhood. Berger et al. (2005) studied the effects of different welfare programs targeting parents on health of children in the US.

Health is a basic indicator of well-being and closely related to poverty and ability to cover costs for health related services. Low income and poverty are linked to risk factors that impacts on children's health and also personal problems leading to a deteriorating health. Subjective well-being reflects how children feel about themselves and their environment. In this study, and following UNICEF, the focus is on selfdefined health, personal and educational well-being. Educational achievement and aspirations are indicators for children's well-being today and in the future. They also reflect the presence of inequality and social exclusion. The overall dimensions include achievement, participation and employment outcomes. The children's opportunity for civic participation at school or in their community depends on the extent of encouragement and support given by their environment. Poor children tend to participate less frequently in organized youth activities. The possibility to spend time with best friends, to have fun and share problems is of high significance in children's lives. Poverty can affect friendship and exclusion conditions of children. Adolescence is a period in children's development, when risk behaviour is very common among young people to be accepted in their peer group. Risk behaviour includes certain types and forms of sexual activity, tobacco and alcohol consumption and drug use, while healthy behaviour covers nutrition and physical activities. The different dimensions and indicators are described below.

The impacts of poverty on health and cognitive development are decisive and stronger among the younger children. Duncan and Brooks-Gunn (2000) find that family poverty has selected effects on child development. Deep or persistent poverty early in childhood affects adversely the ability and achievement of children. They suggest policies to prevent economic deprivation of its effects. Against this background, it is important to identify the conditions under which children are doing well and can develop their full potential. This links to Sen's concepts of capability and deprivation (Sen 1985, 1999, 2000). In this study, capabilities are related to the children's needs, opportunities and choices to make them able to have desirable current and future development (Lister, 2004). 
There is an increasing interest among child welfare practitioners and policy makers towards reducing child poverty by focusing on literacy standards and exclusion from school. In particular, child poverty and social exclusion from a child's perspective (Ridge, 2002) uses child centred research methods to provide richness and context to the debate about how to tackle family poverty and social exclusion of children. It helps to understand the issues and concerns identified as important by low income families and it raises critical issues and an agenda for both policy makers and practitioners. Ridge shows that poor children are suffering from insufficient access to economic and material resources that are necessary for adequate social participation and academic parity.

\section{The Data}

The data used in this study were obtained from the Report Card 7 published by UNICEF INNOCENTI with the title "Child Poverty in Perspective: An Overview of Child Well-being in Rich Countries". The report provides a comprehensive assessment of the lives and well-being of children and adolescents in economically advanced nations. The data cover 33 developed and transition countries and most recent data mainly from 2001 to 2003. The full list of sample countries in alphabetic and non-alphabetic forms is reported in various tables. The children's well-being is represented by 40 well-being indicators. These are used in the computation of multidimensional indices to quantify child well-being in the sample countries. Summary statistics of the data are reported in Table 1 and a full description of the indicators is given in Appendix A and B. For additional information on the sources and background to the data, please see UNICEF (2007).

The indices are composite indices that are multidimensional and quantitatively measure child well-being (CW). The indices are composed of six well-being components: material (MW), health and safety (HS), educational (EW), peer and family relationships $(\mathrm{PF})$, behaviours and risks $(\mathrm{BR})$ and social (SW). Each of the well-being components is generated from a number of well-being indicators. The components are aggregated into one single index by assigning weights to each component prior to their aggregation. The weights are estimated parametrically or assigned non-parametrically on an ad hoc basis. A breakdown of the index into major components provides information about the contribution of individual indicators to each component, which can be useful in the design of child welfare policy of the countries.

The Material Well-being ( $\mathrm{mw})^{7}$ component is composed of three subcomponents: child income poverty, deprivation and work.

\footnotetext{
${ }^{7}$ Following suggestion by two referees, the definition of material child-wellbeing should be extended to include considerations about the impact of size of the families and the intra-household distribution of resources. This is motivated by the fact that considering a child is poor if the household he lives with is below the poverty line may not be sufficient (Bargain and Donni, 2007). For instance, there can be poor children in rich households and rich children in poor households depending on the intra household distribution of material and immaterial resources. The knowledge of the intra-household distribution of resources also allows identification of the children's individual utility level. These considerations may help explaining the relatively lower level of well-being in societies like Russia, where adult addiction to alcohol generates an evident skewed intra-household distribution problem. Unfortunately, we have no access to information on the intra household distribution of resources to incorporate in the material well-being component.
} 
The Child income poverty $(\mathrm{mw} 11)^{8}$ is defined as the percentage of children (017) in households with equivalent income less than 50 percent of the median of the population. Deprivation is based on three indicators including: percentage of children reporting low family affluence, aged 11, 13 and 15 (mw21), percentage of children aged 15 reporting less than six educational possessions (mw22), and the percentage of children aged 15 reporting less than ten books in the home (mw23). The work subcomponent is defined as the percentage of working-age households with children without an employed parent (mw31).

The Health and Safety (hs) component is also composed of three subcomponents: health and birth, immunization and child mortality. The health and birth sub-component is defined by two indicators: infant mortality rate per 1,000 live births (hs11) and low birth weight defined as percentage of births less than 2,500g (hs12). The immunization sub-component is defined based on three indicators as follows: measles: percentage of children immunized aged 12-23 months (hs21), dpt3: percentage of children immunized aged 12-23 months (hs22), and polio 3: percentage of children immunized aged 12-23 months (hs23). The child mortality is based on one indicator, namely deaths from accidents and injuries per 100,000 persons aged less than 19 years, average of latest three years available (hs31).

The Educational Well-being (ew) is composed of three sub-components: achievement, participation and aspirations. Achievement is represented by three indicators namely reading literacy achievement (ew11), mathematics literacy achievement (ew12), and science literacy achievement all measured at age 15 (ew13). Participation is based on one indicator: full-time and part-time students in public and private educational institutions aged 15-19 as a percentage of the population of 15-19 year-olds (ew21). Finally, aspirations is based on 2 indicators: percentage of 15-19 yearolds not in school or employment (ew31) and percentage of pupils aged 15 years aspiring to low skilled work (ew32).

The fourth component labelled as Peer and Family relationships (pf) is obtained from five indicators divided into three sub-components: family structure, family relations and peer relations. Family structure is represented by two indicators: percentage of young people living in a single-parent family structures, (pf11) and percentage of young people living in a step-family structure, both measured at the ages 11, 13 and 15 (pf12). The family relations also are represented by two indicators defined as: percentage of students whose parents eat their main meal with them around a table several times a week (pf21) and percentage of students whose parents spend time just talking to them several times per week, both aged 15 (pf22). The peer relation is based on one single indicator: percentage of young people finding their peers 'kind and helpful' aged 11, 13 and 15 (pf31).

The component of Behaviours and Risks (br) is the most comprehensive and information intensive well-being component. It is composed of three sub-components (risk behaviour, experience of violence and health behaviour) and is based on 12 wellbeing indicators. The risk behaviour is based on six indicators as follows: percentage smoking cigarettes at least once per week, aged 11, 13, and 15 (br11), percentage of young people who have been drunk two or more times, aged 11, 13, and 15 (br12),

8 It should be noted that poverty is multidimensional. For review of the quantitative approaches to multidimensional poverty and its many dimensions see Kakwani and Silber (2006 and 2007). 
percentage of young people who have used cannabis in the last 12 months, aged 15 (br13), adolescent fertility rate, births per 1,000 women aged 15-19 (br14), percentage of young people who have had sexual intercourse, aged 15 (br15), percentage of young people who used a condom during their last sexual intercourse, aged 15 (br16). The experience of violence sub-component is based on two indicators: percentage of young people involved in physical fighting in the previous 12 months (br21), and percentage of young people who were bullied at least once in the last 2 months (br22), in both cases aged 11, 13, and 15 years. The last sub-component of health behaviour is based on four indicators: percentage of young people who eat fruit every day, aged 11, 13, and 15 years (br31), percentage of young people who eat breakfast every school day, aged 11, 13, and 15 years (br32), the mean number of days when young people are physically active for one hour or more of the previous /typical week, aged 11, 13, and 15 (br33), and the percentage of young people who are overweight according to body mass index (bmi), aged 13 and 15 (br34).

The sixth component labelled as Subjective Well-being (sw) is divided into three sub-components covering health, personal and school well-being, which is computed based on six indicators. The health sub-component is defined by using percentage of young people rating their health as 'fair or poor', aged 11, 13 and 15 (sw11). The personal well-being is computed by using the following four indicators: percentage of young people with scores above the middle of the life satisfaction scale, aged 11, 13 and 15 (sw21), percentage of students who agree with the statement 'I feel like an outsider or left out of things', aged 15 (sw22), percentage of students who agree with the statement 'I feel awkward and out of place', aged 15 (sw23), and percentage of students who agree with the statement 'I feel lonely', aged 15 (sw24). The school well-being is also based on: percentage of young people 'liking school a lot', aged 11, 13, 15 (31).

In addition to the above 40 indicators, two country characteristics are used to group the countries into a number of groups distinguished by location, level of development and membership in organizations. Two such characteristics that are used in reporting the results are: country group (cgroup) divided into: Scandinavia (1), North Europe (2), South Europe (3), East Europe (4), North America and others (5), NonOECD (6). The second characteristic is a variable (oecd) indicating whether the country is an OECD members (1), or Non-OECD members (0).

The correlation matrix for the six components and their underlying indicators are reported in Table 2.A to 2.F. The deprivation indicators of percentage of children reporting low family affluence and percentage of children reporting less than six educational possessions are highly correlated (0.76). Concerning health and safety, infant mortality is highly correlated with child mortality from accidents and injuries (0.70). Percentage of children immunized for measles, dpt 3 and polio are also highly correlated (0.70 to 0.73). High negative association are found among the educational well-being indicators of achievement and non-participation in education $(-0.70)$ and between aspiration and non-participation in schooling (-0.89). The peer and family structure relationship show that the number children in single parents and step-family structure are positively correlated (0.87). The subjective well-being indicators of poor health and satisfaction with health are negatively correlated (-0.75). A positive correlation is found between feeling out of place and lonely $(+0.63)$. The correlation between behaviour and risk indicators are low (below $+/-0.50)$. 
The indicators listed above provide a good coverage of child well-being. However, it should be mentioned that child labour is somewhat unjustifiably left out of the child poverty picture. This weakness partly depends on lacking data, and partly depends on the limited literature review not sufficiently careful to contributions coming from economics (for few recent such studies see Brandolini, 2007; Dagum and Costa, 2004; Kakwani and Silber, 2006 and 2007).

\section{The Methodology}

There is a rich literature on the quantitative measurement of previously not measurable outcomes. The outcomes are often multidimensional and represented by several indicators with both positive and negative effects. However, the objective in this study is not to evaluate the effects of certain policy programs, but rather to quantify the state of the outcome. The multidimensionality of the outcome requires the creation of composite indices to have a single measure and also to aggregate the indicators. In this study, the focus is on the construction of an index of child well-being that is multidimensional and decomposable. Such an index will be a useful tool in the quantification of the state of well-being and the evaluation of its impacts on development. In this section, we introduce two approaches of non-parametric and parametric well-being indices frequently used in the construction of such indices.

\subsection{Non-parametric index}

The non-parametric index is a composite index constructed to aggregate a number of indicators of a certain process or outcome. Such indices are used for the measurement of many economic or social phenomena, such as globalization (Heshmati, 2006; Heshmati and Tausch, 2007; Tausch, 2006; Tausch and Heshmati, 2006; Andersen and Herbertsson, 2003; Dreher, 2005; Kearney, 2002 and 2003; Lockwood, 2004; Lockwood and Redoano, 2005; Mahler, 2001), the state of the environment (Kang, 2002), human development (Noorbakhsh, 1998), the trajectory of the development strategy, technology and research (Heshmati and Oh, 2007; Archibugi and Coco, 2004; Grupp and Mogee, 2004), or other types of indices. The famous globalization index is a simple combination of forces driving the integration of ideas, people, and economies, worldwide. It is composed of four major components: economic integration, personal contact, internet technology, and political engagement, each being generated from a number of determinant variables. This index could serve as a model for computation of a child well-being index (CWI).

In the case of child well-being, the index following UNICEF (2007) is composed of six components: material well-being, health and safety, educational wellbeing, peer and family relationships, behaviours and risk, and subjective well-being. The CWI is then estimated parametrically or computed non-parametrically based on the normalization of the child well-being indicators and their subsequent aggregation using an ad hoc weighting system as follows:

$$
C W I_{t}=\sum_{j=1}^{J} \sum_{m=1}^{M} \omega_{j m}\left\{\left(X_{j m i}-X_{j m}^{\min }\right) /\left(X_{j m}^{\max }-X_{j m}^{\min }\right)\right\}
$$


where $i$ indicate country; $m$ and $j$ are within and between component variables; $\omega_{j m}$ are the weights attached to each contributing $\mathrm{X}$-variable within a component and weights attached to each of the six components; and min and max are minimum and maximum values of respective variables across countries in a given year. The index is similar to the very commonly-used index, the United Nations Human Development Programme (UNDP) Human Development Index (HDI), which is based on educational attainment, life expectancy and real GDP per capita. ${ }^{9}$

The index in (1) is suitable for indicators with an expected positive effect on child well-being. In cases where the indicators are expected to have a negative impact on well-being, the corresponding index is written as:

$$
C W I_{i}=\sum_{j=1}^{J} \sum_{m=1}^{M} \omega_{j m}\left\{\left(X_{j m}^{\max }-X_{j m i}\right) /\left(X_{j m}^{\max }-X_{j m}^{\min }\right)\right\}
$$

where the two indices differ only by the numerator of the ratio. Alternatively, prior to the normalization in (1) and aggregation, the negative indicators are transformed to inverses, $(1 / X)$ reversing their expected impact from negative to positive.

The index component's weights in equations (1) and (2) are chosen on an ad hoc basis and are constant across countries. However, this non-parametric index can be used as a benchmark index. Lockwood (2004), in computation of a globalization index, finds the ranking of countries to be sensitive to the way the indicators are measured, normalized and weighted. In this study, we choose the weighting approach similar to the commonly used human development index, where all indicators are given equal weight (see Noorbakhsh, 1998). Ideally, the weights should differ by indicators, countries as well as over time.

\subsection{Parametric index}

The literature on such index numbers is diverse and voluminous. There are at least two other alternative but parametric approaches to the non-parametric index above for computing a child well-being index; using the principal component (PC) or factor analysis (for recent applications see Heshmati, 2006; and Andersen and Herbertsson, 2003). ${ }^{10}$ In this study we adopt the PC approach. Since the two methods in normalized form give PC scores with unit variance, we use only the PC results in the analysis of child well-being.

Principal component analysis is a multivariate technique for examining relationships within a set of interrelated quantitative variables. Given a dataset with J numeric indicators, at most $\mathrm{P}$ principal components can be computed; each is a linear combination of the original indicators with coefficients equal to the Eigenvectors of the correlation of the covariance matrix. The principal components are sorted according to the descending order of the Eigenvalues, which are equal to the variance of the

\footnotetext{
${ }^{9}$ For a review of the HDI, its components, criticisms, alternative measures and suggestions for some improvements of the index, see Noorbakhsh (1998).

${ }^{10}$ For recent surveys on the literature on the use of composite indices in different development research context, see also Archibugi and Coco (2004) and Grupp and Mogee (2004).
} 
components. In short, PC analysis can be viewed as a way to uncover approximate linear dependencies among variables. This method gives a least square solution to the following model:

$$
Y=X B+E
$$

where $Y$ is a $n \times p$ matrix of the centred observed variables, $X$ is the $n \times j$ matrix of scores of the first $j$ principal components, $B$ is a $j \times p$ matrix of Eigenvectors or factor patterns, $E$ is a $n \times p$ matrix of residuals, $n$ is the number of observations, $p$ is the number of partial variables, and $j$ the number of variables or indicators of strategy. Unlike in a traditional least squares estimation method case, where the vertical distance to the fitted line is minimized, here the sum of the squared residuals is measured as distances from the point to the first principal axis.

PC analysis was originally developed by Pearson (1901) and further developed by Hotelling (1933). The method has been employed in many areas including the computation of an environmental index (Kang, 2002) and in the computation of a simple globalization index using trade and financial openness by Agénor (2003). Heshmati and Oh (2007) used the method for computation of Lisbon Development Strategy Index.

Each of the parametric and non-parametric indices and weighted or un-weighted indices has their own advantages and disadvantages. In this study, they are used to measure the state of child well-being among the OECD countries and attribute it to the possible underlying sources of well-being. A breakdown of the index into major components provides possibilities to identify positive and negative sources of wellbeing. The results can be used in the design of economic policy measures to bring about desirable changes in national and international child well-being policies. It could be also useful in the evaluation of child policy measures.

Applying the principal components method, we should be well aware of the limitations or possible limitations of the method used. It should be emphasized that the principal components method is generally a very useful method to reduce the complexity of the data with multi-dimensions such as child well-being. However, the linear combinations of the different dimensions of interest may not be always easy to interpret, less so the is the complex aggregate index. In addition it might be of little help in determining weights embedding a personal or collective value judgment. In sum, a main limitation of the method could be that what is statistically reasonable may not be neither economically nor normatively reasonable in the evaluation of child well-being. This is more evident in particular in cases with data limitations.

\section{Analysis of the Results}

\subsection{Estimation of the Indices and their Components}

Three child well-being indices including one non-parametric and two parametric models are estimated. The non-parametric human development type index with equal weights and the two parametric principal component models are estimated. The Eigenvalues and Eigenvectors of the correlation matrix of the forty well-being indicators are presented in Section A-F of Table 3. Twelve of the Eigenvalues are bigger than 1.00 and 
are subsequently used in computation of the well-being index. These 12 principal components together explain 85.94 percent of the total variations. The contribution of the components to the explanation of the variance is reduced from 19.11 percent by the first component to 2.60 percent by the last component. By looking at the Eigenvectors, it becomes evident which indicators form a component and the nature of their effects. An indicator with an Eigenvector exceeding 0.30 is considered as a contributor to the principal component.

The Eigenvalues and Eigenvectors of the correlation matrix of the six subcomponents indices are presented in Sections A to F of Table 3. The number of Eigenvalues bigger than 1.00 and share of variance explained by these principal components is: material well-being $(2,0.6801)$, health and safety $(2,0.6530)$, educational well being $(2,0.7535)$, peers and family relationships $(3,0.8385)$, behaviour and risk (4, $0.6672)$ and subjective well-being (3, 0.8580). In each sub-component, several of the indicators are statistically significant contributors to the principal component by having an Eigenvector exceeding 0.30 .

The overall variations in the three indices and their underlying six components can be decomposed into within and between countries and regions. The rest of the analysis is based on country and regional heterogeneity in well-being. Due to the crosssectional nature of the data, we cannot discuss the temporal changes over time.

\subsection{Country Heterogeneity in Well-Being}

By using the formulae in equations (1) and (2), the three well-being indices are computed for each of the 33 sample countries. Following the human development type index approach (CWI1), all well-being factors are given identical weights. The index in disaggregate (CWI3) and aggregate (CWI2) forms are reported in Table 4. The countries are ranked by descending order of the overall index (CWI1) in Table 4. The distribution of index and its decomposition is shown in Figure 1. For matters of sensitivity analysis, this simple non-parametric index with equal weights is used as a benchmark model. The results show that Netherlands, Sweden, Denmark, Spain and Iceland are ranked as the five countries with the highest rates of child well-being, while Lithuania, New Zealand, Estonia, UK and Russian Federation have the lowest well-being.

The highest/lowest contributing components to a country rank are: material (Iceland/Lithuania), health and safety (Sweden/Austria), educational (Finland/Israel), peers and family (Italy/New Zealand), behaviour and risks (Greece/UK), and subjective well-being (Israel/Russian Federation). The countries differ in their performance in respect with different well-being components. There is no country among the top 5 that gains the highest score in more than 1 of the 6 components. For instance, Spain, which is ranked in the 4th position, gains low scores in material well-being, health and safety and educational well-being; Netherlands and Denmark ranked as $1^{\text {st }}$ and $3^{\text {rd }}$ perform not well in material well-being, while Iceland in subjective well-being. Among the lowest ranked countries, we find that New Zealand is performing relatively well, but its low rank as the $30^{\text {th }}$ is caused by its poor performance in health and safety and peer and family relationships.

The results from the two parametric principal component analyses are reported in Table 5.A. In the first model, each component is estimated separately and then aggregated into one single index (CWI3) by using the share of the variance explained by 
the component as weights. ${ }^{11}$ In the alternative index, the aggregate index (CWI2) is not decomposed. The distribution of the index and its decomposition is shown in Figure 2. The top 5 countries ranked based on the parametric approach (CWI2) are Netherlands, Sweden, Norway, Spain and Denmark. Norway and Iceland switch their position as a result of changing the method of computation of the index. Iceland lowered rank is due to peer and family, behaviour and risk and subjective well-being, while in the case of Norway, the low rank is attributed to the behaviour and risk component. It should be noted that the weighted parametric (CWI3) method gives similar ranking as the nonparametric approach. The low ranked countries are Latvia, UK, Lithuania, Estonia and Russian Federation.

Surprisingly, the UK is performing extremely poor in child well-being and the Russian Federation occupies the lowest rank in all approaches. The UK is relatively well placed in educational well-being but unable to perform well in the remaining well-being components. Regardless of the method used and the weighting system, the Russian Federation is the worst performing country in providing well-being to its children. In terms of GDP per capita, the Russian Federation is better than many other of the sample countries, but yet no priority is given to allocation of resources to children's well-being.

The rank of individual countries, the disaggregated parametric components as well as the three composite indices are reported in Table 6 . The performance of countries differs by components and there is no indication that for a country to be very good in one component guarantees a high performance in another component. One such example is Greece, which is ranked 1 st in behaviour and risk, but $30^{\text {th }}$ in material well-being. However, there is an indication that the Scandinavian countries and the Netherlands are in general good in most components. In comparison with other developed countries, children have not benefited much from the accumulated wealth and high rate of productivity in USA and UK.

Map 1a and Map 1b shows the results for the non-parametric human development type index approach (CWI1), when all well-being factors are given identical weights. Map 1a shows the results on a global scale, while Map $1 \mathrm{~b}$ the corresponding but on a European scale. It is especially noteworthy from the Lisbon strategy perspective of the European Union (see Heshmati and Tausch, 2007) to catch up with the United States by 2010 to make Europe the most competitive economy of the world, the EU-27, with the notable exception of Austria, Estonia, Lithuania and the $\mathrm{UK}$, is already on equal footing or even ahead of the United States:

\footnotetext{
11 A referee with reference to Brandolini (2007) and Decancq and Lugo (2008) suggested that the discussion about the empirical and normative importance of these weights in the multidimensional measurement of poverty and the tradeoffs among the poverty dimensions is insufficient. This judgment is based on application of deprivation weights in Dagum and Costa (2004). The shares of the variance or weights are reported in Table 3. . In the absence of better al to aggregate the different components into one single index we find the weights coherent with common sense following the recommendations of Decancq and Lugo (2008).
} 
Map 1a: Child-well-being on a global scale - results from the non-parametric index approach (CWI1), when all well-being factors are given identical weights

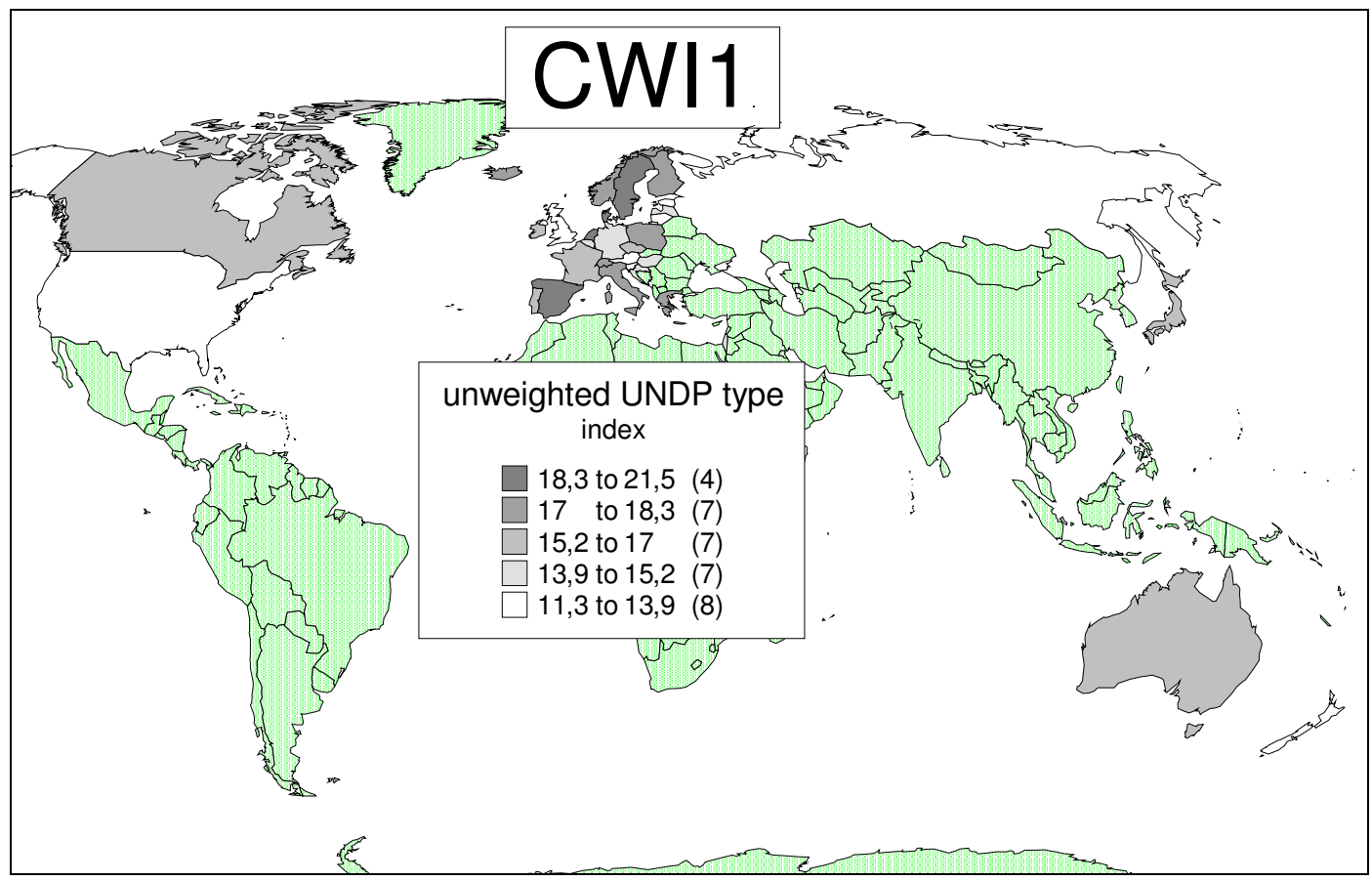

Source: Own compilations from the appendix tables

Map 1b: Child-well-being in the European arena - results from the non-parametric child well-being index approach (CWI1), when all well-being factors are given identical weights

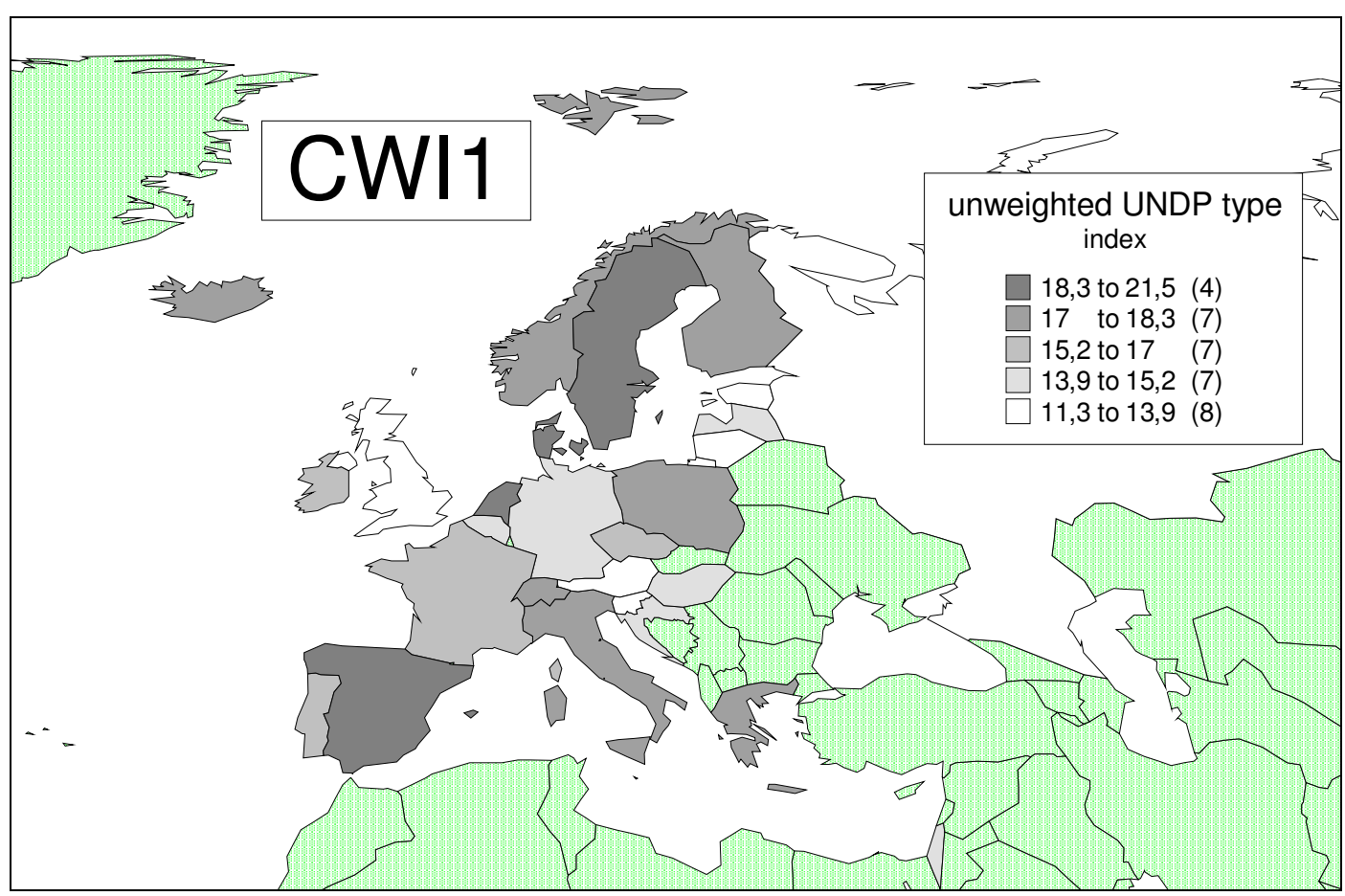

Source: Own compilations from the appendix tables 
Map 2a and Map 2b shows the results for the parametric principal component analysis based index approach (CWI2), when all well-being factors are used jointly in computing the index. Map 2a shows the results on a global scale, while Map 2b the corresponding but on a European scale. Also, the principal components data clearly show that in Lisbon strategy terms, Europe must not shy away from a comparison of its child-well being with the United States, the Lisbon strategy reference country number 1.

Map 2a: Child-well-being on a global scale - results from the aggregate parametric principal components (CWI2) approach

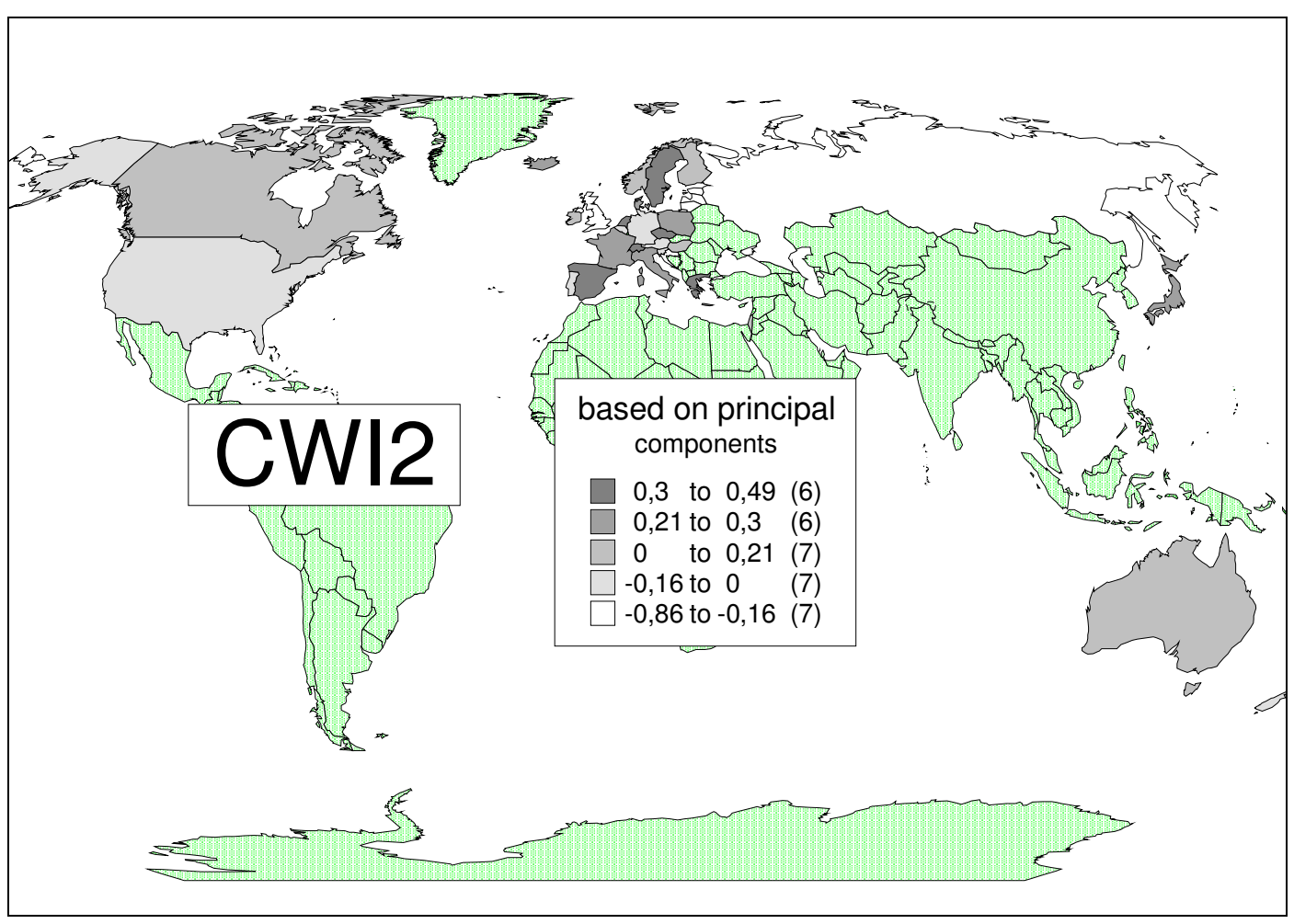

Source: Own compilations from the appendix tables

The principal components data point to the deficiencies in child-well-being in the UK, in Croatia, the Baltic region, and Russia. 
Map 2b: Child-well-being in the European arena - results from the aggregate parametric principal components (CWI2) approach

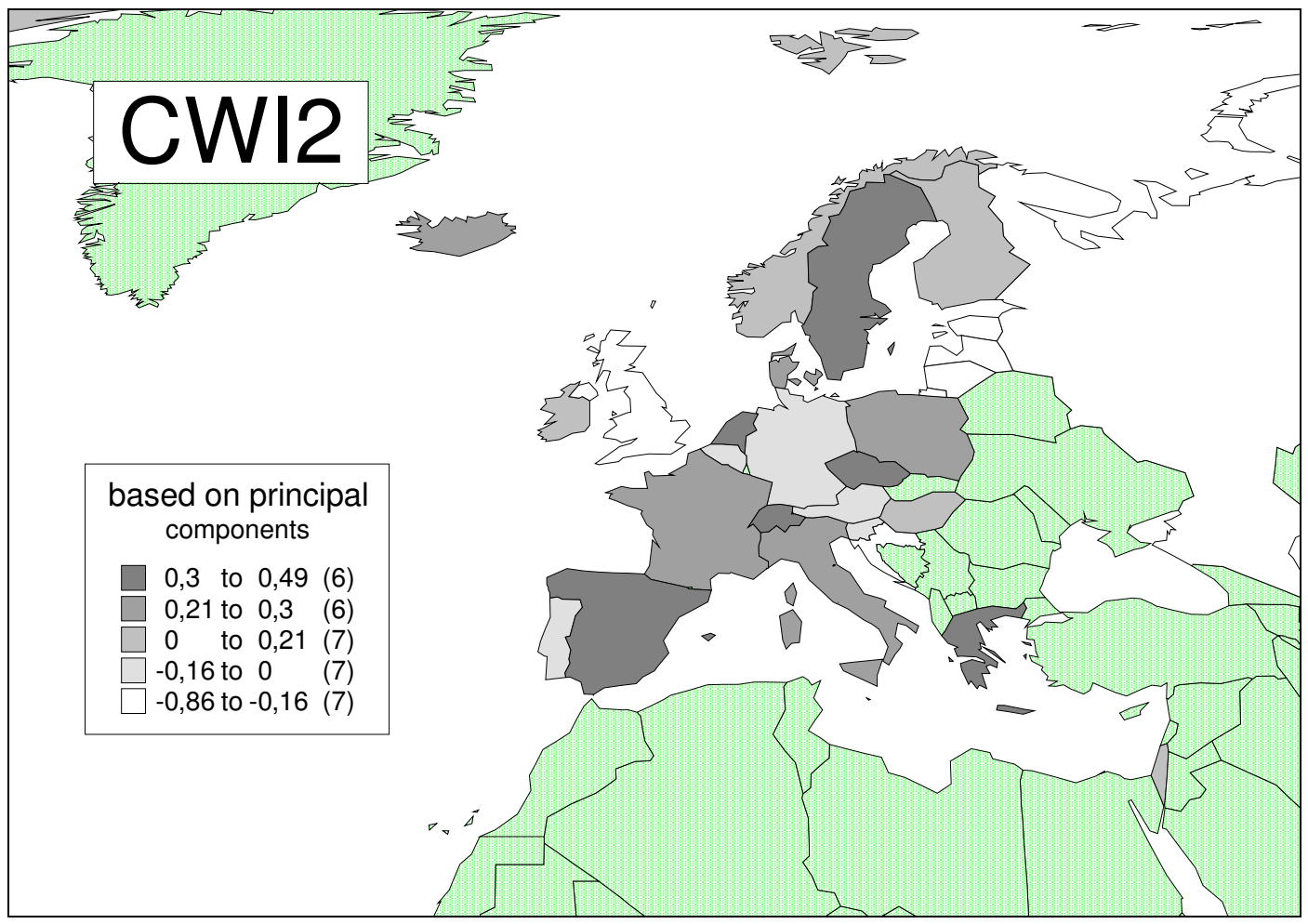

Source: Own compilations from the appendix tables

The point, made by our maps, is also further being developed in the following paragraph, which will deal with the regional heterogeneity in well-being. Finally, the aggregate single index computed by weighing the disaggregated 6 components (CWI3) yields pretty much the same results in terms of the Lisbon strategy competition EU-27USA. Map 3a shows the results on a global scale, while Map 3b the corresponding but on a European scale. 
Map 3a: Child-well-being on a global scale - results from the disaggregated parametric principal component (CWI3) index

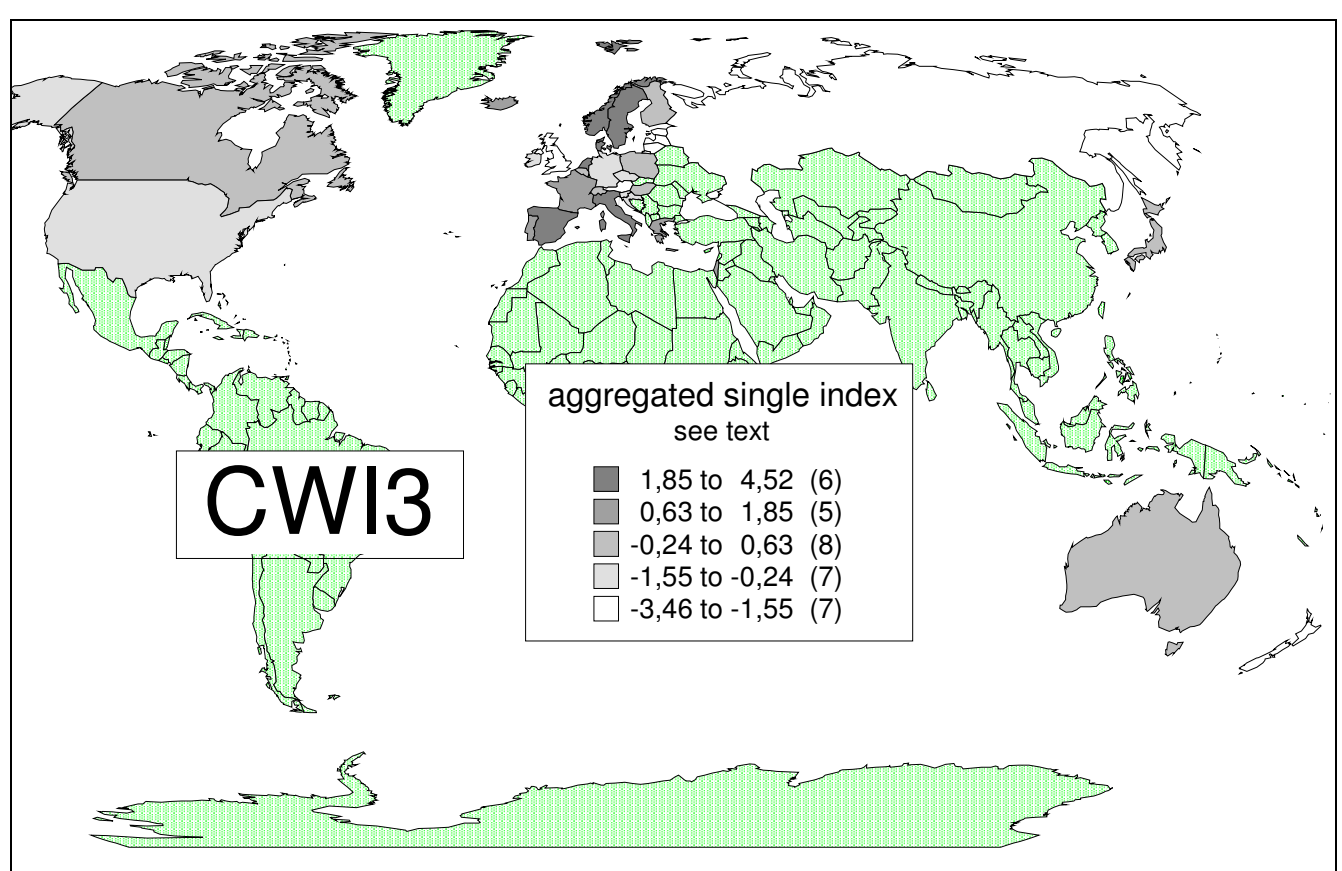

Source: Own compilations from the appendix tables

Again, the child welfare policy deficits in the UK, in Austria, and in the Baltic States clearly emerge:

Map 3b: Child-well-being in the European arena - results from the disaggregated parametric principal component (CWI3) index

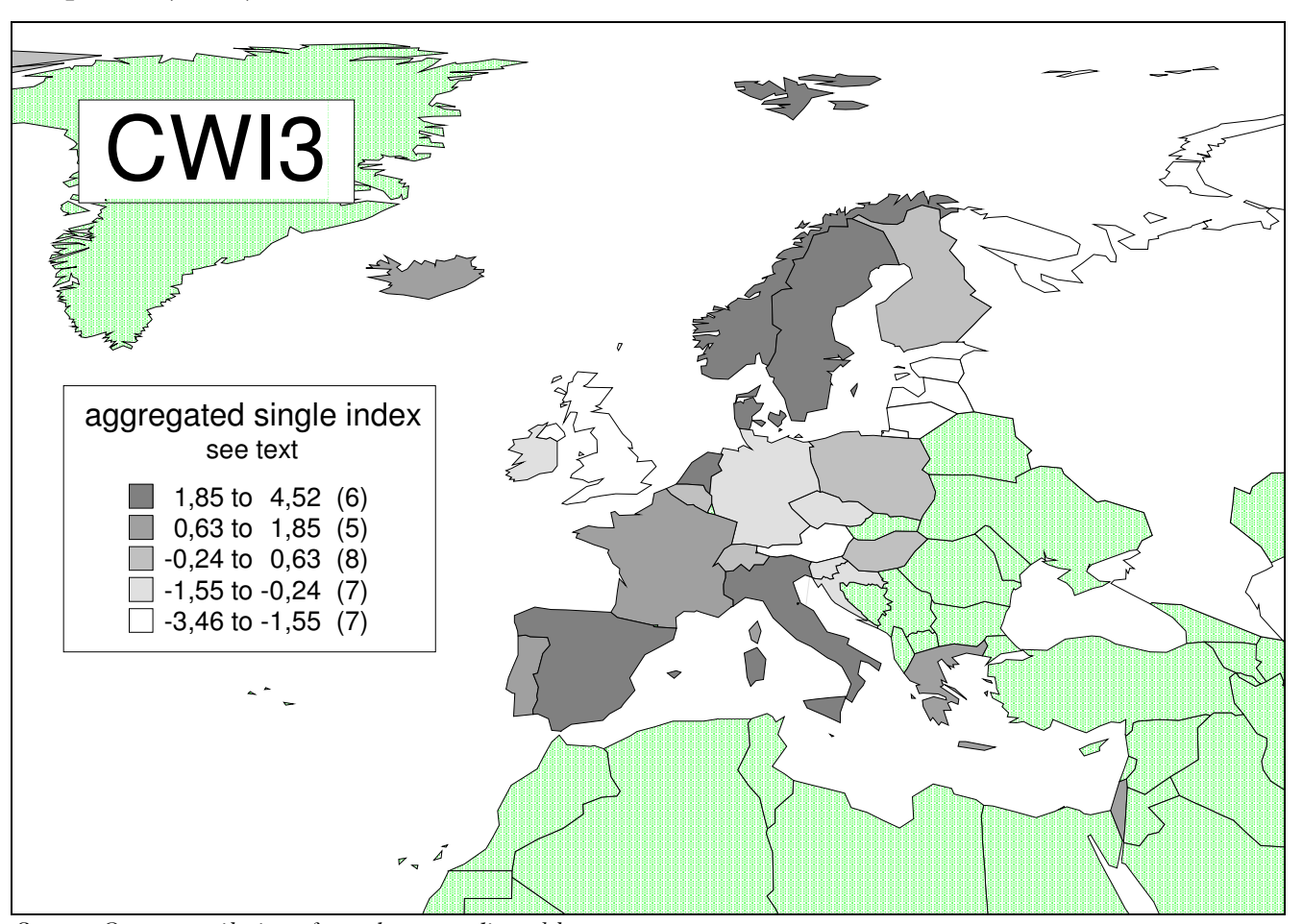

Source: Own compilations from the appendix tables 


\subsection{Regional Heterogeneity in Well-Being}

The countries are grouped into 6 groups by regional location and membership in the OECD. We find a clear indication of the heterogeneity in child well-being across groups of countries. This is confirmed by all the three well-being indices, which give similar rankings. The Scandinavian countries are topping the list by performing best in material well-being, health and safety and educational well-being, while they are not performing well in behaviour and risk and subjective well-being.

The South European countries show exceptional performance in peer and family relationships and behaviour and risk. The East European countries, as expected, show their comparative advantage in health and safety and educational well-being. The North European countries are unexpectedly holding relatively a low position in the provision of well-being for their children. The North American countries are also weak with respect to health and safety, peer and family and subjective well-being. Finally, the Non-OECD countries are weakest in economics and educational well-being.

\subsection{Correlation among Indices and Components}

The correlation matrix of well-being components estimated using principal component analysis and the three indices are reported in Table 7. The between component correlations show that material well-being is positively correlated with educational well-being. Behaviour and risks is also positively correlated with subjective well-being. The remaining paired relationships between the different components are not statistically significant. The three well-being indices are highly correlated with each other (0.82-0.92) suggesting similar ranking between the countries. The highest correlation (0.9236) is found between the disaggregated parametric and non-parametric human development type well-being indices. Further research could take up the task to provide a graph showing the relationship between income inequality and child wellbeing, because taking account of the per capita GDP level, it is probably income distribution, which deeply interacts with child well-being. Unfortunately, we did not have as yet access to really time-matched data on income inequality for the sample countries and the given time period. However, the correlation matrix shows that child well-being is highest correlated with educational and material well-being.

The three indices normalized to the best practice country Netherlands and its value is shown in Figure 3. The picture shows similar trends in the ranking of countries, but yet significant shifts in the position of countries due to the use of the computation method. The main contributors to the aggregate principal component analyses (CWI2) are educational well-being, economic well being and behaviour and risks. The contributors to the non-parametric index (CWI1) are health and safety and educational well-being. Contributors to the disaggregated principal component index are economic well-being, health and risk and subjective well-being components.

\subsection{Efficiency in Provision of Well-Being}

In Table 8.A, we report the efficiency of countries in provision of child wellbeing compared with the sample country with the best practiced well-being. The measure is in the interval 0 to 100 , where 0 is assigned to the country with the lowest 
score and 100 to the country with the highest score. The measure is computed for each of the 6 components and for each of the 3 well-being composite indices. It should be noted that the efficiency measure not only shows the rank, but also the metric distance to the frontier well-being and it is easily interpretable as percentage points. Distribution of efficiency based on the non-parametric index and its decomposition is shown in Figure 4. The efficiency of countries measured by the three index methods is shown in Figure 5. In general, all the three methods show similar performances; however, in a few cases we observe significant shifts in the position of countries.

The frontier country (components) are Iceland (material well-being), Sweden (health and safety), Finland (educational well-being), Italy (peer and family relationships), Greece (behaviour and risks), and Israel (subjective well-being). Concerning the composite non-parametric index and disaggregate parametric index, Netherlands is serving as the reference country, while in the case of the parametric aggregate index, Sweden holds the frontier position. We find a wide range of variation in the distribution of efficiency among the countries. For instance the efficiency of frontier countries ranges from 37.54 to 90.18 for Netherlands, 22.80 to 100.00 for Sweden, 12.14 to 100.00 for Italy, 25.63 to 100.00 for Iceland, 00.00 to 100.00 for Israel, 00.00 to 100.00 for Greece, and 18.71 to 100.00 for Finland. In the case of Russian Federation, which is placed at the bottom of the distribution, the rate of efficiency ranges from 00.00 to 53.28. Ideally, in addition to the mean value, future research should compute the range, variance and standard deviation for each country as a measure of concentration and dispersion in performance.

The mean efficiency by country groups, where countries are grouped into 6 groups by geographic location, is reported in Table 8.B. As expected in all three index cases, the Scandinavian countries top the list followed by the South European countries. Surprisingly, the North European countries are holding the third position as a country group and the gap to the South European countries is quite large. It was previously mentioned that in the case of the non-parametric index and disaggregate parametric index, Netherlands served as the reference country, while in the case of parametric aggregate index, Sweden held the frontier position. The North American and NonOECD country groups are the least efficient country groups in the provision of child well-being with less than 40 efficiency reported performance points compared with the reference countries.

\subsection{Guidelines to Improve the Index}

There is a growing literature on the measurement of the child well-being, inequality, poverty, health, growth and labour market evaluations. ${ }^{12}$ However, the link

\footnotetext{
12 For a selection of research see: Bradshaw (2002); Mayhew (2005) and Brooks and Hanafin (2005) on child-well-being; Bradshaw (2006) on the measurement of child poverty using income data; Cantanero et al. (2005) on effects of income inequality on population health; Förster and D'Ercole (2005) on income distribution and poverty; Coles and Richardson (2005) on education and well-being of children; Gregg et al. (2005) on the effects of mothers return to work on child development; Haveman et al. (1997) on childhood poverty, adolescent schooling and fertility; NicGabbainn and Sixsmith (2005) on children's understanding of well-being; Peters and Mullis (1997) on the role of family income on adolescent achievement; Rodgers and Pryor (1998) on the effects of divorce and separation; Santos (1999) on the human rights; European Commission, (2003) and Papadopoulos and Tsaklogou (2003) on
} 
between child well-being and a number of indicators such as income inequality, poverty, growth, and labour market outcomes are not investigated much. With the exception of a partial view in some studies, the relationship between, for instance inequalities in opportunities, child well-being and labour market outcomes, there were no attempts made to statistically estimate and test such multi-dimensional relationships. The issue of structural equation approach accounting for causal relationships between different factors is discussed in Bollen and Lennox (1991).

The well-being index in this paper is defined in three different ways: the human development type index and the two principal component based indices. In the first index case, all underlying factors are given identical weights. The assumptions of equal weights are very strong and it might have major implications for the index, its interpretation and the ranking of countries. For instance, factors like parents employment might have implications for children's school enrolment and their access to heath care in one country but not in another with guaranteed and free services to children. One way to avoid the assumption of equal weights is to assign a number of factors on an ad hoc extra weights basis

Traditionally, in the literature, researchers using the principal component analysis methodology use the first principal component to arrive at a single "omnibus" measurement scale, but in this study, we use a more sophisticated approach, relying on the weighted average of the several principal components with Eigenvalues greater than 1.0. In order to make inferences about the choice of index, it would be desirable to investigate the sensitivity of the index and the ranking of countries with respect to the choice of alternative combinations of the principal components. The indices above serve as a major first step to measure a proper composite index of child well-being. There exist several other indices introduced by a number of researchers. The indices in this study are superior to the above indices due to the large number of indicators used, the different computation methods applied and the sensitivity analysis carried out.

Despite significant progress made in the construction of a well-being index, several essential improvements are still necessary. One improvement will be achieved by a further consideration in future research about the impact of size of families and the intra-household distribution of resources. Another key improvement is that the index should take an axiomatic approach that sets out its desirable properties and provides a family of indexes that fulfil such properties. The literature already deals with an axiomatic approach for multivariate indices of poverty, but not exhaustively yet in the context of child well-being. Improvements should also involve the identification of other key dimensions of well-being, accounting for differences in level of development and regional location. The index or indices should fully quantify child well-being regardless of economic and geographic location of countries. In addition to the current components, it or they should incorporate several other country-specific relevant components.

Industrialized countries dominate the current sample, with different welfare characteristics than developing countries. The over-weighting of the advanced industrial countries in the sample results in biased level and changes in the mean well-being. The sample of countries should be expanded in future research to include more developing

social exclusion; and Sobolewsky and Amato (2005) on the economic hardship in childhood and its effects on well-being in adulthood. 
and transition countries. Provided that the relevant data are being gathered by international organizations, this would enable researchers to control for unobservable country-specific effects and to model the temporal patterns of key variables. Access to such panel data would also enable the identification of well-being effects by performance comparisons of countries over time, before and after child welfare reforms and by the use of matching techniques to construct counterfactuals. This would provide valuable information on child well-being, its consequences and redistributive policies. The index or indices should be designed in such a way that they can further be used for international, regional and within-region comparisons. These improvements will affect positively the analysis of the determinants of child well-being by paying more attention to the country samples, measurement problems, data issues and data sources.

\section{Policy Implications}

In this paper, based on the child welfare indices and their underlying components, we computed efficiency levels for individual countries in child well-being policy. The efficiency level was then compared to that of the countries with the best practice well-being policy. We have also suggested several improvements for the data collection, for the processing and for the computation of data. Having identified performances of sample countries and identified the strength and weakness of different welfare systems, in this section we will further analyze implications of the UNICEF study and the conclusions one would be able to draw from our own data analysis.

For one, it is certain that whatever indicator is being constructed from the available data, there is a very close correlation between the indicators used (see Graph 1). The non-parametric UNDP type (CWI1) index and the aggregate principal components (CWI2) index have a common variance of more than $75.6 \%$ :

Graph 1: The correlation between non-parametric (CWI1) index and the aggregate parametric principal components index (CWI2) approaches

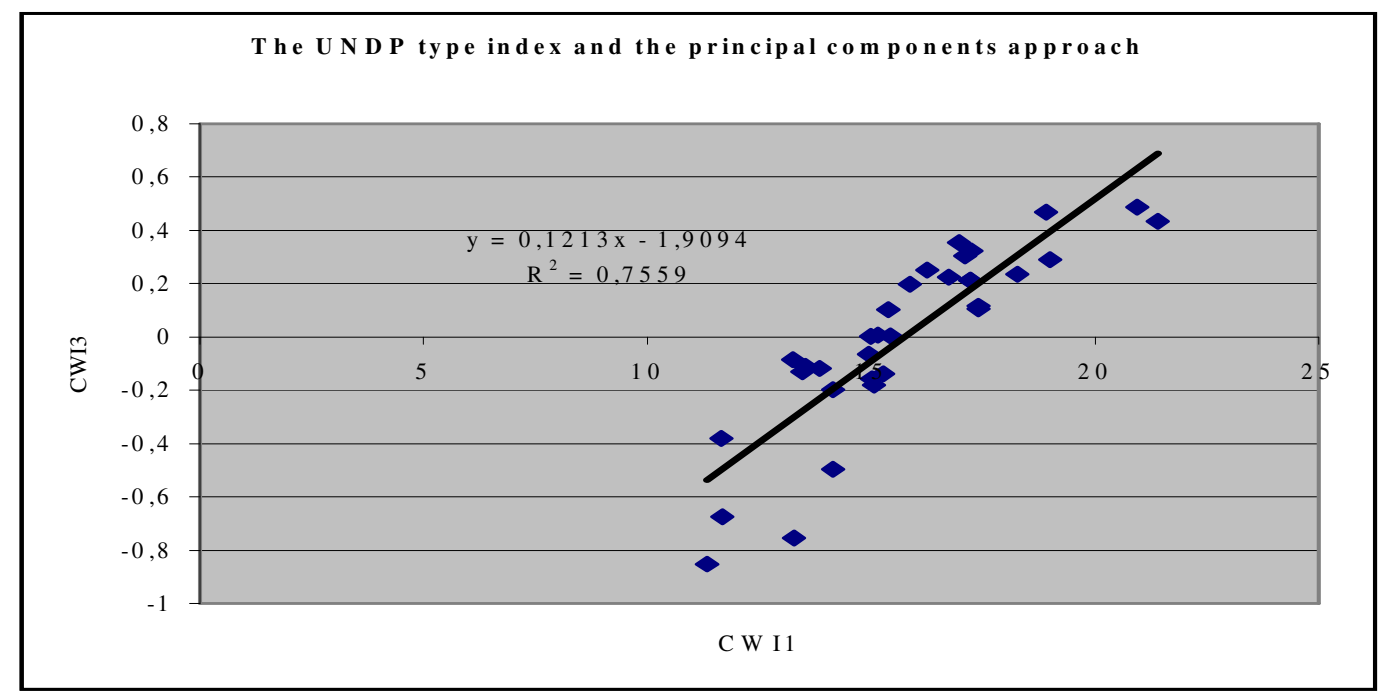

Source: Own compilations from the appendix tables

The non-parametric UNDP type CWI1 index with same weights assigned to each indicator and the disaggregated parametric principal component based (CWI3) 
index are even stronger related to one another. Their joint variance is $85.3 \%$ (see Graph 2):

Graph 2: The non-parametric UNDP type (CWI1) index and the disaggregate parametric principal component (CWI3) index approaches

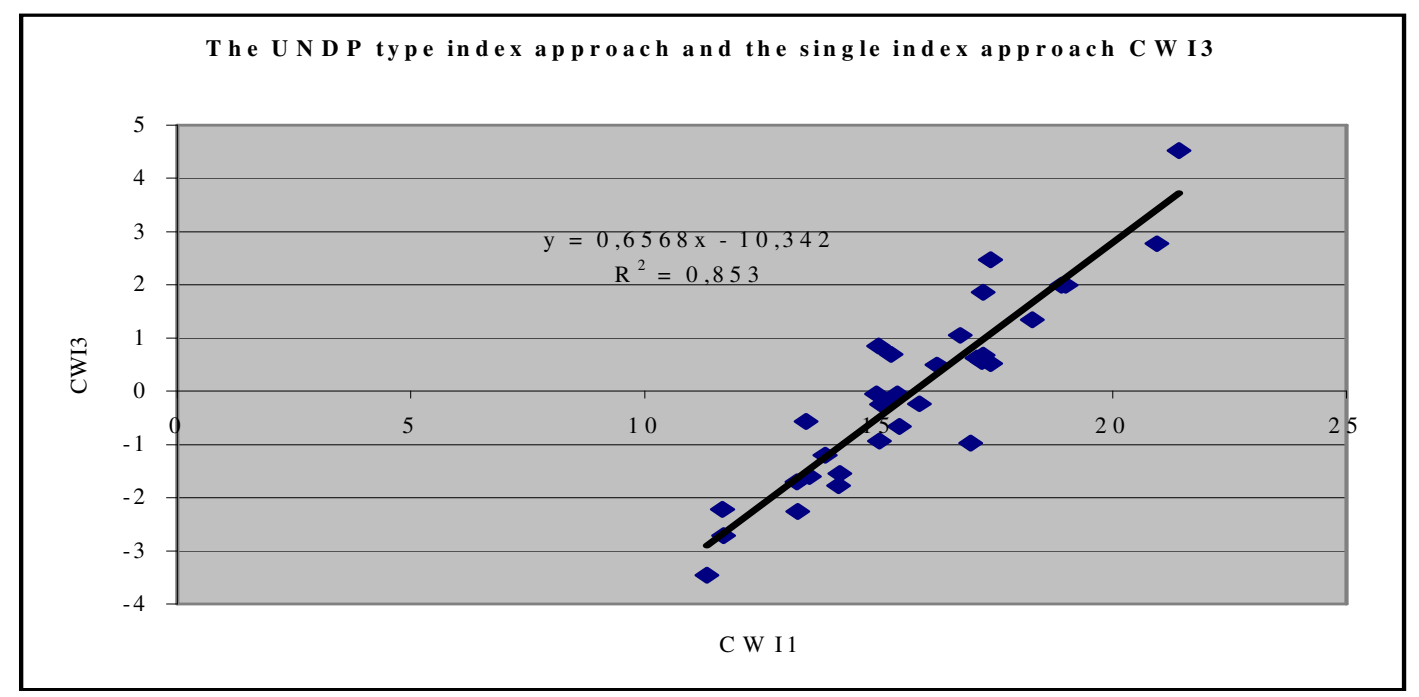

Source: Own compilations from the appendix tables

The disaggregated principal components solution (the CWI3-index) also have $67.8 \%$ of its variance in common with the aggregate principal component (CWI2) index (see Graph 3).

Graph 3: The correlation between parametric aggregate principal components (CWI2) index and the decomposed principal component (CWI3) index

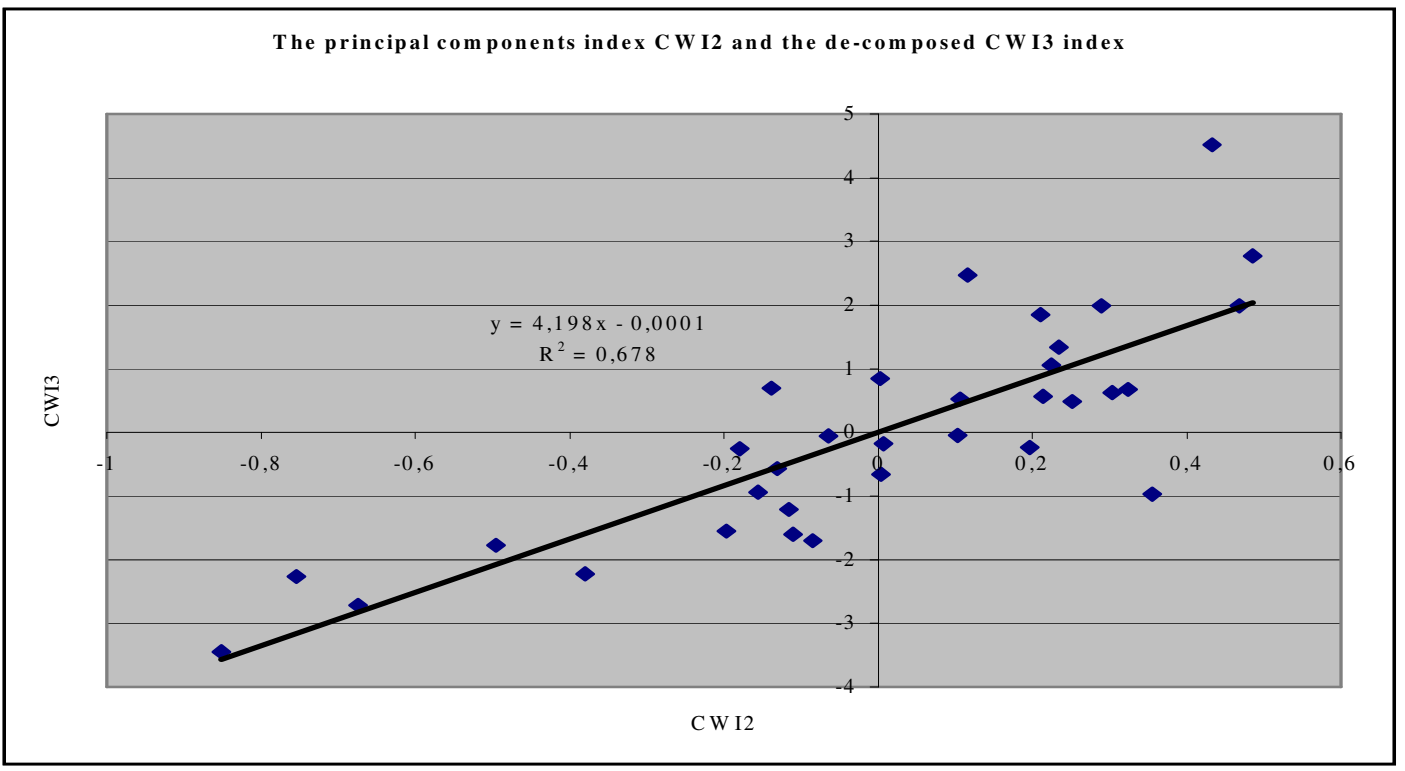

Source: Own compilations from the appendix tables 
Finally, we also try to answer the question, whether or not the UNICEF (2007) ranking procedure, which was based on average rankings of the 6 well-being dimensions (material well-being, health and safety, educational well-being, family and peer relationships, behaviours and risks, and subjective well-being) perhaps contributed to the very bad overall ranking, which the United Kingdom experienced in the UNICEF study.

To answer this question, we compared the rankings of the CWI1 measure and the CWI2 measure as shown on Map 4a on the global scale and on Map 4b at the European level (see also Table 9 and 10):

Map 4a: The bias of the non-parametric human development (CWI1) index approach over the results of the aggregate principal components (CWI2) approach on a global scale

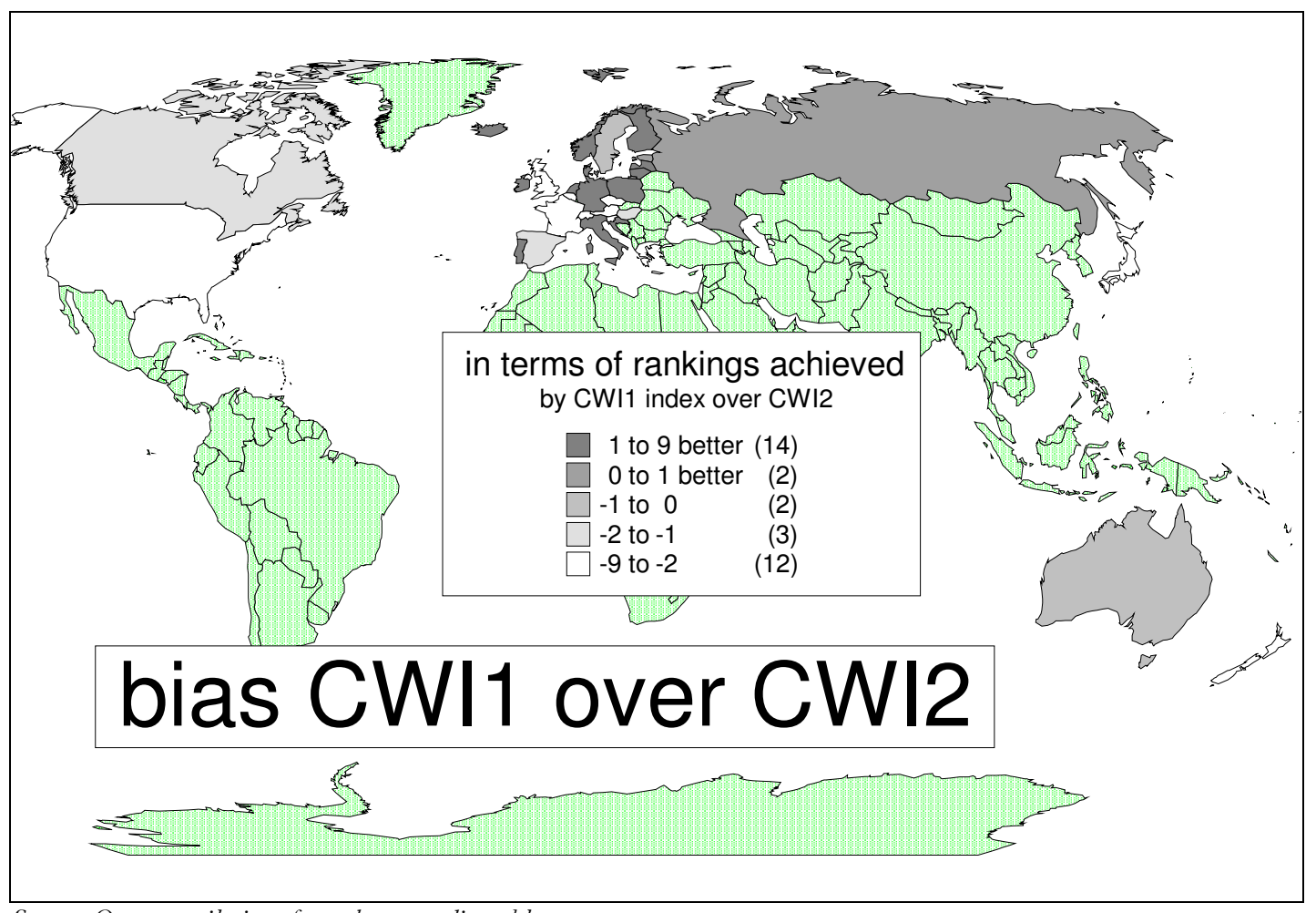

Source: Own compilations from the appendix tables 
Map 4b: The bias of the non-parametric human development (CWI1) index approach over the results of the aggregate principal components (CWI2) approach on a European scale

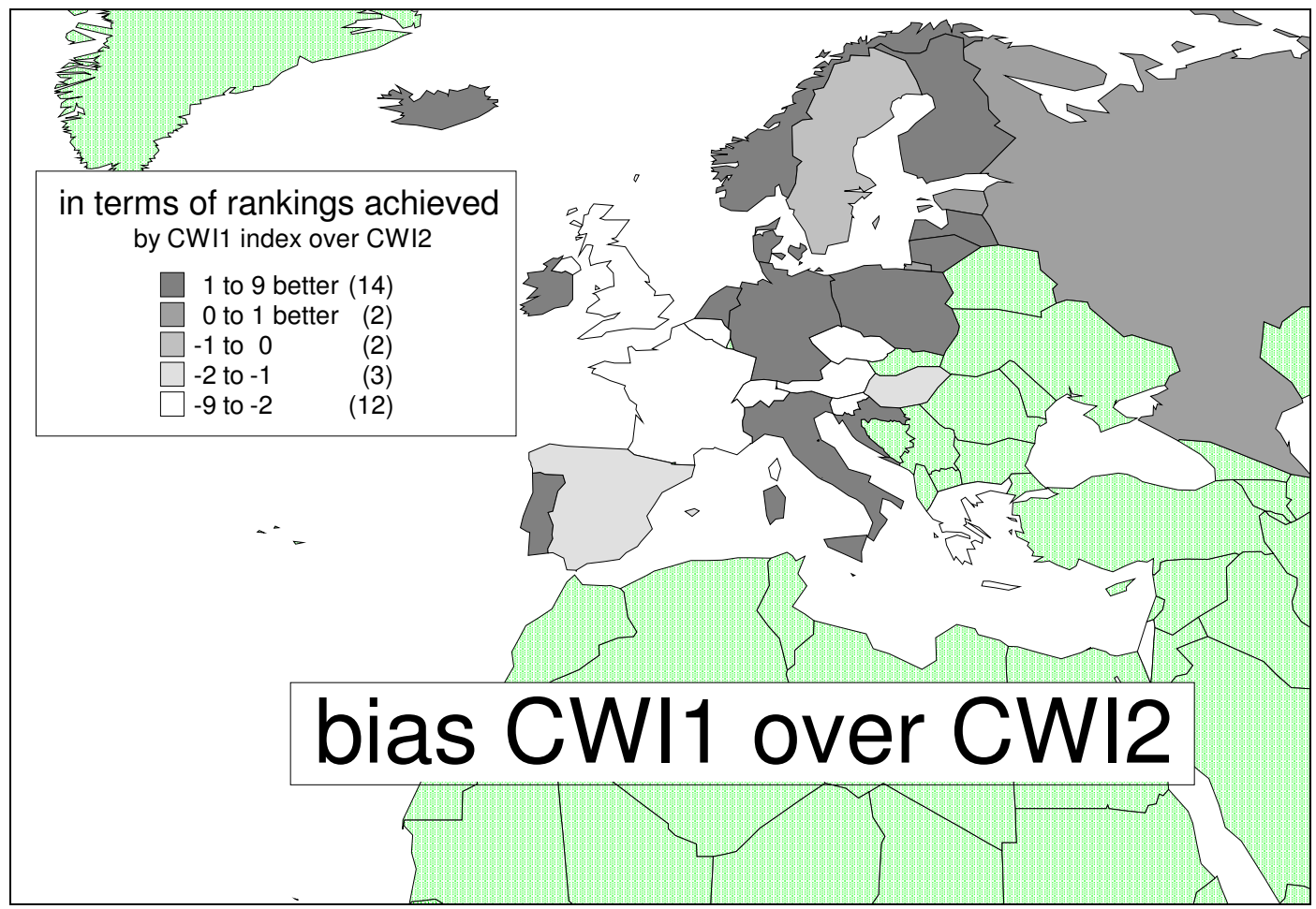

Source: Own compilations from the appendix tables

Based on this analysis, we can say that the non-parametric solution to aggregate the UNICEF data indeed presents a bias in favour of some continental European countries, the Irish Republic and Iceland vis-à-vis models such as Britain, the United States, and New Zealand, where for many years neo-liberal policies were dominating the political economy. However, France, Austria and several other "European social model countries" are also unfavourably treated by the application of the non-parametric approach.

Finally, we compare the simple aggregate rankings of the UNICEF 2007 study with our own results. The results from CWI1 are shown on Graph 4 and those related to CWI on Graph 5. Apart from the fact that the UK always comes out on the bottom of the list, the results are also quite robust to the other rankings achieved: 
Graph 4: The average UNICEF (2007) rankings and the non-parametric CWI1 index measure

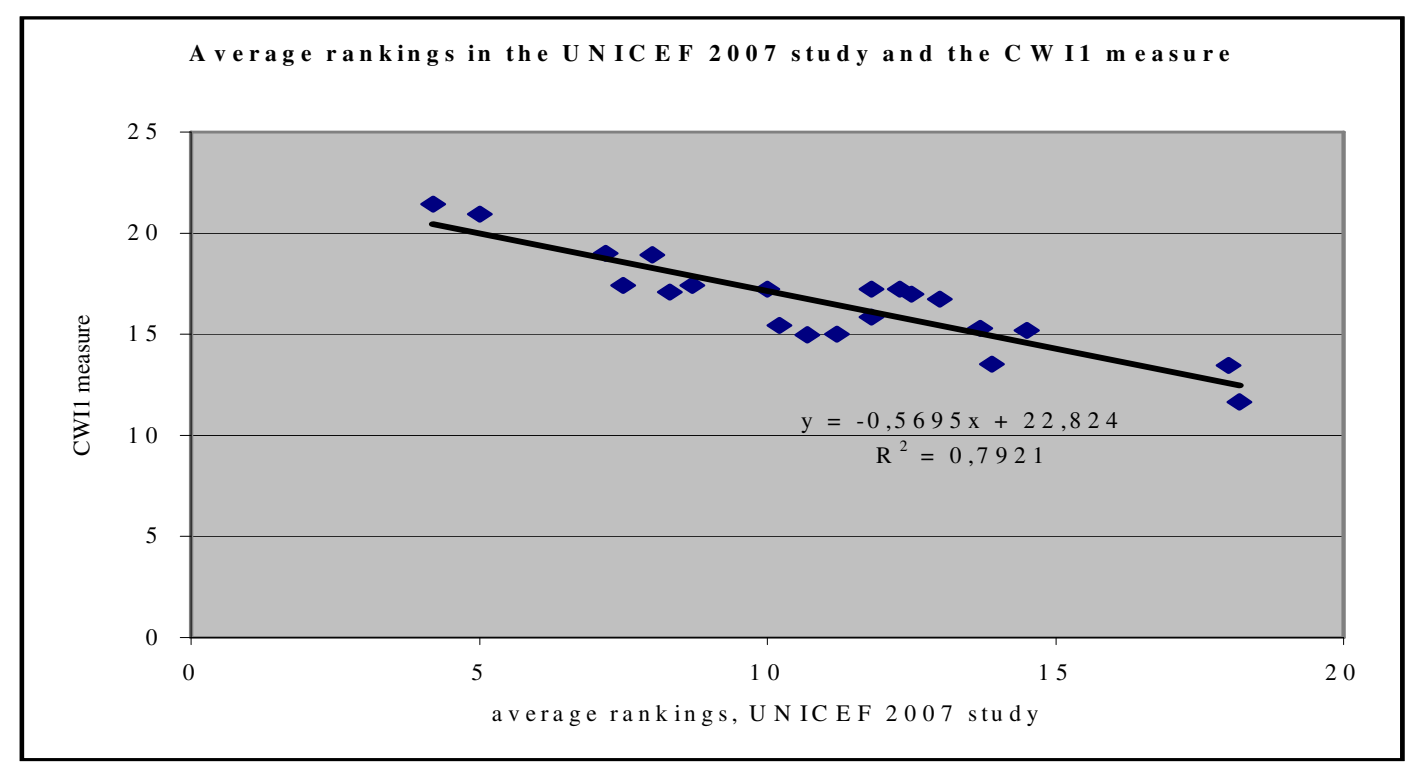

Source: Own compilations from the appendix tables

Graph 5: The average UNICEF (2007) rankings and the aggregate parametric principal component (CWI2) index

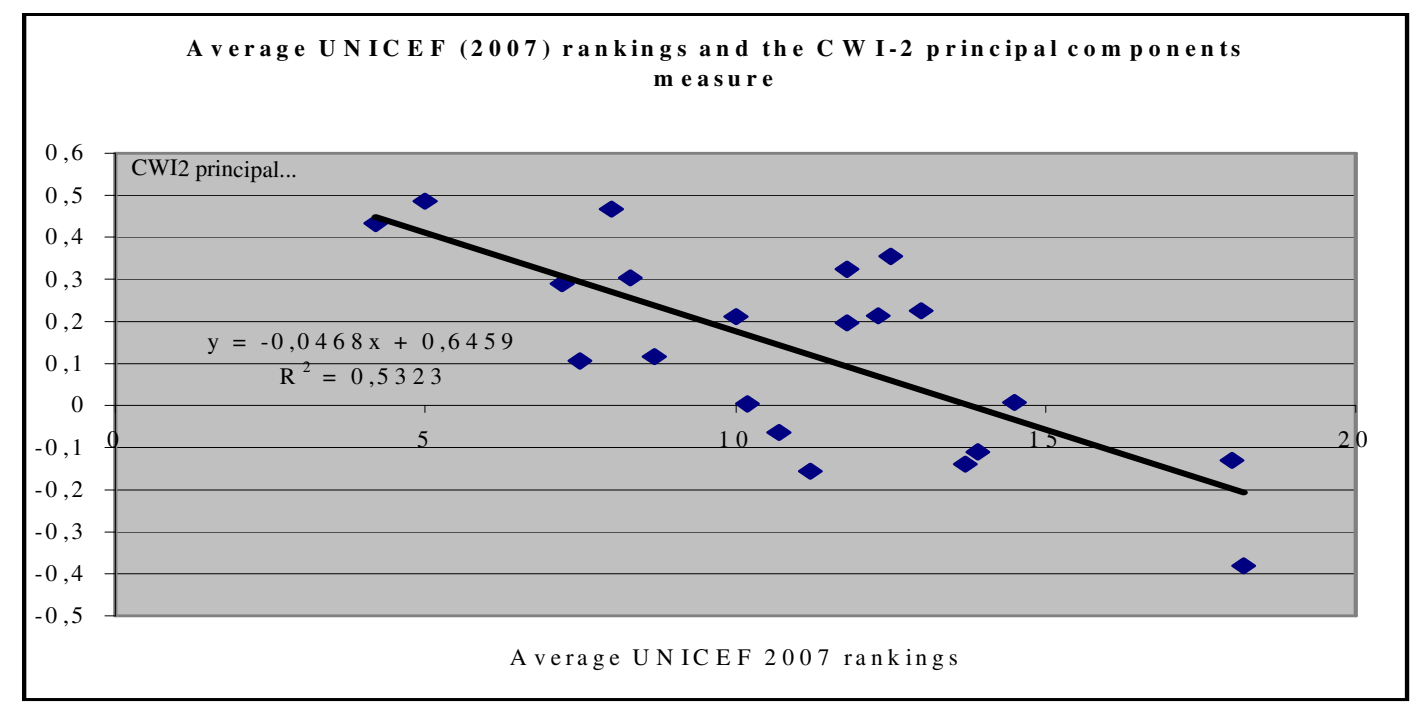

Source: Own compilations from the appendix tables

The consistently bad ranking of the United Kingdom in all analyses has been linked in the literature by some critics, most notably from the British political Left, to the "working tax credit" system, which was the flagship of New Labour's social policies (Daguerre, 2005; Field and Cacket, 2007). According to these critics, these tax credits were badly designed:

- Despite the huge costs, only a quarter of children in poor working households receiving tax credits are taken out of poverty because of them. Over 700,000 children in poor working households are not receiving tax credits; 
- A further result of the poor design of the tax credits system is that two parent households need far greater earnings than a lone parent to move past the poverty line. In 2004-05, two parents with two children had to earn $£ 240$ a week to have a net income of $£ 295$, to be above the poverty line. Contrary, a lone parent with the same number of children needed to earn just $f 76$ a week to gain a net income of $£ 230, £ 5$ above the poverty line; and

- With tax credits not making allowance for the second adult in the household, two parent families needed to work far longer to achieve the same level of income (Daguerre, 2005; Field and Cacket, 2007)

\section{Summary and Conclusions}

In this study, we present a composite index that quantifies the level of child well-being to rank developing countries in their child well-being policy. The index is composed of six main components including: material well-being, health and safety, educational well-being, peer and family relationships, behaviours and risks and subjective well-being. Three indices are computed. The human development type index, which is nonparametric, is compared with the alternative parametric principal components index. The latter is estimated in two forms: aggregated index and index disaggregated into six components. In the former, weights are assigned on an ad hoc basis to each indicator and factor component, while in the latter the weights are estimated. The non-parametric index, despite its limitations, is used more frequently in practice and can serve as a benchmark index.

The computation results show that countries differ significantly in their wellbeing performance. We observe some degree of heterogeneity by regional location or economic region. For instance, the Scandinavian countries as a region perform quite well in comparison with other regions in and outside Europe. However, we find no evidence suggesting that if a country is performing well in one component will also perform well in other components. The low rank of the countries is to some extent linked to their economic conditions and inability to address these issues effectively. However, exceptions are found, where low performance of countries like USA and UK has the highest GDP per capita. This suggests the existence of weak relationships between the level of development and children's well-being. The high-ranked countries share somewhat similar patterns in various index component distributions. The mean well-being by region shows that regions systematically differ in their performance.

The empirical results show that the UK is performing extremely poor in child well-being and the Russian Federation occupies the lowest rank in all approaches. The UK is relatively well placed in educational well-being but unable to perform well in the remaining well-being components. Regardless of the method used and the weighting system, the Russian Federation is the worst performing country in providing well-being to its children. The performance of countries differs by components and there is no indication that for a country to be very good in one component guarantees a high performance in another component. There is an indication that the Scandinavian countries and the Netherlands are in general good in most components. In comparison with other developed countries, children have not benefited much from the accumulated wealth and high rate of productivity in USA and UK 
Although the current version of the index quantifies the level of well-being well, it has certain limitations and the results should be interpreted with caution. It should be considered as a relatively simple and partial measure. We have addressed a number of extensions to overcome some of the shortcomings, which concern the axiomatic approach to set out the desirable properties of the index, identification and incorporation of more dimensions or components and the use of non-parametric and parametric estimation of the index to avoid the choice of weights attached to each index component on an ad hoc basis. An expansion of the sample to include more developing and transition countries and data collection covering several consecutive years will certainly shed light on the temporal patterns of well-being and its regional variability.

The current data are aggregate national level data with no within country regional variation or inequality in well-being within a country. A decomposition of the total variation in well-being into between and within country components is desirable. For data limitation reasons, this study focused on only the between country variation. The within country variation might explain much of the variance and, in particular, it can provide useful information about the distributional shifts within cohorts, across family types, and regions. Initial endowments and how countries develop their wellbeing determine the well-being distributional effects. These are important issues in understanding how well-being functions and how to use the generated information in policy formulation and development evaluations.

In view of the above discussion, it should be noted that the simpler approach adopted here was mainly due to problems of data availability. Child well-being is considered a possible source and deriving force of inequality differences across countries and over time. Identification and quantification of its effects will benefit the allocation of resources by policy-makers. This research not only measures but it also gives guidelines on how empirically to link well-being to factors such as inequality, poverty and growth. Although it is in an early stage of development, the paper has identified several directions along which future advances can be made. The breakdown of the index into major components provides possibilities to identify sources of wellbeing and associate it with social and economic policy measures to bring about desirable changes in national, regional and international policies.

\section{References}

Aber L., Gershoff E.T., Brooks-Gunn J. (2002), 'Social Exclusion of Children in the US: Compiling Indicators of Factors from Which and by Which Children Are Excluded', Paper presented at the Conference on Social Exclusion and Children, Columbia University, 3-4 May 2001

Ackermann L. et al. (2003), Understanding and Evaluating Children's Participation: A Review of Contemporary Literature, Plan UK/Plan International

Agénor P.R. (2003), Does Globalization Hurt the Poor?, World Bank, Unpublished manuscript

Andersen T.M., T.T. Herbertsson (2003), 'Measuring Globalization'. IZA Discussion Paper, 817, Bonn, IZA

Archibugi D., A. Coco (2004), 'A New Indicator of Technological Capabilities for Developed and Developing Countries (ArCo)', World Development, 32(4), 629-654 
Asher S.R., Paquette J.A. (2003) 'Loneliness and Peer Relations in Childhood', Current Directions in Psychological Science, 12, 75-78

Attree P. (2004), 'Growing Up in Disadvantage. A Systematic Review of the Qualitative Evidence', Child: Care, Health and Development, 30(6), 679-89

Bargain O., Donni O. (2007), 'A Theory of Child Targeting', IZA Discussion Paper, 2669

Brandolini A. (2007), 'On Synthetic Indices of Multidimensional Well-being: Health and Income inequalities in France, Germany, Italy and the United Kingdom', CHILD Working Paper, 7

Ben-Arieh A. (1997), 'International Project on Indicators of Children's Well-Being', Focus, 19(1), 61-65, Madison, WI, University of Wisconsin-Madison, Institute of Research on Poverty

Ben-Arieh A. (1999), 'The International Effort to Measure and Monitor the State of Children: A Summary and Agenda for Future', Implementing the U.N. Convention on the Rights of the Child: A Standard of Living Adequate for Development, A.B. Andrews, N.K. Kaufman, 33-46, Westport, CT, Praeger

Ben-Arieh A. and Wintersberger H. (1997), 'Monitoring and Measuring the State of Children', Beyond Survival, 62, Vienna, European Centre for Social Welfare Policy Research

Ben-Arieh A. et al. (2001), 'Measuring and Monitoring Children's Well-being Netherlands', Beyond the Numbers: How do we monitor the State of Our Children, Ben-Arieh A., George R., Kluwer Academic Press.

Beresford B., Sloper T., Bradshaw J. (2005), 'Physical Health', The Well-being of Children in the UK (second edition), Bradshaw J., Mayhew E., 65-107, London, Save the Children

Berger L.M., Hill J., Waldvogel J. (2005) 'Maternity Leave, Early Maternal Employment and Child Health and Development in the US', Economic Journal, 115, 29-47

Bollen K., Lennox R. (1991), 'Conventional Wisdom on Measurement: A Structural Equation Perspective', Psychological Bulletin, 110(2), 305-14

Bradbury B., Jäntti M. (1999), 'Child Poverty across Industrialized Nations', Innocenti Occasional Papers, Economic and Social Policy Series, 71

Bradshaw J. (2001), Poverty: The Outcomes for Children, London, Family Policy Studies Centre/National Children's Bureau

Bradshaw J. (2002), 'Child Poverty and Child Outcomes', Children and Society, 16(2), 131-40

Bradshaw J. (2006), 'Some Problems in the Measurement of Child Poverty Using Income Data', Economic Well-being, Wintersberger H., Cost Action 12 book

Bradshaw J. (2002), The Well-being of Children in the UK, London, Save the Children

Bradshaw J. et al. (1993), 'A comparative study of child support in fifteen countries', Journal of European Social Policy, 3(4), 255-271

Bradshaw J., Hoelscher P., Richardson D. (2006), 'Comparing Child Well-Being in OECD Countries: Concepts and Methods', Innocenti Working Paper, 2006-3

Bradshaw J., Mayhew E. (2005), The Well-being of Children in the UK (second edition), London, Save the Children

Bradshaw J., Hoelscher P., Richardson D. (2007), 'An Index of Child Well-being in the European Union', Social Indicators Research, 80(1), 133-177

Bronfenbrenner U. (1979), The Ecology of Human Development. Experiments by Nature and Design, Cambridge MA, Harvard University Press

Bronfenbrenner U., Morris P. (1998), 'The Ecology of Developmental Processes', Handbook of Child Psychology, volume 1, Theoretical Models of Human Development (fifth edition), Damon W., Lerner R., New York, Wiley 
Brooks A.M., Hanafin S. (2005), Measuring Child Well-being. An Inventory of Key Indicators, Components and Indicator Selection Criteria to Support the Development of a National Set of Child WellBeing Indicators, Dublin, The National Children's Office, Available at http://www.nco.ie, last accessed at 05.11.2005

Cantanero D., Pascual M., Sarabia J.M. (2005), 'Effects of Income Inequality on Population Health: New Evidence from the European Community Household Panel', Applied Economics, 37, 87-91

Coles B., Richardson D. (2005), 'Education', The Well-being of Children in the UK (Second edition), Bradshaw, J. and Mayhew, E., London, Save the Children, 262-88

Corak M. (2005), 'Principles and Practicalities in Measuring Child Poverty for the Rich Countries', Innocenti Working Paper 2005-01, Florence, UNICEF Innocenti Research Centre

Daguerre A. (2005), 'Hartz IV international. Hilfsbedürftige sollen arbeiten - und dankbar sein', Le Monde Diplomatique, August 2005, available at:

http://www.monde-diplomatique.de/pm/2005/07/08/a0016.text.name,askBxa7Pw.n,0

Dagum C., Costa M. (2004), 'Analysis and Measurement of Poverty, Univariate and Multivariate Approaches and Their Policy Implications A Case Study: Italy', Household Behavior, Equivalence Scales, Welfare and Poverty, C. Dagum, G. Ferrari, Heidelberg, Physica-Verlag

Decancq K., Lugo M.A. (2008), 'Setting Weights in Multidimensional Indices of Well-being,' Working Paper, University of Oxford Department of Economics, May 2008

Dreher A. (2005), Does Globalization Affect Growth? Empirical Evidence from a New Index, University of Konstanz Department of Economics, Unpublished Manuscript

Duncan G., Brooks-Gunn J. (2000), Family Poverty, Welfare Reform, and Child Development, Child Development, 71(1), 188-196

European Commission (2003), Joint Report on Social Exclusion Summarising the Results of the Examination of the National Action Plans for Social Inclusion (2003-2005), Brussels

Field F., Cacket B. (2007), Welfare isn't working. Child Poverty, Freely available at http://www.reform.co.uk/filestore/pdf/070611\%20Welfare $\% 20$ isn't $\% 20$ working $\% 20$ \%20child \%20poverty.pdf

Förster M., D'Ercole M. (2005), 'Income Distribution and Poverty in OECD Countries in the Second Half of the 1990s'. OECD Social, Employment and Migration Working Papers, Paris, OECD

Gregg P. et al. (2005), 'The Effects of a Mother's Return to Work Decision on Child Development in the UK', Economic Journal, 115, 48-80

Grupp H., Mogee M.E. (2004), 'Indicators of National Science and Technology Policy: How Robust are Composite Indicators?', Research Policy, 33, 1373-1384

Hanafin S., Brooks A.M. (2005), Report on the Development of a National Set of Child Well-being Indicators in Ireland, Dublin, The National Children's Office, Available at http://www.nco.ie, last accessed at 05.11.2005

Haveman R., Wolfe B. and Wilson K. (1997), 'Childhood Poverty and Adolescent Schooling and Fertility Outcomes: Reduced-form and Structural Estimates', Consequences of Growing Up Poor, Duncan G., Brooks-Gunn J., 419-60, New York, Russell Sage Foundation

Heshmati A. (2006), 'Measurement of a Multidimensional Index of Globalization', Global Economy Journal, 6(2), Paper 1

Heshmati A., Oh J-E. (2006), 'Alternative Composite Lisbon Development Strategy Indices: A Comparison of EU, USA, Japan and Korea', The European Journal of Comparative Economics, 3(2), 133-170

Heshmati A., Tausch A. (2007), Roadmap to Bangalore? Globalization, the EU's Lisbon Process and the Structures of Global Inequality, New York, Nova Science Publishers 
Hotelling H. (1933), 'Analysis of a Complex of Statistical Variables into Principal Components', Journal of Educational Psychology, 24, 417-441 and 498-520

Gabel S.G., Kamerman S.B. (2006), 'Investing in Children: Public Commitment in Twenty-One Industrialized Countries', Social Service Review, 80(2), 239-263

Kakwani N., Silber J. (2006), Quantitative Approaches to Multidimensional Poverty Measurement, New York, Palgrave-Macmillan

Kakwani N., Silber J. (2007), The Many Dimensions of Poverty, New York, Palgrave-Macmillan

Kamerman S.B. et al. (2003), 'Social Policies, Family Types and Child Outcomes in Selected OECD Countries', OECD Social, Employment and Migration Working Papers, 6, Paris, OECD

Kang S.M. (2002), 'A Sensitivity Analysis of the Korean Composite Environmental Index'. Ecological Economics, 43, 159-174

Kearney A.T. Inc., The Carnegie Endowment for International Peace (2002), 'Globalization's Last Hurrah?', Foreign Policy, January/February, 38-51

Kearney A.T. Inc., The Carnegie Endowment for International Peace (2003), 'Measuring Globalization: Who's Up, Who's Down?', Foreign Policy, January/February, 60-72

Kolar V., Soriano G. (2000), Parenting in Australian Families. A Comparative Study of Anglo, Torres Strait, Islander and Vietnamese Communities, Australian Institute of Family Studies, Available at http://www.aifs.gov.au/institute/pubs/resrep5.pdf

Land K.C. (2005), The Foundation for Child Development: Child and Youth Well-Being Index(CWI), 1975-2003 with Projections for 2004, Durham, Duke University, Available at: http://www.soc.duke.edu/ $\sim$ cwi/

Land K.C. (2006), The Foundation for Child Development: Child and Youth Well-being Index (CWI), 1975-2004, with Projections for 2005, Durham, Duke University, Available at: http://www.soc.duke.edu/ cwi/.

Land K.C. (2007), The Foundation for Child Development: Child and Youth Well-being Index (CWI), 1975-2005, with Projections for 2006, Durham, Duke University, Available at: http://www.soc.duke.edu/ cwi/.

Land K.C. (2007), '2007 Special Focus Report on International Comparison', The Foundation for Child Development: Child and Youth Well-being Index (CWI) Project, Durham, Duke University, Available at: http://www.soc.duke.edu/ cwi/.

Lindström B., Eriksson M. (2005), 'Salutogenesis', Journal of Epidemiology and Community Health, 59, 440-42

Lippman L. (2004), Indicators of Child, Family and Community Connections, Office of the Assistant Secretary for Planning and Evaluation, US Department of Health and Human Services

Lister R. (2004), Poverty, Cambridge, Polity Press

Lockwood B. (2004), 'How Robust is the Foreign Policy-Kearney Globalization Index?', The World Economy, 27, 507-523

Lockwood B. and M. Redoano (2005), 'The CSGR Globalization Index: An Introductory Guide', CSGR Working Paper 155/04

Mahler V.A. (2001), 'Economic Globalization, Domestic Politics and Income Inequality in the Developed Countries: A Cross-National Analysis', Luxembourg Income Study Working Paper 2001:273 Luxembourg

Mayhew E. (2005), The Well-being of Children in the UK (second edition), London, Save the Children, 134-60

NicGabhainn S., Sixsmith J. (2005), Children's Understanding of Well-being, Dublin, The National Children's Office, Available at http://www.nco.ie, last accessed at 05.11.2005. 
Noorbakhsh F. (1998), 'The Human Development Index: Some Technical Issues and Alternative Indices', Journal of International Development, 10, 589-605

Papadopoulos F., Tsakloglou P. (2003), Social Exclusion in the EU: A Capability-Based Approach, Unpublished paper, Athens, May 2003

Pearson K. (1901), 'On Lines and Planes of Closest fit to Systems of Points in Space', Philosophical Magazine, 6(2), 559-72

Peters H.E., Mullis N.C. (1997), 'The Role of Family Income and Sources of Income on Adolescent Achievement', Consequences of Growing Up Poor, Duncan G., Brooks-Gunn J., 34081, New York, Russell Sage Foundation

Ridge T. (2002), Childhood Poverty and Social Exclusion, From a Child's Perspective, Bristol, The Policy Press

Rodgers B., Pryor J. (1998), Divorce and Separation: The Outcomes for Children, York, Joseph Rowntree Foundation

Santos Pais M. (1999), 'A Human Rights Conceptual Framework for UNICEF', Innocenti Essay, 9, Florence, UNICEF Innocenti Research Centre

Sen A. (1985), Commodities and Capabilities, Amsterdam, Elsevier

Sen A. (1999), Development as Freedom, Oxford, Oxford University Press

Sen A. (2000), 'Social Exclusion: Concept, Application, and Scrutiny', Social Development Papers, Office of Environment and Social Development.

Sobolewski J.M. and Amato P.R. (2005), 'Economic Hardship in the Family of Origin and Children's Psychological Well-being in Adulthood', Journal of Marriage and Family, 67, 141-56

Stevens K. et al. (2005), 'Focus on Families. Reinforcing the Importance of Family. Families with Dependent Children - Successful Outcomes Project', Report on literature review and focus groups, Wellington, Families Commission, Available at

http://www.familiescommission.govt.nz/download/focus-on-families.pdf

Sturgis P. (2004), 'Analysing Complex Survey Data: Dimensioning, Stratification and Weights', Social Research Update, 43, Downloaded at http://sru.soc.surrey.ac.uk/SRU43.html, January 2006

Tausch A. (2006) 'On heroes, villains and statisticians', The Vienna Institute for International Economic Studies Monthly Report, 7, July 2006, 20-23, Vienna, The Vienna Institute for International Economic Studies (wiiw)

Tausch A., Almas Heshmati (2006) 'Turkey and the Lisbon process. A short research note on the position of Turkey on a new "Lisbon Strategy Index" (LSI)', Insight Turkey, 8(2), 7-18, Ankara Institute for Turkish Policy Studies, ANKAM

UNICEF (2005), 'Child Poverty in Rich Countries', Innocenti Report Card, 6, Florence, UNICEF Innocenti Research Centre

UNICEF (2007), 'Child Poverty in Perspective: An Overview of Child Well-being in Rich Countries', Report Card 2006-07, UNICEF Innocenti Research Centre

WHO/Europe (2006), European Health for All Database, Online version, downloaded at http://data.euro.who.int/hfadb/, January 2006 
Table 1. Summary statistics of child we11-being data after imputation, $\mathrm{n}=33$.

\begin{tabular}{|c|c|c|c|c|c|c|}
\hline $\begin{array}{l}\text { Variable } \\
========\end{array}$ & Mean & Std Dev & Minimum & Maximum & Coeffiar & t-value \\
\hline \multicolumn{7}{|c|}{ A. Material We11-being (MW): } \\
\hline mw11 & 11.056 & 4.525 & 2.400 & 21.700 & 40.929 & 14.04 \\
\hline mw21 & 24.536 & 14.993 & 5.800 & 58.300 & 61.105 & 9.40 \\
\hline mw22 & 31.571 & 16.340 & 8.400 & 72.700 & 51.758 & 11.10 \\
\hline mw23 & 7.167 & 2.967 & 1.900 & 12.900 & 41.395 & 13.88 \\
\hline mw31 & 4.961 & 2.498 & 0.400 & 11.300 & 50.340 & 11.41 \\
\hline \multicolumn{7}{|c|}{ B. Health and Safety (HS): } \\
\hline hs11 & 5.336 & 2.522 & 2.400 & 16.000 & 47.268 & 12.15 \\
\hline hs12 & 6.182 & 1.411 & 3.100 & 9.100 & 22.825 & 25.17 \\
\hline hs21 & 91.455 & 6.974 & 75.000 & 99.000 & 7.625 & 75.34 \\
\hline hs22 & 94.242 & 4.062 & 83.000 & 99.000 & 4.310 & 133.27 \\
\hline hs23 & 93.364 & 5.165 & 81.000 & 99.000 & 5.532 & 103.84 \\
\hline hs31 & 19.239 & 12.912 & 7.300 & 60.000 & 67.117 & 8.56 \\
\hline \multicolumn{7}{|c|}{ C. Educational we11-being (EW): } \\
\hline ew11 & 490.798 & 23.536 & 442.000 & 000 & 4.796 & 119.79 \\
\hline ew12 & 495.354 & 29.513 & 433.000 & 544.000 & 5.958 & 96.42 \\
\hline w13 & 493.828 & 29.567 & 402.000 & 548.000 & 5.987 & 95.95 \\
\hline ew21 & 73.538 & 16.609 & 29.300 & 93.900 & 22.585 & 25.44 \\
\hline ew31 & 11.357 & 8.287 & 2.700 & 25.200 & 72.971 & 7.87 \\
\hline ew32 & 28.766 & 7.691 & 14.400 & 50.300 & 26.735 & 21.49 \\
\hline \multicolumn{7}{|c|}{ D. Peer and Family relationships (PF): } \\
\hline $\mathrm{pf11}$ & 13.086 & 4.048 & 4.800 & 20.800 & 30.936 & 18.57 \\
\hline pf12 & 8.214 & 4.295 & 1.200 & 16.000 & 52.291 & 10.99 \\
\hline pf21 & 78.656 & 9.684 & 58.300 & 93.800 & 12.311 & 46.66 \\
\hline pf22 & 60.707 & 12.306 & 36.900 & 90.200 & 20.272 & 28.34 \\
\hline pf31 & 292.152 & 1312.108 & 43.300 & 7601.000 & 449.119 & 1.28 \\
\hline \multicolumn{7}{|c|}{ E. Behaviours and Risks (BR): } \\
\hline br11 & 10.677 & 2.491 & 6.100 & 16.400 & 23.335 & 24.62 \\
\hline$r 12$ & 19.564 & 15.161 & 8.000 & 79.400 & 77.492 & 7.41 \\
\hline r13 & 19.631 & 11.086 & 4.200 & 40.400 & 56.470 & 10.17 \\
\hline br14 & 18.583 & 11.044 & 4.000 & 46.000 & 59.432 & 9.67 \\
\hline r15 & 23.581 & 4.693 & 15.100 & 38.100 & 19.901 & 28.87 \\
\hline r16 & 75.292 & 5.999 & 65.300 & 89.100 & 7.968 & 72.09 \\
\hline$r 21$ & 39.190 & 5.375 & 25.100 & 49.000 & 13.715 & 41.89 \\
\hline br22 & 32.336 & 9.943 & 15.000 & 64.300 & 30.750 & 18.68 \\
\hline r31 & 32.655 & 7.521 & 20.100 & 47.800 & 23.031 & 24.94 \\
\hline r32 & 62.817 & 11.441 & 39.200 & 80.800 & 18.213 & 31.54 \\
\hline r33 & 3.895 & 0.383 & 3.100 & 4.500 & 9.840 & 58.38 \\
\hline br34 & 13.108 & 5.593 & 4.400 & 25.500 & 42.672 & 13.46 \\
\hline \multicolumn{7}{|c|}{ F. Subjective wel1-being (SW): } \\
\hline sw11 & 16.297 & 5.772 & 9.000 & 32.400 & 35.415 & 16.22 \\
\hline sw21 & 84.735 & 4.460 & 75.200 & 94.200 & 5.264 & 109.14 \\
\hline sw22 & 6.194 & 1.833 & 2.300 & 9.800 & 29.598 & 19.41 \\
\hline sw23 & 9.694 & 2.881 & 3.600 & 18.100 & 29.718 & 19.33 \\
\hline sw24 & 7.385 & 4.421 & 2.700 & 29.800 & 59.869 & 9.60 \\
\hline sw31 & 23.080 & 7.558 & 8.000 & 38.900 & 32.746 & 17.54 \\
\hline \multicolumn{7}{|c|}{ G. Country Characteristics: } \\
\hline OECD & 0.758 & 0.435 & 0.000 & 1.000 & 57.446 & 10.00 \\
\hline roup & 3.606 & 1.853 & 1.000 & 6.000 & 51.386 & 11.18 \\
\hline
\end{tabular}

Note: The variable definitions are found in Appendix A 
Table 2.A Pearson correlation matrix after imputation, material we11-being.

\begin{tabular}{|c|c|c|c|c|c|}
\hline \multicolumn{2}{|c|}{$\operatorname{mw} 11$} & mw21 & mw22 & mw23 & mw31 \\
\hline \multicolumn{6}{|c|}{ ="=="=="=="=="==" } \\
\hline \multirow[t]{2}{*}{ mw11 } & 1.0000 & 0.2035 & 0.2784 & 0.3456 & 0.0954 \\
\hline & & 0.2558 & 0.1166 & 0.0488 & 0.5973 \\
\hline \multirow[t]{2}{*}{ mw21 } & 0.2035 & 1.0000 & 0.7605 & -0.3689 & 0.2319 \\
\hline & 0.2558 & & 0.0001 & 0.0346 & 0.1941 \\
\hline \multirow[t]{2}{*}{ mw22 } & 0.2784 & 0.7605 & 1.0000 & -0.2051 & -0.0245 \\
\hline & 0.1166 & 0.0001 & & 0.2522 & 0.8919 \\
\hline \multirow[t]{2}{*}{ mw23 } & 0.3456 & -0.3689 & -0.2051 & 1.0000 & -0.2950 \\
\hline & 0.0488 & 0.0346 & 0.2522 & & 0.0956 \\
\hline \multirow[t]{2}{*}{ mw31 } & 0.0954 & 0.2319 & -0.0245 & -0.2950 & 1.0000 \\
\hline & 0.5973 & 0.1941 & 0.8919 & 0.0956 & \\
\hline
\end{tabular}

Note: The variable definitions are found in Appendix A

Table 2.B Pearson correlation matrix after imputation, health and safety.

\begin{tabular}{|c|c|c|c|c|c|c|}
\hline \multicolumn{2}{|c|}{ hs11 } & hs 12 & hs21 & hs22 & hs23 & hs31 \\
\hline \multicolumn{7}{|c|}{ 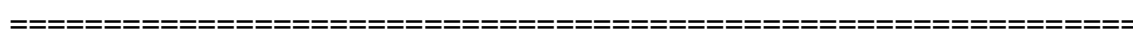 } \\
\hline \multirow[t]{2}{*}{ hs11 } & 1.0000 & -0.0435 & 0.2415 & 0.1333 & 0.2419 & 0.7005 \\
\hline & & 0.8099 & 0.1757 & 0.4596 & 0.1749 & 0.0001 \\
\hline \multirow[t]{2}{*}{ hs 12} & -0.0435 & 1.0000 & -0.0658 & -0.1033 & -0.2812 & -0.0341 \\
\hline & 0.8099 & & 0.7159 & 0.5671 & 0.1129 & 0.8506 \\
\hline \multirow[t]{2}{*}{ hs21 } & 0.2415 & -0.0658 & 1.0000 & 0.7019 & 0.4256 & 0.3178 \\
\hline & 0.1757 & 0.7159 & & 0.0001 & 0.0135 & 0.0714 \\
\hline \multirow[t]{2}{*}{ hs 22} & 0.1333 & -0.1033 & 0.7019 & 1.0000 & 0.7269 & 0.1793 \\
\hline & 0.4596 & 0.5671 & 0.0001 & & 0.0001 & 0.3179 \\
\hline \multirow[t]{2}{*}{ hs23 } & 0.2419 & -0.2812 & 0.4256 & 0.7269 & 1.0000 & 0.1400 \\
\hline & 0.1749 & 0.1129 & 0.0135 & 0.0001 & & 0.4371 \\
\hline \multirow[t]{2}{*}{ hs31 } & 0.7005 & -0.0341 & 0.3178 & 0.1793 & 0.1400 & 1.0000 \\
\hline & 0.0001 & 0.8506 & 0.0714 & 0.3179 & 0.4371 & \\
\hline
\end{tabular}

Note: The variable definitions are found in Appendix A 
Table 2.C Pearson correlation matrix after imputation, educational we11being.

\begin{tabular}{|c|c|c|c|c|c|c|}
\hline \multicolumn{2}{|c|}{ ew11 } & ew12 & ew13 & ew21 & ew31 & ew32 \\
\hline \multicolumn{7}{|c|}{ 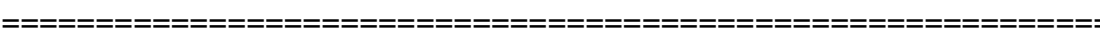 } \\
\hline \multirow[t]{2}{*}{ ew11 } & 1.0000 & 0.8592 & 0.6560 & 0.6325 & -0.7023 & -0.0943 \\
\hline & & 0.0001 & 0.0001 & 0.0001 & 0.0001 & 0.6017 \\
\hline \multirow[t]{2}{*}{ ew12 } & 0.8592 & 1.0000 & 0.7019 & 0.6065 & -0.6659 & 0.2294 \\
\hline & 0.0001 & & 0.0001 & 0.0002 & 0.0001 & 0.1990 \\
\hline \multirow[t]{2}{*}{ ew13 } & 0.6560 & 0.7019 & 1.0000 & 0.3318 & -0.3847 & 0.1523 \\
\hline & 0.0001 & 0.0001 & & 0.0592 & & 0.3975 \\
\hline \multirow[t]{2}{*}{ ew21 } & 0.6325 & 0.6065 & 0.3318 & 1.0000 & -0.8908 & -0.0129 \\
\hline & 0.0001 & 0.0002 & 0.0592 & & 001 & 0.9430 \\
\hline \multirow[t]{2}{*}{ ew31 } & -0.7023 & -0.6659 & -0.3847 & -0.8908 & 1.0000 & 0.1139 \\
\hline & 0.0001 & 0.0001 & 0.0270 & 0.0001 & & 0.5276 \\
\hline \multirow[t]{2}{*}{ ew32 } & -0.0943 & 0.2294 & 0.1523 & -0.0129 & 0.1139 & 1.0000 \\
\hline & 0.6017 & 0.1990 & 0.3975 & 0.9430 & 0.5276 & \\
\hline
\end{tabular}

Note: The variable definitions are found in Appendix A

Table 2.D Pearson correlation matrix after imputation, peers and family.

\begin{tabular}{|c|c|c|c|c|c|}
\hline & pf11 & pf12 & $p f 21$ & $\mathrm{pf} 22$ & pf31 \\
\hline pf11 & 1.0000 & $\begin{array}{l}0.8663 \\
0.0001\end{array}$ & $\begin{array}{r}-0.1327 \\
0.4614\end{array}$ & $\begin{array}{l}0.0007 \\
0.9965\end{array}$ & $\begin{array}{r}-0.0149 \\
0.9343\end{array}$ \\
\hline pf12 & $\begin{array}{l}0.8663 \\
0.0001\end{array}$ & 1.0000 & $\begin{array}{r}-0.1292 \\
0.4733\end{array}$ & $\begin{array}{r}-0.0387 \\
0.8306\end{array}$ & $\begin{array}{l}0.0397 \\
0.8261\end{array}$ \\
\hline pf21 & $\begin{array}{r}-0.1327 \\
0.4614\end{array}$ & $\begin{array}{r}-0.1292 \\
0.4733\end{array}$ & 1.0000 & $\begin{array}{l}0.2069 \\
0.2480\end{array}$ & $\begin{array}{l}0.0543 \\
0.7641\end{array}$ \\
\hline pf22 & $\begin{array}{l}0.0007 \\
0.9965\end{array}$ & $\begin{array}{r}-0.0387 \\
0.8306\end{array}$ & $\begin{array}{l}0.2069 \\
0.2480\end{array}$ & 1.0000 & $\begin{array}{r}-0.2674 \\
0.1324\end{array}$ \\
\hline pf31 & $\begin{array}{r}-0.0149 \\
0.9343\end{array}$ & $\begin{array}{l}0.0397 \\
0.8261\end{array}$ & $\begin{array}{l}0.0543 \\
0.7641\end{array}$ & $\begin{array}{r}-0.2674 \\
0.1324\end{array}$ & 1.0000 \\
\hline
\end{tabular}

Note: The variable definitions are found in Appendix A 
Table 2.E Pearson correlation matrix after imputation, behaviours and risks.

\begin{tabular}{|c|c|c|c|c|c|c|c|c|c|c|c|c|}
\hline & br11 & br12 & br13 & br14 & br15 & br16 & br21 & br22 & br31 & br32 & br33 & br 34 \\
\hline & $======$ & $=====$ & $======$ & $======$ & $======$ & $:=====$ & $:=====$ & $======$ & $:=====$ & $=====$ & $====$ & $:==$ \\
\hline \multirow[t]{2}{*}{ br11 } & 1.0000 & 0.1573 & -0.1545 & 0.0762 & -0.0423 & -0.0259 & 0.1311 & 0.2938 & 0.1034 & 0.2839 & -0.2805 & -0.4757 \\
\hline & & 0.3820 & 0.3906 & 0.6733 & 0.8148 & 0.8861 & 0.4668 & 0.0970 & 0.5668 & 0.1093 & 0.1138 & 0.0051 \\
\hline \multirow[t]{2}{*}{ br12 } & 0.1573 & 1.0000 & -0.2739 & 0.4674 & 0.2164 & -0.1425 & 0.2517 & 0.0447 & 0.0020 & -0.0006 & -0.0437 & 0.0213 \\
\hline & 0.3820 & & 0.1229 & 0.0061 & 0.2262 & 0.4286 & 0.1575 & 0.8046 & 0.9910 & 0.9974 & 0.8090 & 0.9061 \\
\hline \multirow[t]{2}{*}{ br13 } & -0.1545 & -0.2739 & 1.0000 & -0.1491 & 0.1722 & 0.1404 & -0.1419 & -0.0697 & 0.2064 & -0.2406 & 0.3948 & 0.4573 \\
\hline & 0.3906 & 0.1229 & & 0.4075 & 0.3379 & 0.4357 & 0.4308 & 0.6996 & 0.2491 & 0.1773 & 0.0230 & 0.0074 \\
\hline \multirow[t]{2}{*}{ br14 } & 0.0762 & 0.4674 & -0.1491 & 1.0000 & -0.0804 & 0.1231 & 0.4325 & 0.4046 & -0.1824 & -0.1682 & 0.1793 & 0.0663 \\
\hline & 0.6733 & 0.0061 & 0.4075 & & 0.6563 & 0.4949 & 0.0119 & 0.0195 & 0.3096 & 0.3495 & 0.3179 & 0.7139 \\
\hline \multirow[t]{2}{*}{ br15 } & -0.0423 & 0.2164 & 0.1722 & -0.0804 & 1.0000 & -0.5500 & -0.1504 & -0.1739 & -0.2031 & -0.0254 & 0.0397 & 0.1758 \\
\hline & 0.8148 & 0.2262 & 0.3379 & 0.6563 & & 0.0009 & 0.4033 & 0.3330 & 0.2568 & 0.8880 & 0.8261 & 0.3278 \\
\hline \multirow[t]{2}{*}{ br16 } & -0.0259 & -0.1425 & 0.1404 & 0.1231 & -0.5500 & 1.0000 & 0.2709 & 0.0916 & 0.2246 & -0.3174 & 0.0439 & 0.1280 \\
\hline & 0.8861 & 0.4286 & 0.4357 & 0.4949 & 0.0009 & & 0.1272 & 0.6118 & 0.2089 & 0.0718 & 0.8083 & 0.4778 \\
\hline \multirow[t]{2}{*}{ br21 } & 0.1311 & 0.2517 & -0.1419 & 0.4325 & -0.1504 & 0.2709 & 1.0000 & 0.1173 & -0.0304 & -0.2370 & 0.3385 & 0.0804 \\
\hline & 0.4668 & 0.1575 & 0.4308 & 0.0119 & 0.4033 & 0.1272 & & 0.5153 & 0.8663 & 0.1840 & 0.0540 & 0.6565 \\
\hline \multirow[t]{2}{*}{ br22 } & 0.2938 & 0.0447 & -0.0697 & 0.4046 & -0.1739 & 0.0916 & 0.1173 & 1.0000 & -0.3589 & 0.2152 & -0.1013 & -0.3061 \\
\hline & 0.0970 & 0.8046 & 0.6996 & 0.0195 & 0.3330 & 0.6118 & 0.5153 & & 0.0402 & 0.2291 & 0.5746 & 0.0832 \\
\hline \multirow[t]{2}{*}{ br31 } & 0.1034 & 0.0020 & 0.2064 & -0.1824 & -0.2031 & 0.2246 & -0.0304 & -0.3589 & 1.0000 & -0.1503 & 0.0434 & 0.2943 \\
\hline & 0.5668 & 0.9910 & 0.2491 & 0.3096 & 0.2568 & 0.2089 & 0.8663 & 0.0402 & & 0.4037 & 0.8105 & 0.0964 \\
\hline \multirow[t]{2}{*}{ br32 } & 0.2839 & -0.0006 & -0.2406 & -0.1682 & -0.0254 & -0.3174 & -0.2370 & 0.2152 & -0.1503 & 1.0000 & -0.3892 & -0.5234 \\
\hline & 0.1093 & 0.9974 & 0.1773 & 0.3495 & 0.8880 & 0.0718 & 0.1840 & 0.2291 & 0.4037 & & 0.0251 & 0.0018 \\
\hline \multirow[t]{2}{*}{ br33 } & -0.2805 & -0.0437 & 0.3948 & 0.1793 & 0.0397 & 0.0439 & 0.3385 & -0.1013 & 0.0434 & -0.3892 & 1.0000 & 0.3347 \\
\hline & 0.1138 & 0.8090 & 0.0230 & 0.3179 & 0.8261 & 0.8083 & 0.0540 & 0.5746 & 0.8105 & 0.0251 & & 0.0569 \\
\hline
\end{tabular}




\begin{tabular}{|c|c|c|c|c|c|c|}
\hline br34 & $\begin{array}{r}-0.4757 \\
0.0051\end{array}$ & $\begin{array}{l}0.0213 \\
0.9061\end{array}$ & $\begin{array}{l}0.4573 \\
0.0074\end{array}$ & $\begin{array}{l}0.0663 \\
0.7139\end{array}$ & $\begin{array}{l}0.1758 \\
0.3278\end{array}$ & $\begin{array}{l}0.1280 \\
0.4778\end{array}$ \\
\hline & sw11 & sw21 & sw22 & sw23 & sw24 & \\
\hline & $===$ & & $==$ & & & $t=$ \\
\hline v11 & 1.0000 & $\begin{array}{r}-0.7511 \\
0.0001\end{array}$ & $\begin{array}{r}-0.1013 \\
0.5745\end{array}$ & $\begin{array}{l}0.2464 \\
0.1669\end{array}$ & $\begin{array}{l}0.1442 \\
0.4233\end{array}$ & $\begin{array}{l}0.1180 \\
0.5129\end{array}$ \\
\hline v21 & $\begin{array}{r}-0.7511 \\
0.0001\end{array}$ & 1.0000 & $\begin{array}{r}-0.0370 \\
0.8378\end{array}$ & $\begin{array}{r}-0.2078 \\
0.2457\end{array}$ & $\begin{array}{r}-0.1690 \\
0.3470\end{array}$ & $\begin{array}{l}0.1496 \\
0.4058\end{array}$ \\
\hline v22 & $\begin{array}{r}-0.1013 \\
0.5745\end{array}$ & $\begin{array}{r}-0.0370 \\
0.8378\end{array}$ & 1.0000 & $\begin{array}{l}0.3049 \\
0.0844\end{array}$ & $\begin{array}{l}0.1971 \\
0.2714\end{array}$ & $\begin{array}{r}-0.1651 \\
0.3583\end{array}$ \\
\hline N23 & $\begin{array}{l}0.2464 \\
0.1669\end{array}$ & $\begin{array}{r}-0.2078 \\
0.2457\end{array}$ & $\begin{array}{l}0.3049 \\
0.0844\end{array}$ & 1.0000 & $\begin{array}{l}0.6266 \\
0.0001\end{array}$ & $\begin{array}{r}-0.0245 \\
0.8922\end{array}$ \\
\hline v24 & $\begin{array}{l}0.1442 \\
0.4233\end{array}$ & $\begin{array}{r}-0.1690 \\
0.3470\end{array}$ & $\begin{array}{l}0.1971 \\
0.2714\end{array}$ & $\begin{array}{l}0.6266 \\
0.0001\end{array}$ & 1.0000 & $\begin{array}{r}-0.0417 \\
0.8175\end{array}$ \\
\hline 31 & $\begin{array}{l}0.1180 \\
0.5129\end{array}$ & $\begin{array}{l}0.1496 \\
0.4058\end{array}$ & $\begin{array}{r}-0.1651 \\
0.3583\end{array}$ & $\begin{array}{r}-0.0245 \\
0.8922\end{array}$ & $\begin{array}{r}-0.0417 \\
0.8175\end{array}$ & 1.0000 \\
\hline
\end{tabular}

Note: The variable definitions are found in Appendix A 
Table 3. The Eigenvalues and Eigenvectors of the correlation matrix of child we11-being (CWI2) indicators.

\begin{tabular}{|c|c|c|c|c|c|c|c|c|c|c|c|c|}
\hline \multicolumn{13}{|c|}{ A-E. Eigenvalues of the Correlation Matrix } \\
\hline 1 & \multicolumn{2}{|c|}{7.6441} & 2.4046 & 0.1911 & \multicolumn{2}{|c|}{0.1911} & & & & & & \\
\hline 2 & \multicolumn{2}{|c|}{5.2394} & 1.1022 & 0.1310 & \multicolumn{2}{|c|}{0.3221} & & & & & & \\
\hline 3 & \multicolumn{2}{|c|}{4.1371} & 1.0594 & 0.1034 & \multicolumn{2}{|c|}{0.4255} & & & & & & \\
\hline 4 & \multicolumn{2}{|c|}{3.0777} & 0.3367 & 0.0769 & \multicolumn{2}{|c|}{0.5025} & & & & & & \\
\hline 5 & \multicolumn{2}{|c|}{2.7409} & 0.3865 & 0.0685 & \multicolumn{2}{|c|}{0.5710} & & & & & & \\
\hline 6 & \multicolumn{2}{|c|}{2.3543} & 0.2448 & 0.0589 & \multicolumn{2}{|c|}{0.6298} & & & & & & \\
\hline 7 & \multicolumn{2}{|c|}{2.1095} & 0.3124 & 0.0527 & \multicolumn{2}{|c|}{0.6826} & & & & & & \\
\hline 8 & \multicolumn{2}{|c|}{1.7970} & 0.1989 & 0.0449 & \multicolumn{2}{|c|}{0.7275} & & & & & & \\
\hline 9 & \multicolumn{2}{|c|}{1.5981} & 0.2583 & 0.0400 & \multicolumn{2}{|c|}{0.7675} & & & & & & \\
\hline 10 & \multicolumn{2}{|c|}{1.3397} & 0.0427 & 0.0335 & \multicolumn{2}{|c|}{0.8010} & & & & & & \\
\hline 11 & \multicolumn{2}{|c|}{1.2970} & 0.2579 & 0.0324 & \multicolumn{2}{|c|}{0.8334} & & & & & & \\
\hline 12 & \multicolumn{2}{|c|}{1.0390} & & 0.0260 & 0.8 & 594 & & & & & & \\
\hline Eige! & vectors & & & & & & & & & & & \\
\hline & Prin1 & Prin2 & Prin3 & Prin4 & Prin5 & Prin6 & Prin7 & Prin8 & Prin9 & Prin10 & Prin11 & Prin12 \\
\hline mw11 & 0.2098 & -0.1785 & 0.2193 & -0.1032 & -0.0200 & 0.1801 & 0.0505 & -0.0859 & 0.0293 & -0.0337 & -0.1839 & 0.0251 \\
\hline mw21 & 0.2981 & 0.0122 & -0.0021 & -0.1132 & -0.0625 & -0.0162 & -0.0963 & -0.1261 & 0.1201 & -0.0607 & 0.1526 & 0.2067 \\
\hline mw22 & 0.2231 & 0.0117 & 0.1355 & -0.2838 & -0.0452 & -0.1340 & -0.0087 & 0.0650 & 0.0295 & 0.0615 & -0.1363 & 0.2413 \\
\hline mw23 & -0.0399 & -0.1750 & 0.0328 & -0.0941 & 0.1430 & 0.2237 & 0.1224 & 0.4055 & -0.0545 & 0.1117 & -0.0963 & 0.3812 \\
\hline mw31 & 0.0901 & 0.0539 & -0.1517 & 0.1881 & 0.1105 & 0.1529 & -0.4302 & -0.0304 & 0.2422 & 0.0117 & -0.1067 & -0.1646 \\
\hline hs11 & 0.2641 & 0.0506 & 0.1496 & -0.0085 & -0.0117 & 0.1554 & -0.1522 & 0.1528 & -0.0060 & 0.0823 & -0.2556 & 0.0501 \\
\hline hs 12 & 0.0545 & -0.2546 & 0.1125 & -0.2326 & -0.0406 & 0.1407 & -0.0171 & -0.0827 & -0.1132 & 0.3641 & -0.0349 & -0.0341 \\
\hline hs21 & -0.1083 & -0.1598 & 0.0630 & 0.0133 & 0.2225 & 0.2474 & -0.0240 & 0.2120 & 0.3644 & -0.1381 & 0.2006 & -0.0724 \\
\hline hs22 & -0.0574 & -0.2024 & 0.2305 & 0.1791 & 0.2643 & 0.1471 & -0.0007 & 0.0329 & 0.1460 & -0.2117 & 0.0642 & -0.0189 \\
\hline hs23 & -0.1086 & -0.2186 & 0.3098 & 0.1120 & 0.0128 & 0.0054 & 0.1654 & 0.0628 & -0.0192 & -0.1425 & 0.1231 & -0.0477 \\
\hline hs31 & 0.1886 & 0.1020 & 0.1293 & 0.1106 & -0.1600 & 0.2248 & -0.0380 & 0.0048 & -0.3019 & -0.0787 & 0.2157 & -0.0076 \\
\hline ew11 & 0.2824 & -0.0159 & -0.1231 & -0.0216 & 0.1074 & -0.0647 & 0.1889 & -0.0062 & -0.1169 & 0.0743 & 0.1987 & -0.1433 \\
\hline ew12 & 0.2964 & -0.0975 & -0.1088 & 0.0766 & 0.0983 & -0.0811 & 0.0064 & 0.1190 & -0.1311 & 0.0828 & 0.1576 & -0.1090 \\
\hline ew13 & 0.1798 & -0.0592 & -0.1762 & 0.1580 & 0.3306 & 0.0902 & 0.0056 & -0.0974 & -0.2781 & 0.1161 & 0.0980 & 0.0788 \\
\hline ew21 & 0.2664 & 0.0526 & 0.0730 & 0.0889 & 0.0631 & -0.1740 & 0.2476 & 0.0900 & 0.0782 & 0.0785 & -0.0053 & -0.0377 \\
\hline ew31 & 0.2485 & -0.0606 & 0.0709 & 0.0024 & -0.1252 & 0.0475 & 0.2077 & 0.0121 & 0.2633 & 0.0353 & 0.2132 & 0.1180 \\
\hline ew32 & -0.0370 & 0.0441 & -0.1010 & 0.0671 & -0.0735 & 0.0228 & 0.4641 & -0.3413 & 0.2425 & 0.0028 & 0.0030 & -0.1115 \\
\hline pf11 & -0.1367 & 0.2390 & 0.1755 & 0.1485 & -0.1746 & 0.1696 & 0.0059 & -0.0103 & -0.2481 & 0.0350 & -0.0041 & -0.0116 \\
\hline pf12 & -0.1582 & 0.2632 & 0.1022 & 0.1111 & -0.1093 & 0.2438 & 0.1047 & -0.1013 & -0.0934 & 0.1819 & 0.0005 & -0.0494 \\
\hline
\end{tabular}




\begin{tabular}{|c|c|c|c|c|c|c|c|c|c|c|c|c|}
\hline $\mathrm{pf} 21$ & 0.0595 & -0.1445 & 0.1827 & 0.3108 & -0.2267 & -0.0056 & -0.1946 & -0.0852 & 0.0481 & 0.1723 & 0.0386 & 0.1134 \\
\hline$f 22$ & -0.0526 & -0.1350 & 0.0287 & 0.2758 & 0.1135 & 0.0673 & 0.0870 & -0.1128 & -0.2433 & -0.3510 & 0.0632 & 0.1388 \\
\hline f31 & 0.0179 & 0.0107 & 0.0268 & -0.0740 & -0.3239 & -0.1599 & -0.0101 & 0.3977 & 0.1814 & -0.1007 & 0.0379 & -0.3787 \\
\hline-11 & 0.0988 & 0.1802 & -0.1025 & -0.0815 & 0.1092 & 0.2698 & 0.0640 & -0.3333 & 0.2889 & -0.0089 & -0.0288 & -0.0332 \\
\hline 12 & 0.0332 & 0.2311 & 0.1648 & 0.1570 & 0.1619 & -0.2310 & 0.0949 & -0.0724 & 0.2380 & 0.1321 & -0.1128 & 0.1483 \\
\hline 13 & -0.1130 & 0.0255 & 0.1442 & -0.2333 & -0.0384 & 0.3348 & 0.0005 & -0.1875 & -0.0317 & 0.1306 & -0.0473 & -0.0365 \\
\hline b & 0.2085 & 0.0412 & 0.1311 & 0.2300 & 0.0842 & 0.0479 & -0.3 & -0.0094 & 0.0710 & 0.0932 & 0.1087 & -0.1310 \\
\hline r15 & -0.2075 & 0.0172 & 0.0581 & 0.1297 & 0.1556 & 0.0176 & 0.1057 & 0.1322 & 0.1680 & 0.4299 & 0.1370 & 0.0791 \\
\hline 16 & -0.1685 & 0.2505 & -0.0093 & 0.1775 & 0.1601 & -0.1357 & -0.0657 & 0.0175 & -0.0114 & 0.1916 & 0.0836 & 0.1878 \\
\hline 21 & 0.1708 & -0.0878 & 0.2214 & 0.2017 & 0.0315 & -0.0462 & 0.0803 & -0.1453 & 0.1149 & -0.1730 & -0.1687 & 0.1341 \\
\hline 22 & 0.1147 & 0.1423 & 0.0642 & -0.0687 & -0.1039 & 0.3679 & 0.1207 & 0.1079 & 0.0352 & -0.0063 & 0.1588 & -0.1980 \\
\hline-31 & -0.0187 & 0.1740 & -0.0289 & 0.2831 & -0.2493 & 0.1262 & 0.1512 & 0.3084 & 0.0573 & 0.0023 & 0.0880 & 0.1251 \\
\hline & 0.0346 & -0.2575 & 0.1642 & 0.1020 & -0.1592 & -0.1095 & 0.0428 & -0.1715 & -0.0208 & 0.2676 & 0.2110 & -0.1678 \\
\hline & 0.0486 & 0.0601 & -0.3213 & -0.1168 & 0.1719 & 0.1385 & -0.0033 & 0.0988 & 0.0327 & 0.0672 & 0.3547 & 0.0339 \\
\hline & -0.1568 & -0.2696 & 0.0915 & -0.0511 & 0.0053 & -0.1003 & -0.0876 & -0.0747 & 0.0335 & 0.2928 & 0.1685 & -0.0362 \\
\hline $\mathrm{s}$ & 0.0967 & 0.2405 & 0.2123 & 0.0389 & 0.2073 & -0.0484 & 0.1007 & 0.1699 & 0.0089 & 0.1663 & -0.2111 & -0.1374 \\
\hline 21 & 0.2151 & 0.2537 & 0.1450 & -0.0178 & 0.1022 & -0.0205 & 0.0223 & 0.0074 & -0.1196 & -0.0068 & 0.0516 & -0.1100 \\
\hline sw22 & -0.1357 & 0.1338 & 0.2616 & -0.1854 & 0.1247 & -0.0591 & -0.2524 & -0.0903 & 0.0760 & -0.0799 & 0.1546 & -0.1212 \\
\hline 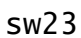 & -0.0502 & 0.1468 & 0.2500 & -0.2819 & 0.2331 & 0.0289 & 0.0501 & 0.0512 & -0.0452 & -0.1034 & 0.1224 & 0.0745 \\
\hline w2 & -0.0333 & 0.1516 & 0.2838 & -0.1536 & 0.1058 & -0.2582 & -0.0041 & -0.0597 & -0.1109 & -0.1149 & 0.3330 & -0.0364 \\
\hline 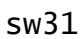 & 0.0244 & 0.1331 & -0.0113 & -0.0733 & -0.2941 & -0.0095 & -0.1752 & -0.0657 & 0.1637 & -0.0568 & 0.3061 & 0.4798 \\
\hline
\end{tabular}

Note: The variable definitions are found in Appendix A 
Table 3. Continuous (CWI3)

\begin{tabular}{|c|c|c|c|c|}
\hline \multicolumn{5}{|c|}{$======$} \\
\hline \multicolumn{5}{|c|}{ A.MW Eigenvalues of the Correlation Matrix } \\
\hline & Eigenvalues & Difference & Proportion & Cumulative \\
\hline 1 & 2.0471 & 0.6939 & 0.4094 & 0.4094 \\
\hline 2 & 1.3532 & 0.5225 & 0.2706 & 0.6801 \\
\hline 3 & 0.8307 & 0.3355 & 0.1661 & 0.8462 \\
\hline 4 & 0.4952 & & 0.0990 & 0.9452 \\
\hline \multicolumn{5}{|c|}{ Eigenvectors } \\
\hline & Prin1 & Prin2 & Prin3 & Prin4 \\
\hline mw11 & 0.5392 & -0.1790 & 0.3023 & -0.7518 \\
\hline mw21 & 0.5828 & 0.3265 & -0.0429 & 0.1860 \\
\hline mw22 & 0.6027 & -0.0371 & -0.2485 & 0.4562 \\
\hline mw23 & 0.0685 & -0.6748 & 0.5827 & 0.4099 \\
\hline mw31 & -0.0395 & 0.6360 & 0.7109 & 0.1544 \\
\hline \multicolumn{5}{|c|}{ B.HS Eigenvalues of the Correlation Matrix } \\
\hline & Eigenvalues & Difference & Proportion & Cumulative \\
\hline 1 & 2.3531 & 0.7884 & 0.3922 & 0.3922 \\
\hline 2 & 1.5648 & 0.6122 & 0.2608 & 0.6530 \\
\hline 3 & 0.9526 & 0.2545 & 0.1588 & 0.8117 \\
\hline 4 & 0.6981 & & 0.1163 & 0.9281 \\
\hline \multicolumn{5}{|c|}{ Eigenvectors } \\
\hline & Prin1 & Prin2 & Prin3 & Prin4 \\
\hline hs11 & -0.1662 & 0.6621 & 0.0976 & 0.4841 \\
\hline hs12 & 0.1570 & 0.3808 & 0.8022 & -0.3515 \\
\hline hs21 & 0.5399 & -0.0336 & 0.0799 & 0.5530 \\
\hline hs22 & 0.5843 & 0.1864 & -0.2138 & 0.1336 \\
\hline hs23 & 0.5293 & 0.1349 & -0.2262 & -0.5265 \\
\hline hs31 & -0.1859 & 0.6020 & -0.4935 & -0.2025 \\
\hline \multicolumn{5}{|c|}{ C.EW Eigenva7ues of the Correlation Matrix } \\
\hline & Eigenvalues & Difference & Proportion & Cumulative \\
\hline 1 & 3.2644 & 2.0077 & 0.5441 & 0.5441 \\
\hline 2 & 1.2566 & 0.4189 & 0.2094 & 0.7535 \\
\hline 3 & 0.8377 & 0.5442 & 0.1396 & 0.8931 \\
\hline 4 & 0.2934 & & 0.0489 & 0.9421 \\
\hline \multicolumn{5}{|c|}{ Eigenvectors } \\
\hline & Prin1 & Prin2 & Prin3 & Prin4 \\
\hline ew11 & 0.5081 & -0.0415 & 0.2140 & 0.0873 \\
\hline ew12 & 0.5065 & -0.2509 & -0.0229 & 0.1704 \\
\hline ew13 & 0.3887 & -0.4098 & 0.4573 & 0.0205 \\
\hline ew21 & 0.4454 & 0.2738 & -0.2886 & -0.7909 \\
\hline ew31 & 0.3676 & 0.4614 & -0.4407 & 0.5807 \\
\hline ew32 & 0.0229 & 0.6923 & 0.6832 & 0.0050 \\
\hline \multicolumn{5}{|c|}{ D.PF Eigenvalues of the Correlation Matrix } \\
\hline & Eigenvalues & Difference & Proportion & Cumulative \\
\hline 1 & 1.8343 & 0.5375 & 0.3669 & 0.3669 \\
\hline 2 & 1.2968 & 0.2357 & 0.2594 & 0.6263 \\
\hline 3 & 1.0611 & 0.4274 & 0.2122 & 0.8385 \\
\hline 4 & 0.6336 & & 0.1267 & 0.9652 \\
\hline \multicolumn{5}{|c|}{ Eigenvectors } \\
\hline & Prin1 & Prin2 & Prin3 & Prin4 \\
\hline $\mathrm{pf11}$ & 0.6959 & -0.1099 & 0.0959 & -0.0018 \\
\hline $\mathrm{pf} 12$ & 0.6946 & -0.1387 & -0.0493 & 0.0494 \\
\hline $\mathrm{pf} 21$ & 0.0603 & 0.3959 & 0.7846 & -0.4611 \\
\hline
\end{tabular}



pf22
0.1065
0.7290
0.0219
0.6756
pf31
$-0.1347$
$-0.5294$
0.6100
0.5730

E.BR Eigenvalues of the Correlation Matrix

\begin{tabular}{|c|c|c|c|c|}
\hline & Eigenvalues & Differen & Proportion & Cumulative \\
\hline 1 & 2.5199 & 0.4337 & 0.2100 & 0.2100 \\
\hline 2 & 2.0861 & 0.1295 & 0.1738 & 0.3838 \\
\hline 3 & 1.9565 & 0.6331 & 0.1630 & 0.5469 \\
\hline 4 & 1.3234 & & 0.1103 & 0.6572 \\
\hline \multicolumn{5}{|c|}{ Eigenvectors } \\
\hline & Prin1 & Prin2 & Prin3 & Prin4 \\
\hline br11 & 0.4220 & -0.0603 & -0.1650 & 0.4312 \\
\hline br12 & 0.2250 & 0.1019 & 0.5352 & 0.2899 \\
\hline br13 & -0.1100 & 0.1518 & -0.2913 & 0.6617 \\
\hline br14 & 0.1508 & -0.3450 & 0.2764 & 0.0265 \\
\hline br15 & -0.1198 & 0.4788 & 0.2590 & 0.0806 \\
\hline br16 & 0.1566 & 0.5093 & 0.3213 & 0.0899 \\
\hline br21 & 0.0106 & -0.4656 & 0.3707 & 0.1117 \\
\hline br22 & 0.3500 & -0.1609 & -0.1797 & 0.2262 \\
\hline br31 & 0.2601 & 0.1245 & 0.2069 & -0.3067 \\
\hline br32 & -0.4122 & -0.2446 & 0.1635 & 0.0891 \\
\hline br33 & 0.2691 & 0.1484 & -0.3373 & -0.3095 \\
\hline br34 & -0.5146 & 0.1226 & -0.0378 & 0.1231 \\
\hline
\end{tabular}

F.SW Eigenvalues of the Correlation Matrix

\begin{tabular}{|c|c|c|c|c|}
\hline & Eigenvalues & Difference & Proportion & Cumulative \\
\hline 1 & 2.8068 & 1.5425 & 0.4678 & 0.4678 \\
\hline 2 & 1.2643 & 0.1874 & 0.2107 & 0.6785 \\
\hline 3 & 1.0768 & 0.7150 & 0.1795 & 0.8580 \\
\hline 4 & 0.3617 & & 0.0603 & 0.9183 \\
\hline \multicolumn{5}{|c|}{ Eigenvectors } \\
\hline & Prin1 & Prin2 & Prin3 & Prin4 \\
\hline sw11 & 0.4028 & -0.5722 & -0.0499 & 0.0377 \\
\hline sw21 & 0.3823 & -0.5278 & 0.3726 & -0.0937 \\
\hline sw22 & 0.4451 & 0.4473 & -0.1288 & -0.4152 \\
\hline sw23 & 0.4759 & 0.2131 & -0.2552 & 0.7984 \\
\hline sw24 & 0.5147 & 0.2298 & 0.0349 & -0.3583 \\
\hline sw31 & 0.0436 & 0.3089 & 0.8807 & 0.2266 \\
\hline
\end{tabular}

Note: The variable definitions are found in Appendix A 
Table 4. Summary of unweighted human development type child we11-being index (CWI1) by country.

\begin{tabular}{|c|c|c|c|c|c|c|c|c|}
\hline Obs & country & matwe1 & helsaf & eduwe1 & peefam & behris & subwe1 & CWI1 \\
\hline & -ー-ー-ー-ー- & $=--1$ & ----- & $==-=$ & $==-=-=$ & $======$ & $======$ & $======$ \\
\hline 1 & Netherlands & 1.209 & 4.308 & 4.075 & 1.944 & 5.896 & 3.985 & 21.417 \\
\hline 2 & Sweden & 2.045 & 4.947 & 3.902 & 1.099 & 6.105 & 2.852 & 20.950 \\
\hline 3 & Denmark & 1.778 & 4.128 & 3.991 & 1.510 & 5.275 & 2.321 & 19.002 \\
\hline 4 & spain & 0.875 & 3.798 & 2.889 & 1.883 & 5.890 & 3.578 & 18.913 \\
\hline 5 & Iceland & 2.732 & 4.634 & 3.497 & 1.164 & 4.324 & 1.927 & 18.278 \\
\hline 6 & Finland & 1.615 & 4.416 & 4.404 & 0.996 & 3.445 & 2.517 & 17.393 \\
\hline 7 & Norway & 2.658 & 3.028 & 3.837 & 1.437 & 3.936 & 2.494 & 17.391 \\
\hline 8 & Greece & 0.503 & 2.126 & 2.678 & 2.250 & 6.416 & 3.260 & 17.234 \\
\hline 9 & Italy & 0.590 & 3.431 & 2.531 & 3.045 & 5.149 & 2.479 & 17.225 \\
\hline 10 & Poland & 0.294 & 3.684 & 4.203 & 1.580 & 5.906 & 1.554 & 17.220 \\
\hline 11 & Switzerland & 1.167 & 2.988 & 3.369 & 1.426 & 5.377 & 2.777 & 17.104 \\
\hline 12 & Czech Rep & 1.532 & 3.876 & 3.497 & 1.261 & 4.801 & 2.001 & 16.967 \\
\hline 13 & France & 0.880 & 3.547 & 3.065 & 1.732 & 5.384 & 2.128 & 16.736 \\
\hline 14 & Japan & 1.597 & 3.088 & 3.492 & 1.278 & 5.256 & 1.536 & 16.247 \\
\hline 15 & Canada & 1.146 & 2.841 & 4.097 & 0.741 & 4.979 & 2.061 & 15.864 \\
\hline 16 & Ireland & 0.489 & 1.652 & 3.806 & 1.599 & 5.134 & 2.758 & 15.438 \\
\hline 17 & Australia & 1.276 & 3.083 & 4.045 & 0.668 & 4.291 & 2.031 & 15.395 \\
\hline 18 & Portugal & 0.518 & 3.556 & 2.663 & 1.902 & 4.548 & 2.087 & 15.275 \\
\hline 19 & Hungary & 0.593 & 3.612 & 3.020 & 1.735 & 4.012 & 2.195 & 15.166 \\
\hline 20 & Malta & 0.493 & 3.808 & 1.181 & 2.647 & 4.538 & 2.404 & 15.071 \\
\hline 21 & Germany & 0.975 & 3.013 & 2.754 & 2.006 & 3.878 & 2.396 & 15.022 \\
\hline 22 & Israel & 0.953 & 2.834 & 1.052 & 0.625 & 4.378 & 5.161 & 15.003 \\
\hline 23 & Belgium & 0.955 & 2.314 & 4.202 & 1.687 & 3.773 & 2.028 & 14.960 \\
\hline 24 & croatia & 0.491 & 3.253 & 1.479 & 1.891 & 5.432 & 1.612 & 14.159 \\
\hline 25 & Latvia & 0.694 & 3.402 & 2.270 & 1.296 & 4.934 & 1.546 & 14.143 \\
\hline 26 & slovenia & 0.658 & 3.035 & 1.479 & 1.643 & 4.173 & 2.863 & 13.851 \\
\hline 27 & Austria & 1.017 & 1.234 & 2.880 & 0.766 & 4.802 & 2.827 & 13.526 \\
\hline 28 & USA & 0.797 & 2.467 & 3.610 & 0.791 & 4.283 & 1.513 & 13.461 \\
\hline 29 & Lithuania & 0.465 & 3.556 & 1.479 & 1.234 & 5.030 & 1.516 & 13.280 \\
\hline 30 & New Zealand & 1.009 & 1.713 & 3.746 & 0.525 & 4.307 & 1.951 & 13.250 \\
\hline 31 & Estonia & 0.504 & 3.560 & 1.479 & 1.082 & 3.612 & 1.446 & 11.683 \\
\hline 32 & UK & 0.775 & 2.573 & 3.207 & 0.757 & 2.534 & 1.813 & 11.659 \\
\hline 33 & Russian Fed & 0.488 & 2.853 & 1.470 & 1.868 & 3.839 & 0.813 & 11.330 \\
\hline
\end{tabular}


Table 5.A Summary of weighted principal component indices by country.

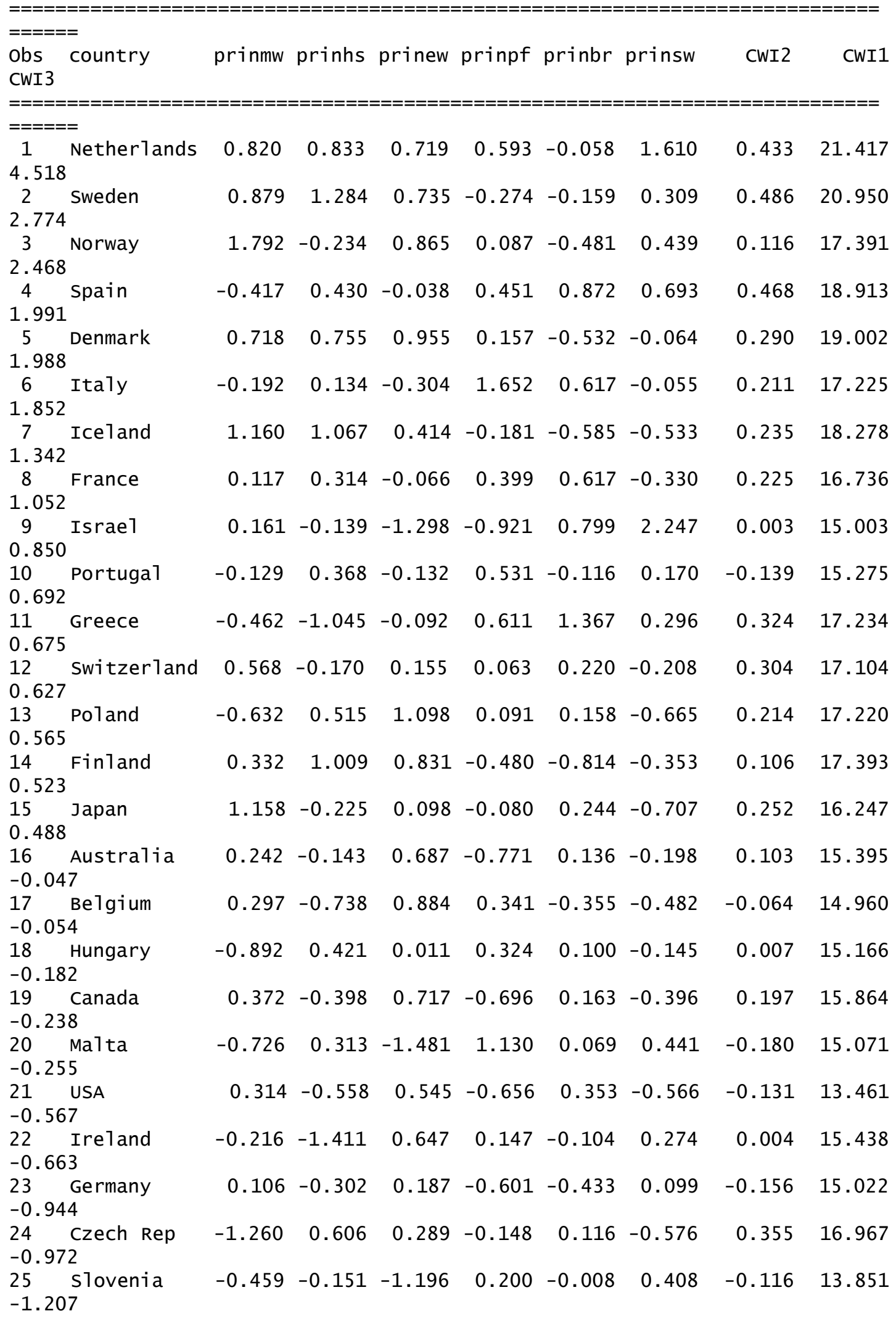




$\begin{array}{lllllllll}26 \quad \text { Croatia } & -0.728 & 0.072 & -1.196 & 0.425 & 0.252 & -0.374 & -0.197 & 14.159 \\ -1.550 & & & & & & & & \\ 27 \quad \text { Austria } & 0.354 & -1.821 & -0.137 & -0.699 & 0.256 & 0.448 & -0.110 & 13.526 \\ -1.599 & & & & & & & & \\ 28 \quad \text { New Zealand } & 0.154 & -1.239 & 0.425 & -0.941 & 0.165 & -0.265 & -0.085 & 13.250 \\ -1.702 & & & & & & & & \\ \begin{array}{l}29 \quad \text { Latvia } \\ -1.770\end{array} & -1.096 & 0.341 & -0.667 & -0.083 & -0.146 & -0.119 & -0.495 & 14.143 \\ \begin{array}{l}30 \quad \text { UK } \\ -2.225\end{array} & 0.114 & -0.686 & 0.028 & -0.688 & -0.828 & -0.164 & -0.380 & 11.659 \\ \begin{array}{l}31 \quad \text { Lithuania } \\ -2.261\end{array} & -0.772 & 0.406 & -1.196 & -0.180 & -0.524 & 0.005 & -0.754 & 13.280 \\ 32 \quad \text { Estonia } & -0.708 & 0.486 & -1.196 & -0.327 & -0.496 & -0.476 & -0.674 & 11.683 \\ -2.718 & & & & & & & & \\ 33 \quad \text { Russian Fed } & -0.968 & -0.094 & -1.293 & 0.527 & -0.863 & -0.760 & -0.851 & 11.330 \\ -3.451 & \end{array}$

Table 5.B Summary of weighted principal component indices by country group.

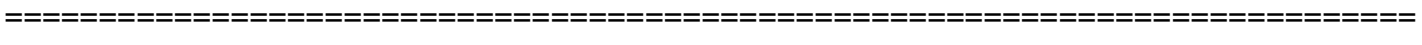

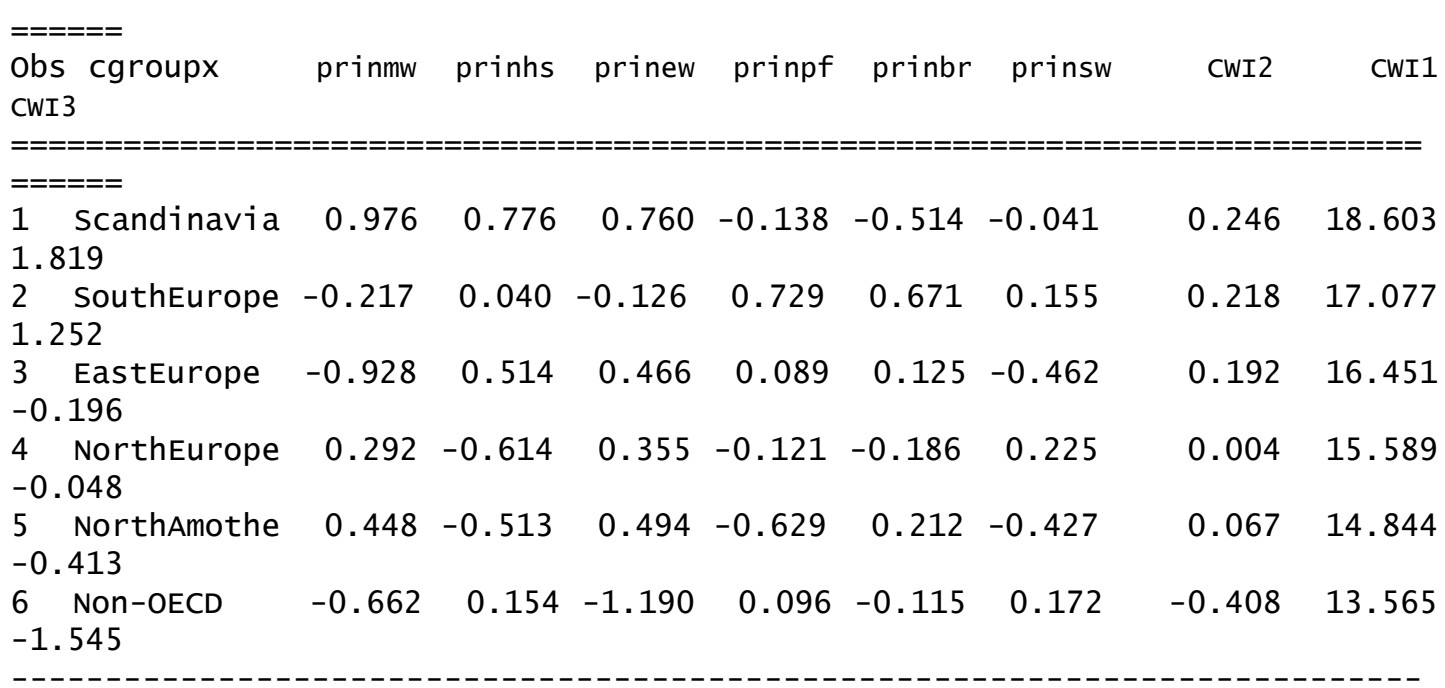


Table 6 . Rank of countries by weighted principal component indices.

\begin{tabular}{|c|c|c|c|c|c|c|c|c|c|}
\hline $\begin{array}{l}=== \\
\text { Obs } \\
\text { CWI3 }\end{array}$ & country & CWI2 & matwe1 & helsaf & eduwe1 & peefam & behris & socwe 1 & CWI1 \\
\hline \multicolumn{10}{|c|}{ 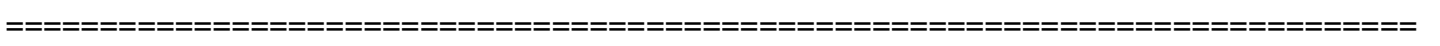 } \\
\hline$===$ & & & & & & & & & \\
\hline $\begin{array}{r}1 \\
16\end{array}$ & Australia & 16 & 13 & 20 & 9 & 31 & 14 & 19 & 17 \\
\hline $\begin{array}{r}2 \\
27\end{array}$ & Austria & 22 & 9 & 33 & 24 & 30 & 7 & 4 & 27 \\
\hline $\begin{array}{r}3 \\
17\end{array}$ & Belgium & 20 & 12 & 29 & 3 & 10 & 24 & 27 & 23 \\
\hline $\begin{array}{r}4 \\
19\end{array}$ & Canada & 13 & 8 & 26 & 8 & 29 & 12 & 25 & 15 \\
\hline $\begin{array}{r}5 \\
26\end{array}$ & croatia & 28 & 28 & 17 & 27 & 8 & 8 & 24 & 24 \\
\hline $\begin{array}{r}6 \\
24\end{array}$ & Czech Rep & 4 & 33 & 6 & 14 & 20 & 15 & 30 & 12 \\
\hline $5^{7}$ & Denmark & 7 & 6 & 5 & 2 & 13 & 29 & 15 & 3 \\
\hline $\begin{array}{r}8 \\
32\end{array}$ & Estonia & 31 & 26 & 8 & 28 & 24 & 27 & 26 & 31 \\
\hline $\begin{array}{r}9 \\
14\end{array}$ & Finland & 15 & 10 & 3 & 5 & 25 & 31 & 23 & 6 \\
\hline $\begin{array}{l}10 \\
8\end{array}$ & France & 10 & 16 & 14 & 21 & 9 & 5 & 22 & 13 \\
\hline $\begin{array}{l}11 \\
23\end{array}$ & Germany & 26 & 18 & 25 & 15 & 26 & 25 & 12 & 21 \\
\hline $\begin{array}{l}12 \\
11\end{array}$ & Greece & 5 & 24 & 30 & 22 & 3 & 1 & 9 & 8 \\
\hline $\begin{array}{l}13 \\
18\end{array}$ & Hungary & 17 & 30 & 10 & 19 & 11 & 16 & 17 & 19 \\
\hline $\begin{array}{l}14 \\
7\end{array}$ & Iceland & 9 & 2 & 2 & 13 & 22 & 30 & 28 & 5 \\
\hline $\begin{array}{l}15 \\
22\end{array}$ & Ireland & 18 & 21 & 32 & 10 & 14 & 20 & 10 & 16 \\
\hline $\begin{array}{l}16 \\
9\end{array}$ & Israel & 19 & 14 & 19 & 32 & 32 & 3 & 1 & 22 \\
\hline $\begin{array}{l}17 \\
6\end{array}$ & Italy & 12 & 20 & 16 & 25 & 1 & 4 & 14 & 9 \\
\hline $\begin{array}{l}18 \\
15\end{array}$ & Japan & 8 & 3 & 23 & 17 & 18 & 9 & 32 & 14 \\
\hline $\begin{array}{l}19 \\
29\end{array}$ & Lativa & 30 & 32 & 13 & 26 & 19 & 22 & 16 & 25 \\
\hline $\begin{array}{l}20 \\
31\end{array}$ & Lithuania & 32 & 29 & 11 & 29 & 21 & 28 & 13 & 29 \\
\hline $\begin{array}{l}21 \\
20\end{array}$ & Malta & 27 & 27 & 15 & 33 & 2 & 17 & 5 & 20 \\
\hline $\begin{array}{l}22 \\
1\end{array}$ & Netherlands & 3 & 5 & 4 & 7 & 4 & 19 & 2 & 1 \\
\hline $\begin{array}{l}23 \\
28\end{array}$ & New Zealand & 21 & 15 & 31 & 12 & 33 & 11 & 21 & 30 \\
\hline $\begin{array}{l}24 \\
3\end{array}$ & Norway & 14 & 1 & 24 & 4 & 16 & 26 & 6 & 7 \\
\hline $\begin{array}{l}25 \\
13\end{array}$ & Poland & 11 & 25 & 7 & 1 & 15 & 13 & 31 & 10 \\
\hline
\end{tabular}


Measurement and Analysis of Child Well-Being in Middle and High Income Countries

\begin{tabular}{|c|c|c|c|c|c|c|c|c|}
\hline $\begin{array}{l}26 \\
10\end{array}$ & Portuga1 & 25 & 19 & 12 & 23 & 5 & 21 & 11 \\
\hline $\begin{array}{l}27 \\
33\end{array}$ & Russian Fed & 33 & 31 & 18 & 31 & 6 & 33 & 33 \\
\hline $\begin{array}{l}28 \\
25\end{array}$ & slovenia & 23 & 23 & 21 & 30 & 12 & 18 & 7 \\
\hline $\begin{array}{l}29 \\
4\end{array}$ & spain & 2 & 22 & 9 & 20 & 7 & 2 & 3 \\
\hline $\begin{array}{l}30 \\
2\end{array}$ & Sweden & 1 & 4 & 1 & 6 & 23 & 23 & 8 \\
\hline $\begin{array}{l}31 \\
12\end{array}$ & Switzerland & 6 & 7 & 22 & 16 & 17 & 10 & 20 \\
\hline $\begin{array}{l}32 \\
30\end{array}$ & UK & 29 & 17 & 28 & 18 & 28 & 32 & 18 \\
\hline $\begin{array}{l}33 \\
21\end{array}$ & USA & 24 & 11 & 27 & 11 & 27 & 6 & 29 \\
\hline
\end{tabular}


Table 7. Pearson's correlation matrix of weighted average indexes, $n=33$.

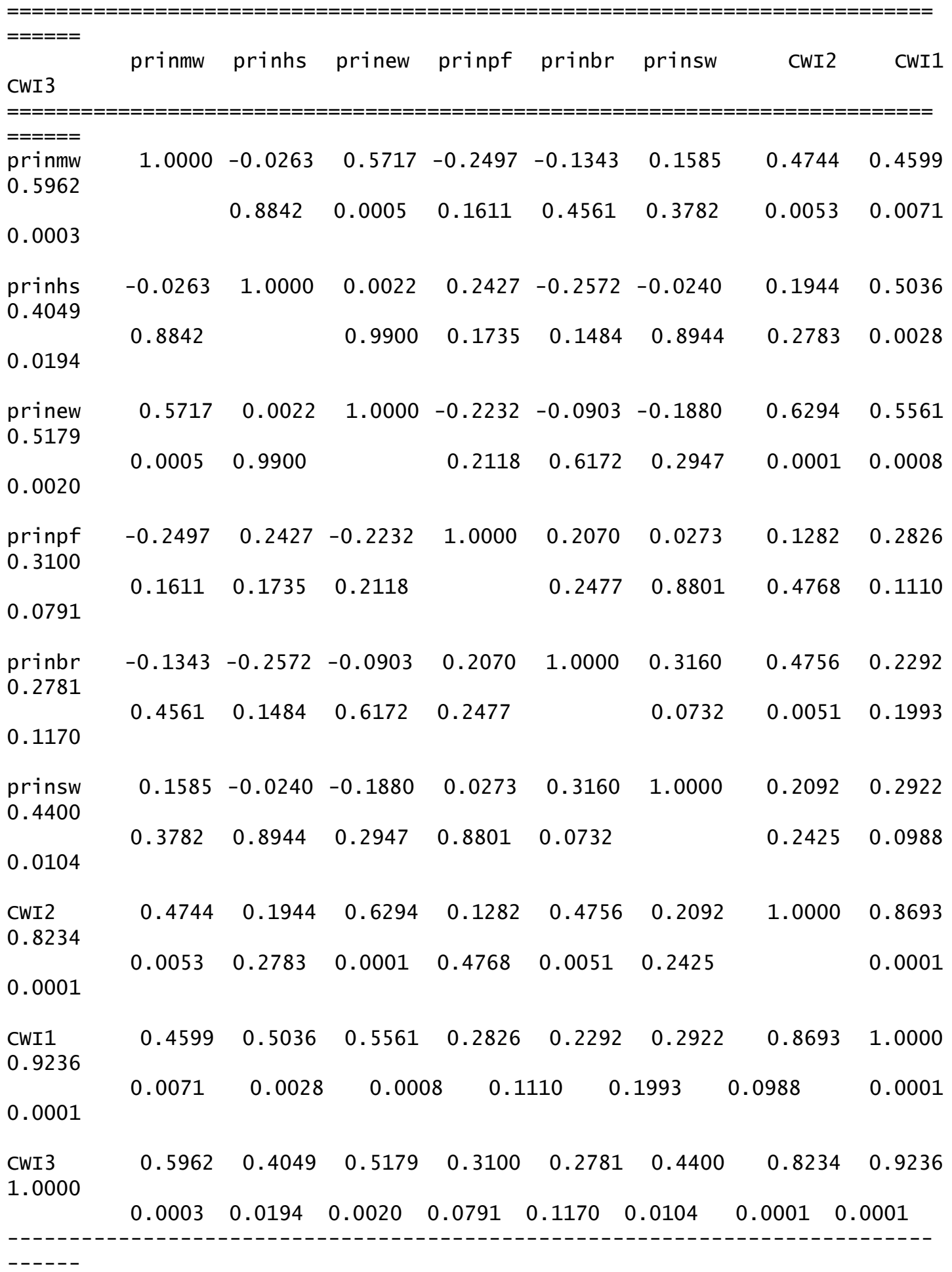


Table 8.A Efficiency of countries compared to best practice country.

\begin{tabular}{|c|c|c|c|c|c|c|c|c|}
\hline $\begin{array}{l}====== \\
\text { Obs country } \\
\text { CWI3 }\end{array}$ & matwe1 & helsaf & eduwe1 & peefam & behris & subwe1 & CWI2 & CWI1 \\
\hline \multicolumn{7}{|c|}{$======$} & $======$ & $=====$ \\
\hline $\begin{array}{c}1 \\
100.00\end{array}$ & 37.54 & 82.79 & 90.18 & 56.31 & 86.59 & 72.96 & 96.06 & 100.00 \\
\hline${ }^{2} .12^{\text {Sweden }}$ & 71.83 & 100.00 & 85.01 & 22.80 & 91.99 & 46.89 & 100.00 & 95.38 \\
\hline $\begin{array}{l}3 \\
74.28^{\text {Norway }}\end{array}$ & 96.95 & 48.32 & 83.09 & 36.21 & 36.12 & 38.67 & 72.37 & 60.09 \\
\hline $\begin{array}{r}4 \text { Spain } \\
68.30\end{array}$ & 23.84 & 69.05 & 54.80 & 53.90 & 86.44 & 63.59 & 98.66 & 75.18 \\
\hline $68.25^{\text {Denmark }}$ & 60.87 & 77.94 & 87.66 & 39.08 & 70.60 & 34.69 & 85.36 & 76.06 \\
\hline $66.54^{\text {Italy }}$ & 12.14 & 59.17 & 44.11 & 100.00 & 67.36 & 38.32 & 79.50 & 58.44 \\
\hline $60.15^{\text {Iceland }}$ & 100.00 & 91.56 & 72.95 & 25.35 & 46.12 & 25.63 & 81.26 & 68.88 \\
\hline${ }_{56.51}^{8}$ France & 24.06 & 62.31 & 60.04 & 47.90 & 73.40 & 30.25 & 80.54 & 53.60 \\
\hline${ }_{53.97^{\text {Israel }}}$ & 27.03 & 43.10 & 0.00 & 3.99 & 47.49 & 100.00 & 63.88 & 36.42 \\
\hline $\begin{array}{l}10 \quad \text { Portugal } \\
51.99\end{array}$ & 9.18 & 62.53 & 48.05 & 54.66 & 51.89 & 29.31 & 53.28 & 39.11 \\
\hline $\begin{array}{l}11 \text { Greece } \\
51.78\end{array}$ & 8.58 & 24.02 & 48.50 & 68.46 & 100.00 & 56.29 & 87.88 & 58.53 \\
\hline $\begin{array}{l}12 \text { Switzerland } \\
51.18\end{array}$ & 35.80 & 47.24 & 69.13 & 35.78 & 73.23 & 45.16 & 86.39 & 57.24 \\
\hline $\begin{array}{l}13 \text { Poland } \\
50.40\end{array}$ & 0.00 & 65.98 & 93.98 & 41.86 & 86.86 & 17.04 & 79.67 & 58.39 \\
\hline $\begin{array}{l}14 \text { Finland } \\
49.87^{\text {F }}\end{array}$ & 54.16 & 85.69 & 100.00 & 18.71 & 23.47 & 39.20 & 71.58 & 60.10 \\
\hline $\begin{array}{l}15 \text { Japan } \\
49.43\end{array}$ & 53.46 & 49.93 & 72.78 & 29.87 & 70.11 & 16.64 & 82.51 & 48.74 \\
\hline $\begin{array}{l}16 \text { Australia } \\
42.72\end{array}$ & 40.30 & 49.81 & 89.29 & 5.70 & 45.26 & 28.01 & 71.40 & 40.30 \\
\hline $\begin{array}{l}17 \text { Belgium } \\
42.63^{\text {Bel }}\end{array}$ & 27.13 & 29.08 & 93.98 & 46.11 & 31.91 & 27.95 & 58.92 & 35.98 \\
\hline $\begin{array}{l}18 \text { Hungary } \\
41.03^{\text {Hor }}\end{array}$ & 12.27 & 64.04 & 58.69 & 48.01 & 38.08 & 31.78 & 64.21 & 38.03 \\
\hline $\begin{array}{l}19 \text { Canada } \\
40.31\end{array}$ & 34.93 & 43.28 & 90.83 & 8.56 & 62.98 & 28.70 & 78.44 & 44.95 \\
\hline $\begin{array}{l}20 \quad \text { Malta } \\
40.11\end{array}$ & 8.16 & 69.33 & 3.83 & 84.19 & 51.63 & 36.60 & 50.23 & 37.09 \\
\hline $\begin{array}{l}21 \\
36.19^{\text {USA }}\end{array}$ & 20.61 & 33.21 & 76.32 & 10.58 & 45.05 & 16.10 & 53.91 & 21.13 \\
\hline $\begin{array}{l}22 \text { Ireland } \\
34.99\end{array}$ & 7.99 & 11.26 & 82.15 & 42.62 & 66.96 & 44.74 & 63.96 & 40.73 \\
\hline $\begin{array}{l}23 \text { Germany } \\
31.46\end{array}$ & 27.94 & 47.92 & 50.77 & 58.77 & 34.62 & 36.40 & 51.99 & 36.60 \\
\hline $\begin{array}{l}24 \quad \text { Czech Rep } \\
31.11\end{array}$ & 50.78 & 71.15 & 72.93 & 29.20 & 58.40 & 27.33 & 90.24 & 55.89 \\
\hline $\begin{array}{l}25 \text { Slovenia } \\
28.16\end{array}$ & 14.91 & 48.51 & 12.72 & 44.37 & 42.22 & 47.16 & 55.02 & 24.99 \\
\hline
\end{tabular}




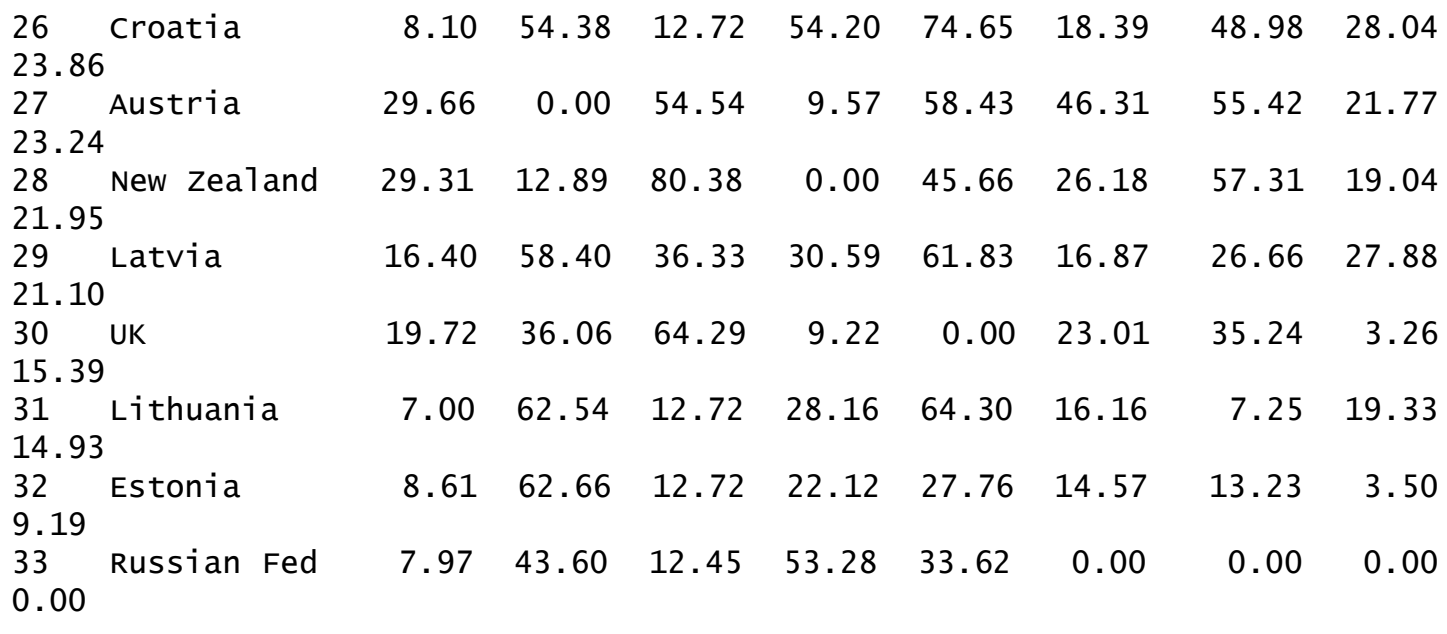

Table 8.B Mean efficiency of country groups compared to best practice country.

\begin{tabular}{|c|c|c|c|c|c|c|c|c|}
\hline $\begin{array}{l}\text { Obs cgroupx } \\
\text { CWI3 }\end{array}$ & matwe1 & helsaf & eduwe 1 & peefam & behris & subwe 1 & CWI2 & CWI1 \\
\hline $\begin{array}{l}============== \\
======\end{array}$ & $=====$ & $=====$ & $=====$ & $======$ & $====$ & $=====$ & $====$ & $===3$ \\
\hline $\begin{array}{l}1 \text { Scandinavia } \\
66.13\end{array}$ & 76.76 & 80.70 & 85.74 & 28.43 & 53.66 & 37.01 & 72.10 & 82.11 \\
\hline $\begin{array}{l}2 \quad \text { SouthEurope } \\
59.02\end{array}$ & 15.56 & 55.42 & 51.10 & 64.98 & 75.82 & 43.55 & 56.97 & 79.97 \\
\hline $\begin{array}{l}3 \quad \text { NorthEurope } \\
42.70\end{array}$ & 26.54 & 36.34 & 72.15 & 36.91 & 50.25 & 42.36 & 42.23 & 64.00 \\
\hline $\begin{array}{l}4 \quad \text { EastEurope } \\
40.84\end{array}$ & 21.02 & 67.06 & 75.20 & 39.69 & 61.11 & 25.38 & 50.77 & 78.04 \\
\hline $\begin{array}{l}5 \quad \text { NorthAmothe } \\
38.12\end{array}$ & 35.72 & 37.82 & 81.92 & 10.94 & 53.81 & 23.13 & 34.83 & 68.72 \\
\hline $\begin{array}{l}6 \quad \text { Non-OECD } \\
23.91\end{array}$ & 12.27 & 55.32 & 12.94 & 40.11 & 50.44 & 31.22 & 22.16 & 33.16 \\
\hline
\end{tabular}


Table 9: The bias of the UNDP type index over the principal components analysis in terms of ranks

\begin{tabular}{|c|c|}
\hline & $\begin{array}{l}\text { bias in favour of the UNDP measure, compared to principal } \\
\text { components, measured by rankings }\end{array}$ \\
\hline Finland & 9 \\
\hline Norway & 7 \\
\hline Portugal & 7 \\
\hline Malta & 7 \\
\hline Germany & 5 \\
\hline Latvia & 5 \\
\hline Denmark & 4 \\
\hline Iceland & 4 \\
\hline Croatia & 4 \\
\hline Italy & 3 \\
\hline Lithuania & 3 \\
\hline Netherlands & 2 \\
\hline Ireland & 2 \\
\hline Poland & 1 \\
\hline Estonia & 0 \\
\hline Russia & 0 \\
\hline Sweden & -1 \\
\hline Australia & -1 \\
\hline Spain & -2 \\
\hline Canada & -2 \\
\hline Hungary & -2 \\
\hline Greece & -3 \\
\hline France & -3 \\
\hline Israel & -3 \\
\hline Belgium & -3 \\
\hline Slovenia & -3 \\
\hline UK & -3 \\
\hline USA & -4 \\
\hline Switzerland & -5 \\
\hline Austria & -5 \\
\hline Japan & -6 \\
\hline Czech R. & -8 \\
\hline New Zealand & -9 \\
\hline
\end{tabular}


Table 10: The CWI1 and CWI2 results and the UNICEF rankings (2007)

\begin{tabular}{|c|c|c|c|}
\hline & CWI1 & CWI2 & $\begin{array}{l}\text { average ranking, UNICEF } \\
2007 \text { study }\end{array}$ \\
\hline Netherlands & 21,417 & 0,433 & 4,2 \\
\hline Sweden & 20,950 & 0,486 & 5,0 \\
\hline Denmark & 19,002 & 0,290 & 7,2 \\
\hline Finland & 17,393 & 0,106 & 7,5 \\
\hline Spain & 18,913 & 0,468 & 8,0 \\
\hline Switzerland & 17,104 & 0,304 & 8,3 \\
\hline Norway & 17,391 & 0,116 & 8,7 \\
\hline Italy & 17,225 & 0,211 & 10,0 \\
\hline Ireland & 15,438 & 0,004 & 10,2 \\
\hline Belgium & 14,960 & $-0,064$ & 10,7 \\
\hline Germany & 15,022 & $-0,156$ & 11,2 \\
\hline Greece & 17,234 & 0,324 & 11,8 \\
\hline Canada & 15,864 & 0,197 & 11,8 \\
\hline Poland & 17,220 & 0,214 & 12,3 \\
\hline Czech R. & 16,967 & 0,355 & 12,5 \\
\hline France & 16,736 & 0,225 & 13,0 \\
\hline Portugal & 15,275 & $-0,139$ & 13,7 \\
\hline Austria & 13,526 & $-0,110$ & 13,9 \\
\hline Hungary & 15,166 & 0,007 & 14,5 \\
\hline USA & 13,461 & $-0,131$ & 18,0 \\
\hline UK & 11,659 & $-0,380$ & 18,2 \\
\hline
\end{tabular}




\section{Appendix A. INNOCENTI (2007-07) UNICEF child well-being data,}

33 observations, 42 variables and 6 dimensions.

MW. Material Well-being

mw1. Child income poverty:

mw11 percentage of children (0-17) in households with equivalent income less than 50 per cent of the median: most recent data.

mw2. Deprivation: 15: 2001.

mw21 percentage of children reporting low family affluence, aged 11, 13 and

mw22 percentage of children aged 15 reporting less than six educational possessions: 2003 .

mw23 percentage of children aged 15 reporting less than ten books in the home: 2003.

mw3. Work:

mw31 percentage of working-age households with children without an employed parent OECD: most recent data.

HS. Health and Safety

hs1. Health at birth:

hs11 infant mortality rate (per 1000 live births): most recent data.

hs12 low birth weight (\% births less than $2500 \mathrm{~g})$ : most recent data.

hs2. Immunization:

hs21 measles: \% children immunized aged 12-23 months: 2003.

hs22 dpt3: \% children immunized aged 12-23 months: 2002 (hs22).

hs23 polio 3: \% children immunized aged 12-23 months: 2002.

hs3. Child mortality:

hs31 deaths from accidents and injuries per 100,000 under 19 years, average of latest three years available.

EW. Educational Well-being

ew1. Achievement:

ew11 reading literacy achievement aged 15: 2003.

ew12 mathematics literacy achievement aged 15: 2003.

ew13 science literacy achievement aged 15: 2003.

ew2. Participation:

ew21 full-time and part-time students in public and private educational institutions aged 15-19 as a percentage of the population of 15-19 year-olds: 2003 .

ew3. Aspirations:

ew31 percentage of 15-19 year-olds not in education or employment: 2003.

ew32 percentage of pupils aged 15 years aspiring to low skilled work: 2003.

PF. Peer and Family relationships

pf1. Family structure: 
pf11 percentage of young people living in single-parent family structures, aged 11, 13 and 15: 2001.

pf12 percentage of young people living in step family structure, aged 11, 13 and 15: 2001.

pf2. Family relations:

pf21 percentage of students whose parents eat their main meal with them around a table several times a week, aged 15: 2000.

pf22 percentage of students whose parents spend time just talking to them several times per week, aged 15: 2000.

pf3. Peer relations:

pf31 percentage of young people finding their peers 'kind and helpful', aged 11, 13 and 15: 2001.

BR. Behaviours and Risks

br1. Risk behaviour: 2001.

br11 percentage smoking cigarettes at least once per week, aged 11, 13, 15:

br12 percentage of young people who have been drunk two or more times, aged 11, 13, 15: 2001.

br13 percentage of young people who have used cannabis in the last 12 months, aged 15: 2001.

br14 adolescent fertility rate, births per 1000 women aged 15-19: 2003.

br15 percentage of young people who have had sexual intercourse, aged 15:

2001.

br16 percentage of young people who used a condom during their last sexual intercourse, aged 15: 2001.

br2. Experience of violence:

br21 percentage of young people involved in physical fighting in previous 12 months, aged 11, 13, 15: 2001.

br22 percentage of young people who were bullied at least once in the last 2 months, aged 11, 13, 15: 2001.

br3. Health behaviour:

br31 percentage of young people who eat fruit every day, aged 11, 13, 15 years: 2001.

br32 percentage of young people who eat breakfast every school day, aged 11, 13, 15 years: 2001.

br33 mean number of days when young people are physically active for one hour or more of the previous /typical week, aged 11, 13, 15: 2001.

br34 percentage of young people who are overweight according to bmi, aged 13 and 15: 2001.

SW. Subjective Well-being

sw1. Health:

sw11 percentage of young people rating their health as 'fair or poor', aged 11, 13 and 15: 2001.

sw2. Personal well-being: 
sw21 percentage of young people with scores above the middle of the life satisfaction scale, aged 11, 13 and 15: 2001.

sw22 percentage of students who agree with the statement 'i feel like an outsider or left out of things', aged 15: 2003.

sw23 percentage of students who agree with the statement 'i feel awkward and out of place', aged 15: 2003.

15: 2003.

sw24 percentage of students who agree with the statement 'i feel lonely', aged

sw3. School well-being:

sw31 percentage of young people 'liking school a lot', aged 11, 13, 15: 2001.

CC. Country Characteristics (2 indicators):

North

cgroup Scandinavia (1), North Europe (2), South Europe (3), East Europe (4),

America and others (5), Non-OECD (6).

OECD OECD members (1), Non-OECD members (0). 


\section{Appendix B. INNOCENTI UNICEF child well-being data.}

MW. material well-being (5 indicators):

mw11

mw21, mw22, mw23

mw31

HS. health and safely (6 indicators):

hs11, hs12

hs 21 , hs 22 , hs 23

hs31

EW. educational well-being (6 indicators):

ew11, ew12, ew13

ew21

ew31, ew32

PF. peer and family relationships (5 indicators):

pf11, pf12

pf21, pf22

pf31

BR. behaviours and risks (12 indicators):

br11, br12, br13, br14, br15, br16

br21, br22

rr31, br32, br33, br34

SW. subjective well-being (6 indicators):

sw11

sw21, sw22, sw23, sw24

sw31

CC. Country Characteristics (2 indicators):

cgroup

OECD 
Measurement and Analysis of Cbild Well-Being in Middle and High Income Countries

Figure 1. Non-parametric index of child well-being (chiwel) and its decomposition by sub-components.

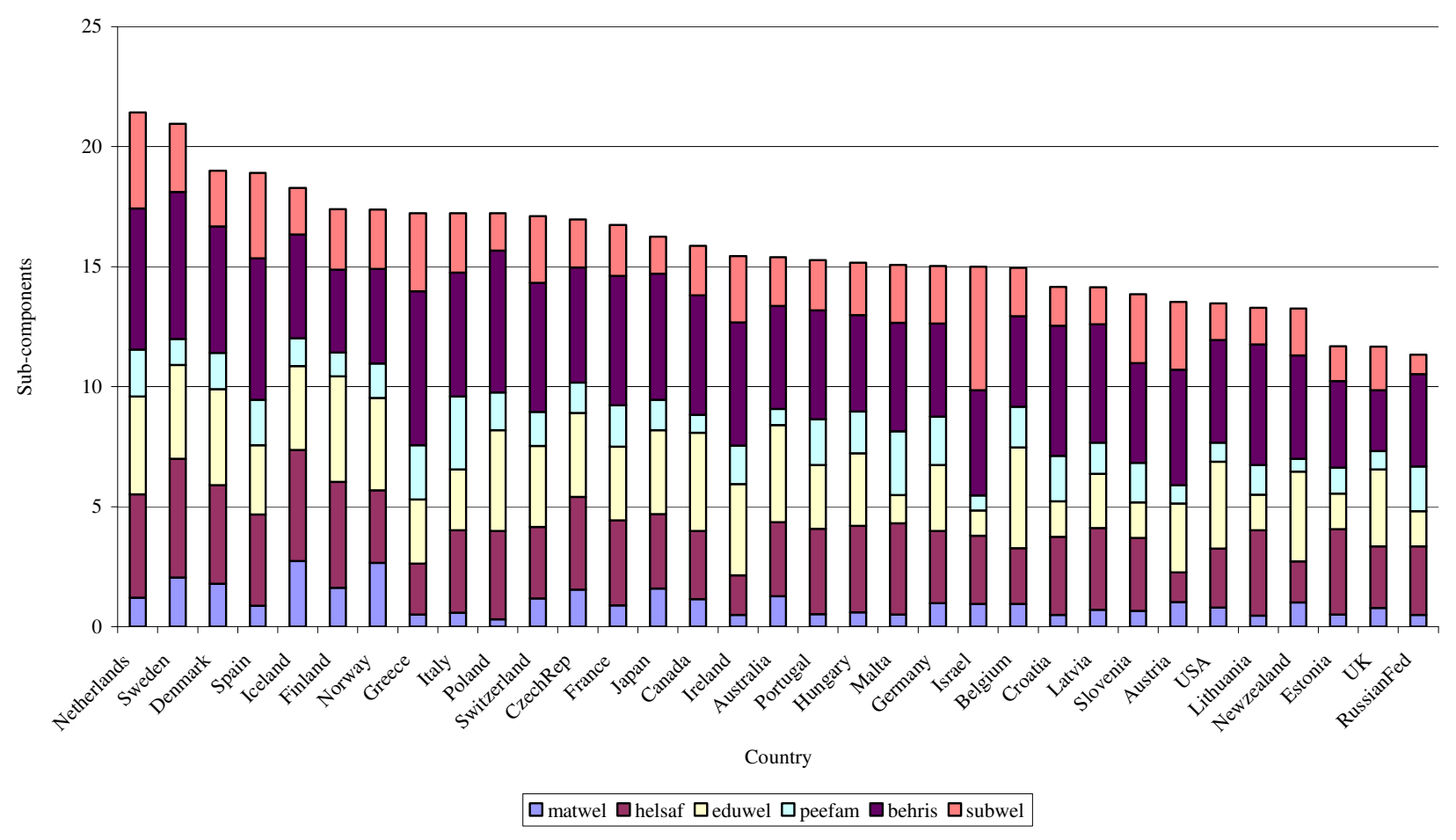

Available online at http://eaces.liuc.it 
Figure 2. Parametric sub-indices of child well-being (prinallx)

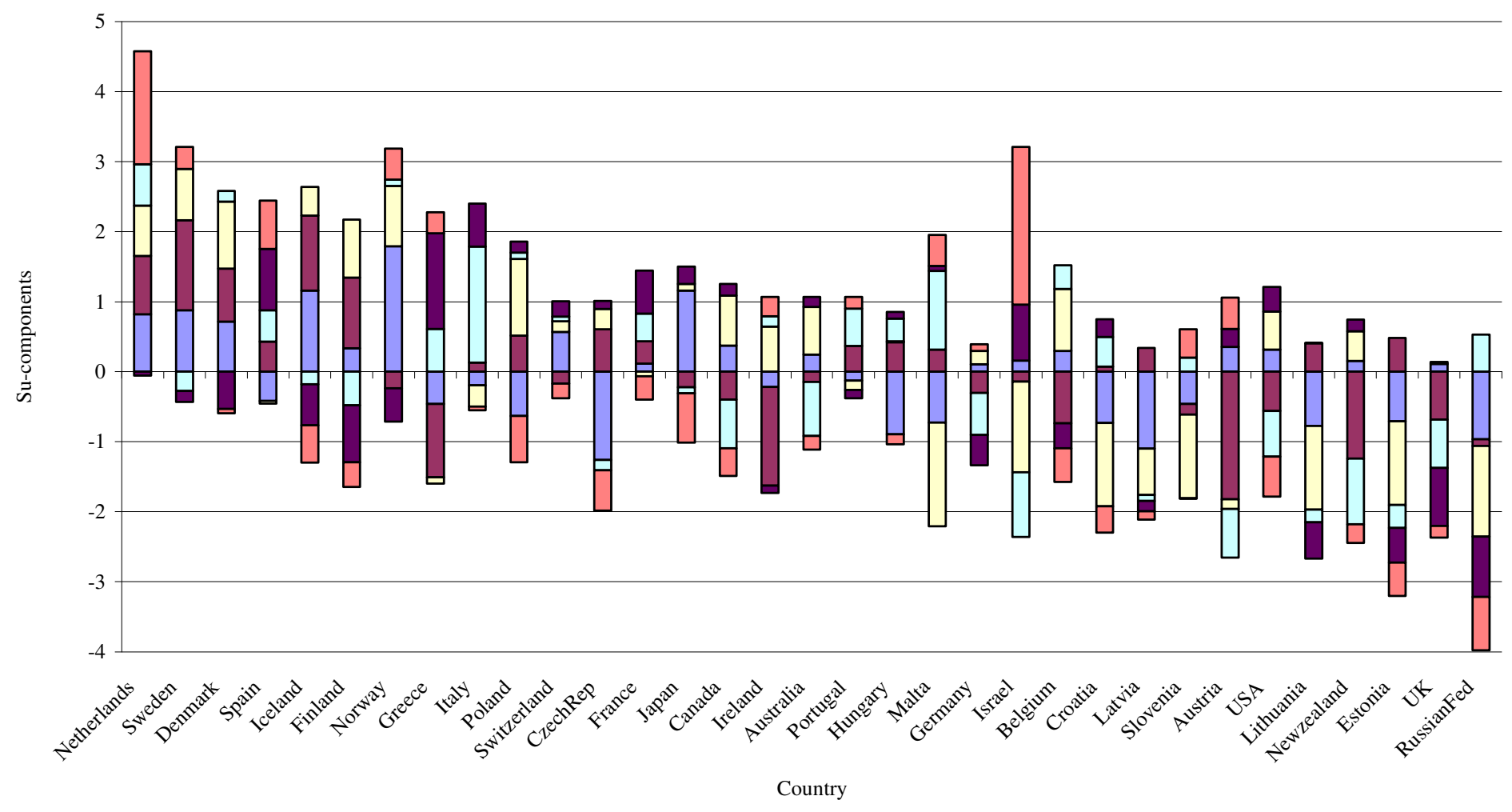

$\square$ prinmw $\square$ prinhs $\square$ prinew $\square$ prinpf $\square$ prinbr $\square$ prinsw 
Figure 3. Normalized parametric and non-parametric child well-being Indices.

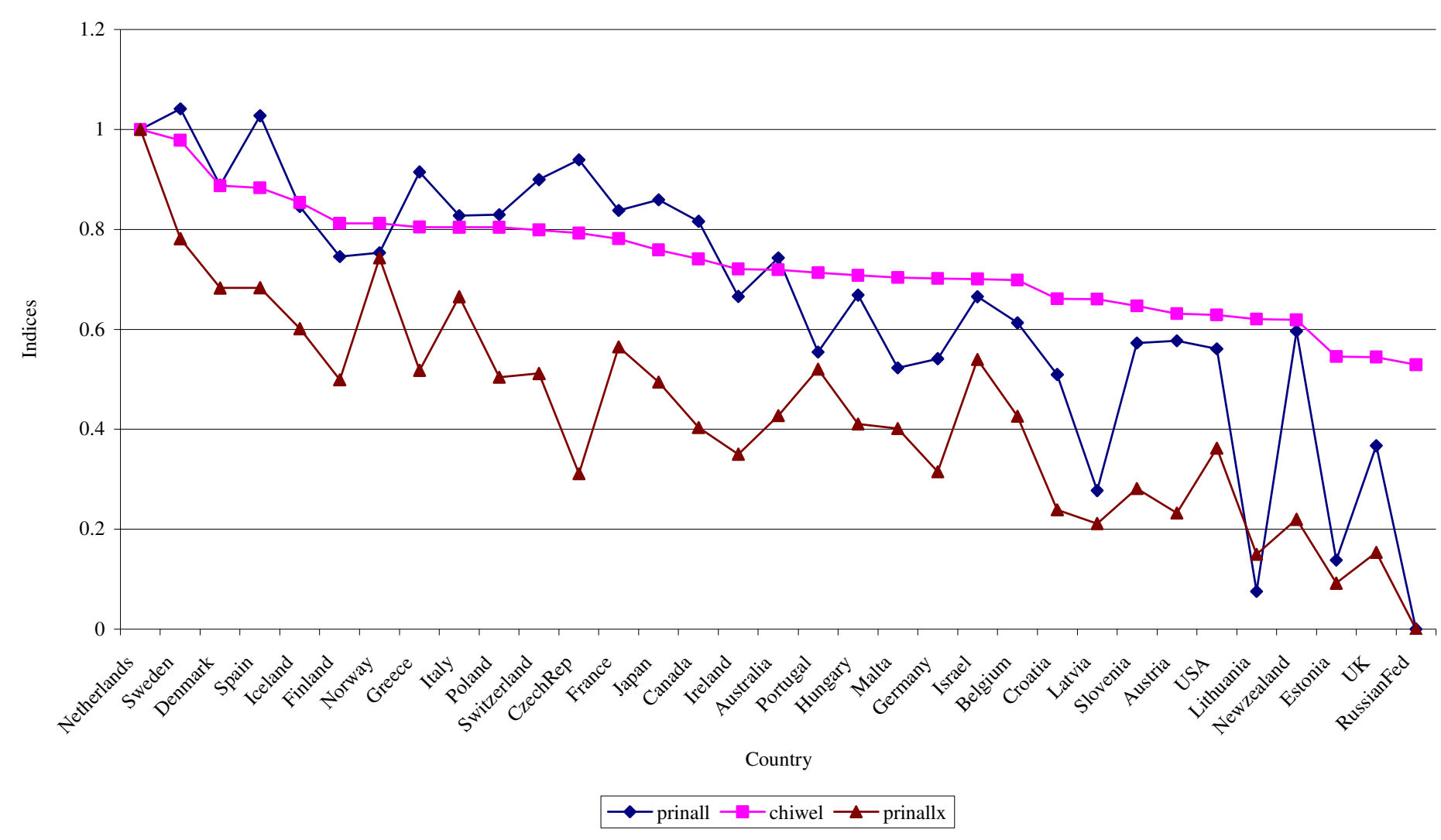


Figure 4. Efficiency based on non-parametric computation of individual well-being indices (chiwel)

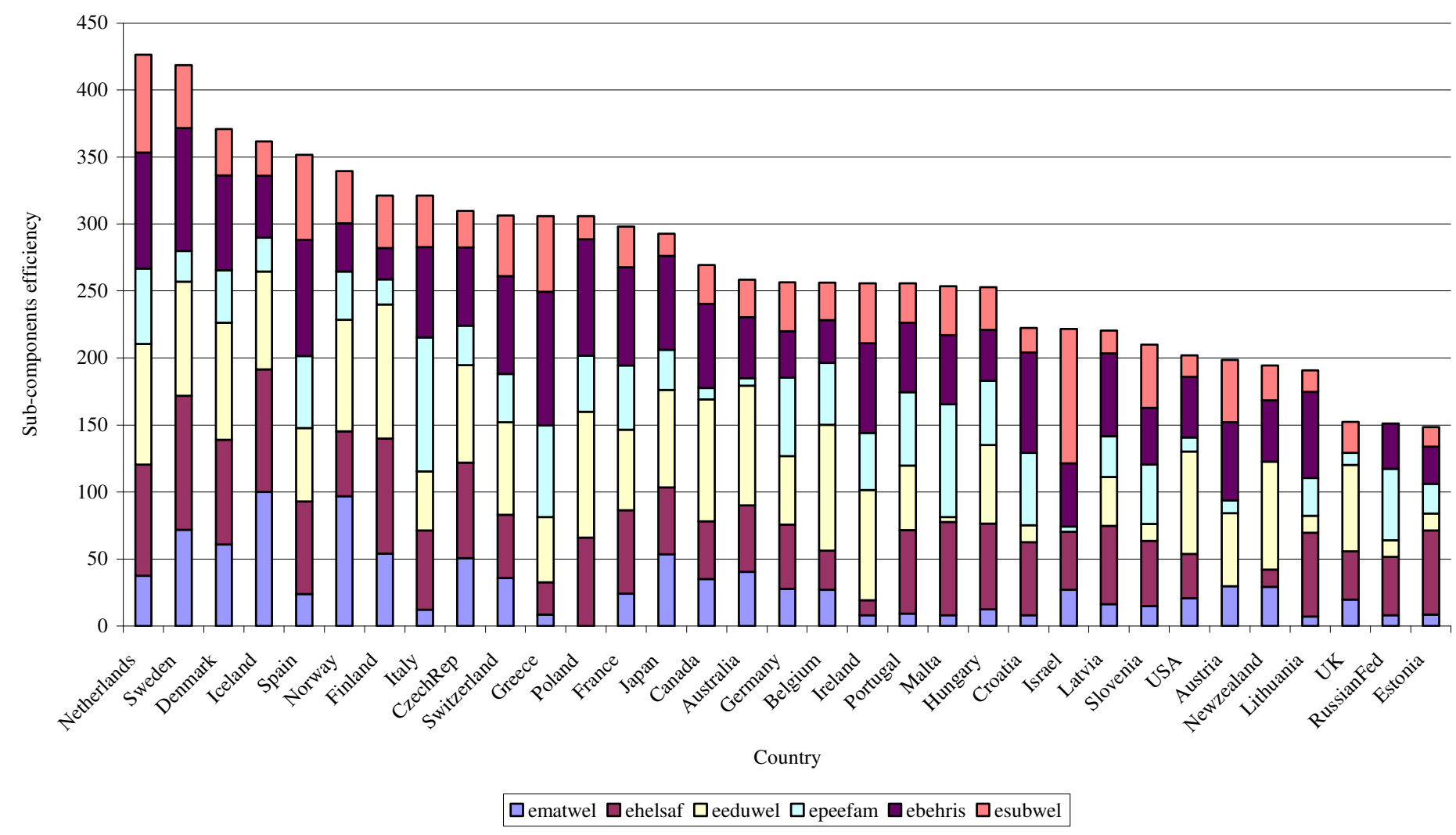


Figure 5. Efficiency based on parametric and non-parametric indices of child well-being.

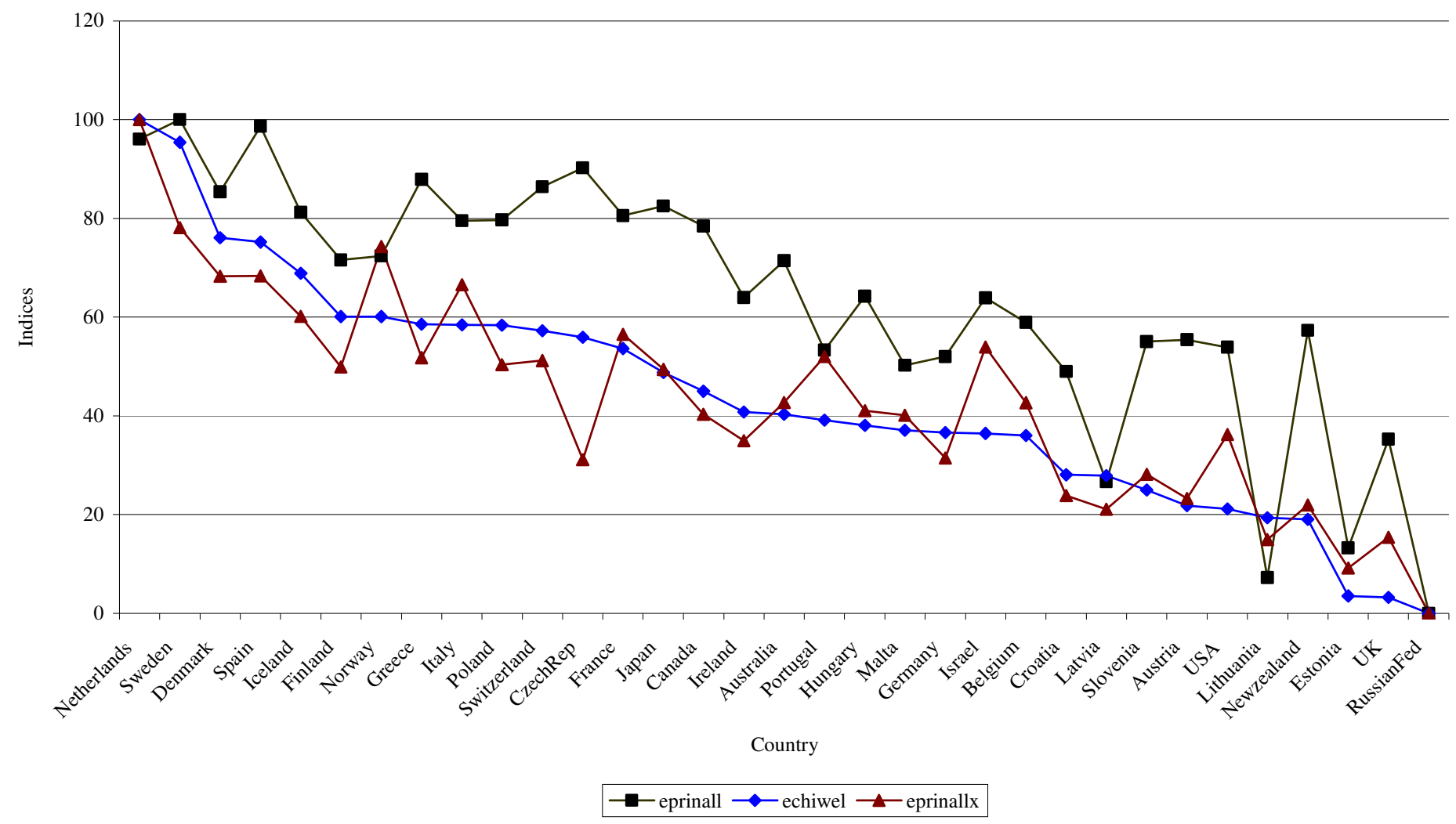

